\title{
2012
}

\section{Religion und Offenbarung}

Arbeitskreis „Episteme der Theologie interreligiös" - 27. bis 29. April 2012 Dokumentation des zweiten Treffens Azhar-Universität, Kairo 
(C) 2013 Orient-Institut Beirut (Max Weber Stiftung)

Das Werk einschließlich aller seiner Teile ist urheberrechtlich geschützt. Jede Verwertung des Werkes außerhalb des Urheberechtsgesetztes bedarf der Zustimmung des Orient-Instituts. Dies gilt insbesondere für Vervielfältigungen jeder Art, Übersetzungen, Mikroverfilmungen sowie für die Einspeicherung in elektronische Systeme.

Orient-Institut Beirut

Rue Hussein Beyhoum 44, Zokak el-Blat

Beirut, Lebanon 


\section{Inhaltsverzeichnis}

Vorwort des Herausgebers. 4

Zur Eröffnung. 7

Hassan ash-Shafii

Wort zum Auftakt 9

Abd al-Aziz Saif an-Nasr

Offenbarung und Religion 15

Reinhold Bernhardt

Religion und Offenbarung

Martin Rösel

Bileam: Die wandernde Prophezeiung...

Joachim Kügler

Religion ist ein Angebot Gottes, sich ihm zu entziehen, ohne ihn zu vergessen

Al-Qasabi Zalat

Die Offenbarung und ihr gegenüber vorgebrachte Anzweifelungen 54

Karlheinz Ruhstorfer

Offenbarung und Religion in christlicher Perspektive

Sonia Lotfy

Wahy als Bestandteil der menschlichen Geformtheit 73

Programm des Arbeitskreises. 79

Teilnehmerliste des Arbeitskreises 80 


\section{Vorwort des Herausgebers}

Der Arbeitskreis „Episteme der Theologie interreligiös“ ist in Kairo vom 27. bis 29. April 2012 zum zweiten Mal zusammengekommen, um sich diesmal mit dem Zusammenhang von Offenbarung und Religion zu befassen. Die Tagung fand am AlAzhar Konferenzzentrum in Nasr City, Kairo statt. Gastgeber waren das Dialogzentrum der Azhar und das Rektorat des Scheichs der ehrwürdigen Azhar (mashyakhat al-azhar ash-sharif) in Zusammenarbeit mit dem Orient-Institut Beirut (OIB). Die Zusammenarbeit zwischen unserem Institut, einem außeruniversitären akademischen Forschungszentrum, und Al-Azhar, der größten und wichtigsten theologischen Ausbildungsstätte des sunnitischen Islam, hat sich als produktiv und belastbar erwiesen, worüber man sehr glücklich sein darf. Denn der Umstand, dass das OIB, anders als z. B. kirchliche Einrichtungen, im Kontrast zur Theologischen Hochschule Al-Azhar eine ausschließlich historisch-philologisch und religionswissenschaftlich bestimmte Herangehensweise vertritt, kann ein Stein des Anstoßes sein. Dies gilt insbesondere seitdem die Thaura ${ }^{1}$, die Revolution vom Januar 2011, einer Politisierung der ägyptischen Gesellschaft Vorschub geleistet und religiös bestimmte Kräfte an die vorderste Front der - nun endlich - offenen Auseinandersetzung um ein konsensfähiges politisches System in Ägypten gestellt hat. Wir sind dem Rektorat des Großscheichs sehr dankbar für das in uns gesetzte Vertrauen.

Das OIB organisiert den Arbeitskreis von protestantischen und katholischen Fachtheologen aus Deutschland und islamischen Theologen aus Ägypten aus Interesse an den Denktraditionen der islamischen Theologie und ihrer modernen Weiterentwicklung. Eine praktische Absicht ist aber auch, einen Beitrag zur Beantwortung von Fragen zu bieten, die allgemein mit der Akkommodation des Islam in Deutschland verbunden sind und mit der Einrichtung von Universitätsinstituten für die Ausbildung in Islamlehre Aktualität gewonnen haben. Wie stellt sich islamische Theologie heute im Fachgespräch mit der christlichen Theologie dar?

Das Unterfangen erhält dadurch Beschränkung und Zuspitzung, dass die islamische Philosophie, wie sie an den Universitäten der arabischen Welt betrieben wird, weitgehend ausgeklammert bleibt bzw. nur Teil des Gesprächs sein kann, insofern sie auch Bestandteil der theologischen Ausbildung ist. Um die Komplexität der Diskussion nicht zu überdehnen, haben wir auch dieses Mal auf die Mitwirkung von imamitischen schiitischen Theologen - also Vertretern der djafaritischen Rechtsschule aus sunnitischer Sicht, verzichtet, obgleich uns dabei ein wichtiger Aspekt innerislamischer Diversität entgeht.

\footnotetext{
${ }^{1}$ Th in der Aussprache wie das englische th.
} 
Die Organisation des Arbeitskreises wäre ohne das Interesse und die Unterstützung von Theologen in Deutschland nicht zustande gekommen (siehe Teilnehmerliste am Ende dieses Bandes).

Der Arbeitskreis „Episteme der Theologie interreligiös“ fragt nach dem wissenschaftstheoretischen und methodologischen Zusammenhang zwischen den Theologien. Auch wenn die Fundamente und Begründungen für die Bekenntnisse, der Glaube und die von ihm induzierte Praxis stets präsent bleiben, geht es doch in erster Linie um einen Dialog der Theologien, der sich auf das konzentriert, was aus vergleichbaren und doch unterschiedlichen Grundlagen im Hinblick auf die intellektuelle Vergegenwärtigung des Glaubens resultiert.

Das erste Treffen zum Thema Schrift, Tradition und Dogma hatte vom 9. - 11. Dezember 2011 an der Stiftung Leucorea in der Lutherstad Wittenberg stattgefunden. Die Beiträge und die ertragreiche Diskussion liegen bereits dokumentiert vor (OIB 2012).

Die erheblichen Unterschiede in den theologischen Auffassungen und Herangehensweisen treten auch zum Thema offenbarung und Religion deutlich hervor, nicht nur in der inner-christlichen Differenzierung, sondern besonders im islamisch-christlichen Vergleich. Der Textbezug auf die Offenbarungsschrift steht für die hier zu Wort kommenden islamischen Theologen an erster Stelle. Auf der Grundlage der Realität und Gültigkeit eines sprachlich vermittelten Offenbarungsgeschehens bleibt die offenbarte Verlautbarung die wichtigste und in der Regel direkt zugängliche Referenz für alle Theologumena. Dabei werden Kernfragen, wie Verständnis und Autorität (Hasan ash-Shafi'i), Authentizität und innere Struktur der Offenbarungsaussagen (Al-Qasabi Zalat) und die Ableitung der Glaubensinhalte (Abd el-Aziz Saif an-Nasr) demonstrativ auf diese Weise abgehandelt. Eine etwas andere Dimension erhält die Diskussion mit der Frage nach der Kontinuität der Offenbarung (Sonia Lotfy). Den Erkenntnisressourcen der modernen Philosophie, Geschichte und Archäologie bieten die deutschen Beiträge Raum. Sie entfalten eine vom historischen Offenbarungsgeschehen abstrahierende Theologie. Die Behandlung des Verhältnisses von Offenbarung und Religion aus der Perspektive der Religionskritik (Reinhold Bernhardt), die Forderung einer geschichtsbewussten Hermeneutik, welche die Spielarten des abendländischen Denkens in die Deutung der Schrift einbezieht (Karlheinz Ruhstorfer), die Auseinandersetzung mit dem Projektionscharakter der Religion, aus dem die Neubewertung des alttestamentlichen Begriffs der Heiligkeit hinausführt (Joachim Kügler) und die Auseinandersetzung mit den in biblischen Texten beschriebenen Offenbarungsakten, die erst durch nachträgliche Deutung erlebter Ereignisse ein OffenbarungsVerständnis etablieren (Martin Rösel), bieten Einblick in das zeitgenössische theologische Denken in Deutschland. 
Unsere Dokumentation des Treffens in Kairo kann aus technischen Gründen die Diskussion der Beiträge nicht wiedergeben. Die angefertigten Tondokumente sind unvollständig, und das Vorhandene kann die außerordentlich ausführliche und engagierte Diskussion nicht einfangen.

Die Konferenzorganisation wurde von Dr. des. Ahmad Abd-Elsalam (Univ. Münster, damals OIB) ausgeführt. Bei der Übersetzung der arabischen Beiträge hat Berenike Metzler (Bamberg/Erlangen, damals Stipendiatin am OIB) die Hauptarbeit geleistet. Johannes Stephan (Bern, Stipendiat des OIB) hat die Beiträge redigiert und in Form gebracht. Ihnen sei an dieser Stelle für ihre engagierte Mitarbeit gedankt.

Die Umschrift der arabischen Begriffe und Eigennamen wurde ans Deutsche angepasst und folgt nicht den Regeln der wissenschaftlichen Transkription. In den arabischen Beiträgen erscheinende Segensformeln werden zum Teil in Abkürzung wiedergegeben: „Gott segne ihn und schenke ihm Heil (sws); Erhaben ist er (t); Gott möge an ihm Wohlgefallen haben (ra). Für Koranzitate wird, wenn nicht anders vermerkt, die Koranübersetzung Hartmut Bobzins (C.H. Beck, München 2010) verwendet.

Stefan Leder, Beirut im Juli 2013 


\section{Zur Eröffnung}

Es ist ein vielversprechender Ansatz, in einem Symposion von Theologen von AlAzhar und deutscher Universitäten das Thema „Episteme der Theologie interreligiös“ mit dem Ziel zu behandeln, die Fragen von Offenbarung in der Religion wissenschaftlich zu durchdringen. Ich zolle den Veranstaltern von AlAzhar und des Orient-Instituts Beirut meine Anerkennung für das innovative gemeinsame Bemühen, mehr Licht in grundlegende Fragen der Theologie und besonders der Exegese $\mathrm{zu}$ bringen. Noch mehr an die Wurzeln von Erkenntnismöglichkeiten kann man kaum gehen. Die Wahl Kairos, geprägt durch die umwälzenden Ereignisse von Januar und Februar 2011, für die Durchführung dieser Veranstaltung, ist eine gute Wahl, denn Kairo steht seit einem Jahr für Offenheit, Neugier und Veränderung. Möge dieser „genius loci“ den Lauf der Konferenz beflügeln und neue Erkenntnis bringen!

Die Ergebnisse des gemeinsamen Bemühens islamischer und christlicher Theologen auf diesem Symposion werden schon allein dadurch Frucht tragen, dass hier ein gemeinsamer Weg gegangen wird.

Aristoteles hat den Begriff „Episteme“ in seinem Werk "Nikomachische Ethik“ verwendet, und mit ihm das theoretische Wissen im Sinne von Erkenntnis bezeichnet, welches er von der „Techne“, dem praktischen Können, aber auch der bloßen unreflektierten Meinung, abgrenzte. Er hat damit früh eine Dualität zwischen dem Bemühen der reinen Wissenschaftler und dem Handeln derjenigen, welche für die praktische Wahrnehmung der staatlichen Aufgaben verantwortlich sind - ich zähle uns Diplomaten dazu - , geschaffen.

Gerade in Phasen, in denen es gilt, Neues zu gestalten, ist es besonders wichtig, nicht einfach tradierte Verhaltensweisen zu wiederholen, sondern reflektiert auf der Basis von Erkenntnis zu handeln. Daraus folgt für Deutschland ganz praktisch die Einführung von Lehrstühlen der Islamwissenschaften, deren Aufgabe es sein soll, Lehrer für den Religionsunterricht muslimischer Schüler auszubilden. Aus der Gesamtzahl von knapp 4 Millionen Muslimen, also fast 5\% der Bevölkerung in Deutschland und der Notwendigkeit den muslimischen Schülern adäquaten Religionsunterricht anzubieten, ermisst sich die besondere Bedeutung des Vorhabens gerade zum jetzigen Zeitpunkt.

Erlauben Sie mir jetzt in wenigen Sätzen den Ansatz zu rekapitulieren, den das Auswärtige Amt im Dialog mit dem Islam im letzten Jahrzehnt verfolgt hat. Dieser Ansatz war praktisch-menschlich ausgerichtet, was selten falsch sein kann. Ziel war 
es, in der islamischen Welt, „minds and hearts“ zu gewinnen, eine „Kultur des Friedens" mitzugestalten, gegründet auf die Erkenntnisse, dass Akte der Rache Hass nicht heilen können und dass die schwersten Missstände, welche Grund für Hass und Gewalt in der internationalen Politik sind, beseitigt werden müssen.

In diesem Zusammenhang verdient ein Leitmotiv für eine Kultur des Friedens, das die Orientalistin Annemarie Schimmel auf der Grundlage einer bekannten Textstelle aus dem Alten Testament intoniert hat, besondere Erwägung. Das Zitat lautet:

"Judentum, christliche Religion und Islam erkennen dasselbe Konzept des Eschatologischen Friedens, wenn Löwe und Lamm zusammen liegen in der Zeit des gerechten Herrschers. Aber der Frieden ist nicht statisch... Frieden ist eine Reise, ein niemals endender Prozeß."

Ganz sicherlich ist es gut, wenn wir, islamische und christliche Wissenschaftler, islamische und christliche Politiker, gerne auch Diplomaten, uns gemeinsam auf diese Reise begeben.

Ich wünsche Ihnen einen sehr erfolgreichen Verlauf der Konferenz als Teil dieser Reise. 
Hassan ash-Shafii

Wort zum Auftakt

Im Namen Gottes, des Erbarmers, des Barmherzigen,

Gott, dem Herrn der Weltbewohner sei Dank und dem Siegel der Gesandten und seinen Brüdern, den Gesandten, sei Segen und Heil.

Es hat mich gefreut, dass der „Arbeitskreis Episteme der Theologie“ zusammen mit dem Dialogzentrum der Azhar und dem Rektorat des Scheichs der ehrwürdigen Azhar (mashyakhat al-azhar ash-sharif) mich zur Teilnahme an der Eröffnungsfeier für das zweite Treffen eingeladen hat. Ich hoffe, dass diese Teilnahme Anteil an der Verwirklichung dessen haben mag, wozu der 13. Vers der Sure al-Hudschurat (Die Gemächer) anspornt: „Siehe, wir erschufen euch als Mann und Frau und machten euch zu Völkern und Stämmen, damit ihr einander kennenlernt. “

Die Religion ist - im Verständnis der drei himmlischen abrahamitischen Religionen - das Wissen um Gott ( $\mathrm{t}$ ) und die Art und Weise seiner Verehrung, so wie es einer der größten Gelehrten der Azhar aus dem 20. Jahrhundert, Dr. Muhammad 'Abdallah Draz, in seinem Buch „Die Religion“ (2007) erklärt hat.

„Religion“ ist in diesen drei Religionen mit der Offenbarung verknüpft, die in der arabischen Sprache bedeutet: die Mitteilung im Verborgenen. So gibt es keine Religion ohne das Prophetentum und kein Prophetentum ohne Offenbarung. Gott ( $t$ ) sagt im Koran aus dem Munde des Messias: „Er sprach: ,Ich bin der Knecht Gottes! Er gab mir das Buch und machte mich zum Propheten. Er verlieh mir Segen, wo immer ich auch war, und trug mir das Gebet und die Armensteuer auf, solange ich am Leben bin. Und Ehrerbietung gegen meine Mutter! Er machte mich zu keinem elenden Gewaltmensch! Und Friede über mir am Tag, da ich geboren wurde, am Tag, an dem ich sterben werde, und an dem Tag, da ich zum Leben auferweckt werde!““2 Der Koran spricht Muhammad (sws) folgendermaßen an: „Siehe, wir offenbarten dir, so wie wir Noah offenbarten und den Propheten nach ihm. Wir offenbarten Abraham und Ismael und Isaak und Jakob; den Stämmen, Jesus, Hiob, Jona, Aaron, Salomo. David gaben wir den Psalter."3

Die Gelehrten unter den Muslimen sehen die Grundlagen der Religion und die Werte der Moral in diesen himmlischen Religionen als eine einzige, wie der edle Koran festlegt: „Gott hat euch von der Religion nur das verordnet, was er Noah geboten hatte und was wir dir eingaben und was wir Abraham und Mose und Jesus geboten

\footnotetext{
${ }^{1}$ Al-Hudschurat (Die Gemächer) 49:13.

${ }^{2}$ Maryam (Maria) 19:30-33.

${ }^{3}$ An-Nisa' (Die Frauen) 4:163.
} 
hatten: ,Haltet euch an die Religion, und spaltet euch ihretwegen nicht. “" ${ }^{4}$ Vielmehr unterscheiden sich die Gesetzgebungen und die Organisation oder die praktische Seite der Religion, jedoch nicht die theologischen Grundlagen und nicht die moralischen Werte: „Für einen jeden von euch haben wir Bahn und Weg gemacht.“5

Gott spricht seinen Propheten Muhammad - Gott segne ihn und seine Brüder, die Propheten und schenke ihm viel Heil - so an: „Dann brachten wir dich, im Hinblick auf die Sache, auf einen gebahnten Weg. So folge ihm. “6 So ist die Übermittlung der Gesetze an die Völker die Aufgabe der Propheten, und der Inhalt der Gesetzgebung und ihre praktische Inkorporation [in die Offenbarungsschrift] ist das Zeugnis Gottes für sie, oder was Ibn Rushd „spontane Unnachahmlichkeit“ nennt.

Die Offenbarung ist das auf die Propheten und die Gesandten herabgesandte Wort Gottes, welches die göttliche Wahrheit - Preis sei ihm - auswählte: „Wenn ein Zeichen zu ihnen kam, sprachen sie: ,Wir werden nicht daran glauben, bis uns das Gleiche gebracht wird, was den Gesandten Gottes gebracht wurde.' Gott weiß sehr wohl, wo er seine Botschaft statthaben lässt. “7 Dazu gehören drei Vorstellungen, wie der Vers 51 der Sure ash-Shura zeigt, die da sind: die Eingebung in das Herz, das Hören der Stimme des Engels ohne seine Schau, sowie die Gegenwart des Engels beim Propheten, der ihn sieht und hört. Darauf wurde bereits verwiesen.

Die Offenbarung - im prophetischen Verständnis - endete jedoch, wie der Koran festlegt, mit der Gesetzgebung Muhammads (sws) und seinem Buch: „Das Wort deines Herrn ist vollendet, in Wahrheit und Geradheit. Es gibt keinen, der seine Worte abändern könnte. Er ist der Hörende, der Wissende. “8 Und er sagt - Preis sei ihm!: „Mohammed ist nicht der Vater einer eurer Männer. Er ist vielmehr Gesandter Gottes und Siegel der Propheten; Gott hat über alles Wissen." ${ }^{\text {" Und Muhammad }}$ (sws) sagt: Wahrlich, ich und die Propheten vor mir sind wie ein Mann, der ein Haus gebaut hat, sich gut darauf verstand und es vollendet hat bis auf den Ort eines Backsteins in einer Ecke. So begannen die Leute, ihn zu umkreisen, darüber erstaunt zu sein und sprachen: Warum ist dieser Backstein nicht gelegt worden? Er sagte: So bin ich der Backstein und so bin ich das Siegel der Propheten. ${ }^{10}$

Dort liegt der Unterschied zwischen der Religion, die die Propheten an ihre Völker übermittelt haben, und zwischen dem religiösen Denken, das auf der Grundlage der Offenbarung in den Dimensionen von Ort und Zeit entstanden ist. Da, wo die Offenbarung außerhalb von Zeit und Raum, d.h. außerhalb der Geschichte, auf sie herabkam, da ist sie das Wort von Gott selbst: „Und Gott sprach mit Mose

\footnotetext{
${ }^{4}$ Ash-Shura (Die Beratung) 42:13.

${ }^{5}$ Al-Ma'ida (Der Tisch) 5:48.

${ }^{6}$ Al-Dschathia (Die auf den Knien liegt) 45:18.

${ }^{7}$ Al-An'am (Das Vieh) 6:124.

${ }^{8}$ Al-An'am (Das Vieh) 6:115.

${ }^{9}$ Al-Ahzab (Die Gruppen) 33:40.

${ }^{10}$ Überliefert durch BUCHARI, G. 3, 1300; und MUSLIM, G. 4, 1790.
} 
unmittelbar"11, auch wenn sie an die Zeitdimension angepasst ist, um der menschlichen Natur zu entsprechen. Denn das eine ist die Schöpfung Gottes und das andere das Wort Gottes, beide sind nicht miteinander austauschbar und im Widerspruch für ihn. Vielmehr sind die Taten der Menschen austauschbar und widersprüchlich. Jene Wahrheit bestätigt die Sure ar-Rum (Die Byzantiner) in großer Klarheit: „Und richte nun dein Antlitz auf die Religion, im rechten Glauben, als göttliche Begabung, mit welcher er die Menschen schuf! Keinen Ersatz gibt es für die Schöpfung Gottes. Das ist die Religion, die Bestand hat. Jedoch die meisten Menschen wissen nicht. Wenn ihr euch voll Reue zu ihm wendet - fürchtet ihn, und haltet das Gebet, und seid nicht solche, die beigesellen, die ihre Religion aufspalten und zu Parteien werden; eine jede Gruppe ist froh darüber, was ihr eigen ist."12 So rühren die Parteiungen und Unterschiede von den Merkmalen des religiösen Denkens her, nicht von der Religion selbst, und von den Phänomenen des menschlichen Lebens in seiner Beziehung zu Religion und Offenbarung, und nicht von den Bestandteilen der Offenbarung selbst.

Ungeachtet des berühmten Prophetenhadiths über das Wesen der Verschiedenheit - zu dem es eine reiche Diskussion gibt, die wir hier nicht behandeln können, - liegt der Maßstab für die ursprüngliche Religion, die repräsentiert ist in der herabgesandten Offenbarung, aus islamischer Perspektive: im edlen Koran. Er ist das unveränderliche [Zeugnis], das sich aus der unverfälschten Mitteilung der herabgesandten Offenbarung durch den Propheten ergibt: „Wir sandten die Mahnung zu dir herab, damit du den Menschen klarmachst, was zu ihnen herabgesandt ward. Vielleicht denken sie ja nach!"13 So sind das Buch und seine Mitteilung durch den Propheten das entscheidende Maß für die richtigen Auffassungen und die praktischen Umsetzungen des Islam im Laufe der Geschichte, und nicht das Gegenteil, wie es einigen Zeitgenossen erscheint. Gott sagt ( $t$ ): „Und wenn ihr über etwas streitet, dann bringt es vor Gott und den Gesandten, wenn ihr an Gott glaubt und an den Jüngsten Tag. Das ist gut und nimmt den besten Ausgang. “14 Er bestätigt jenes in seiner Rede - Preis sei ihm!: „Aber nein, bei deinem Herrn, sie glauben nicht - bis sie dich zum Richter machen über das, was zwischen ihnen strittig ist, und dann bei sich selber keinen Anstoß daran nehmen, was du entschieden hast, und sich gänzlich darein fügen. “15 Nur dass die Anrufung der Rechtsgewalt des Propheten und seine Antwort darauf zu seinen Lebzeiten durch ein unmittelbares Gesuch um Stellungnahme geschah, und man nach seinem Tod auf das Buch Gottes ( $\mathrm{t}$ ) und der feststehenden Sunna seines Propheten zugreifen muss. Aber wie und wer ist es, der uns das Buch erklärt, mit Blick auf die Vielzahl

\footnotetext{
${ }^{11}$ An-Nisa' 4:164.

${ }^{12}$ Ar-Rum (Die Byzantiner) 30:30-32.

${ }^{13}$ An-Nahl (Die Bienen) 16:44.

${ }^{14}$ An-Nisa' (Die Frauen) 4:59.

${ }^{15}$ An-Nisa' (Die Frauen) 4:65.
} 
der vorhandenen Beweisführungen? Und wer führt uns zur Sunna, die Erklärung und Beweis für das Wort Gottes ist, wenn doch die Gelehrten so viele und die Geistlichen so zahlreich sind?

Wir haben noch kein klares Bild von diesem Bereich, und daher ist die Antwort auf die wichtige Frage unvollständig. Sie betrifft das Problem des Verhältnisses zwischen der Religion als ein Phänomen der menschlichen Kultur, wie sie die Geschichte dokumentiert, und der Offenbarung, die im islamischen Verständnis das auf das Herz Muhammads (sws) herabgesandte Wort Gottes ( $t$ ) ist: „Siehe, er ist fürwahr herabgesandt vom Herrn der Weltbewohner. Mit ihm herab kam der getreue Geist in dein Herz, damit du Warner seist, in klarer arabischer Sprache. " ${ }^{16}$ [Wir haben das,] was uns übermittelt wurde, zweifelsfrei sicher in jedem Buchstaben in Hinsicht auf die vollständige Ausführung der Übermittlung, im Hinblick auf die schriftliche Fassung und im Hinblick auf die inhaltliche Korrektheit. Die Verse kamen auf ihn (sws) herab und er trug sie in einem öffentlichen Gebet in seiner edlen Moschee vor, und er befahl ein Buch aus seiner Offenbarung zu machen. Sie schrieben es auf die Materialien, die ihnen in jener Zeit leicht zugänglich waren und er gab sie jedes Jahr an Dschibril zurück, und er bewahrte sie selbst für seine Gefährten auf, die ihn für diese Darreichung begleiteten: „Warum zog dann nicht aus jeder Gruppe von ihnen eine Untergruppe aus, dass sie sich in der Religion belehren lasse und ihre Leute warne, wenn sie zurück zu ihnen kommt? Vielleicht nehmen sie sich ja in acht!"17 Und diese sind diejenigen, die die Entscheidungshoheit im Bereich des Wissens haben, gegenüber denjenigen, die die allgemeine Entscheidungshoheit haben. Die ersten sind die, die eine selbstständige wissenschaftliche Beurteilung (idschtihad) auszuführen vermögen, die anderen sind die, die politisch aktiv sind; die ersten sind die Rechtsgelehrten, die anderen die Befehlshaber; so wie der Gehorsam gegenüber den Befehlshabern in Allem, was nicht Ungehorsam gegenüber Gott bedeutet, nötig ist: „O ihr, die ihr glaubt! Gehorcht Gott, und gehorcht dem Gesandten und denen unter euch, die Befehlsgewalt besitzen! Und wenn ihr über etwas streitet, dann bringt es vor Gott und den Gesandten. “18 So entstanden in der islamischen Zivilgesellschaft eine Institution des Rechts und der Rechtsgelehrten sowie eine Institution des Regierens und der Befehlshaber. Dabei ist die Institution der Rechtsgelehrten auf die Wissenszweige der Offenbarung, des Buches, der Sunna und der arabischen Sprache spezialisiert. An sie wird eine Angelegenheit im Falle eines Streites verwiesen. Dies entspricht der Natur des menschlichen Lebens und der Entwicklung des religiösen Denkens; Gott ( $\mathrm{t}$ ) sagt: „Machen sie sich denn keine Gedanken über den Koran? Wäre er von einem anderen als Gott, so fänden sie gewiss viel Widersprüchliches in ihm. Wenn etwas zu ihnen dringt, was Sicherheit oder Furcht betrifft, verbreiten sie

\footnotetext{
${ }^{16}$ Ash-Shu'ara' (Die Dichter) 26:192-195.

${ }^{17}$ At-Tawba (Die Buße) 9:122.

${ }^{18}$ An-Nisa' (Die Frauen) 4:59.
} 
es. Würden sie es zum Gesandten bringen oder zu denen unter ihnen, die Befehlsgewalt besitzen, dann würden es sicher die erfahren, die es herauszufinden suchen. Wäre nicht Gottes Huld auf euch und sein Erbarmen, so wärt ihr - bis auf wenige - dem Satan gefolgt. “" ${ }^{\text {"19 }}$ Das sind diejenigen, die die Entscheidungshoheit im Bereich des Wissens haben oder Rechtsgelehrte der Gemeinde und ihre Vorbilder sind, die sich keiner Sache außer der Herrschaft der Offenbarung unterworfen haben und den Gesetzen ihrer Auslegung, nicht der Politik und ihren Tendenzen. Und wenn sie nun gleichzeitig zu einem bestimmten Zeitpunkt und an einem bestimmten Ort handeln, heißt das, dass sie in der Geschichte handeln, womit wir direkt auf das Thema der Tagung Bezug genommen haben.

Die Institution des Rechts ist eine der Institutionen der Zivilgesellschaft. Wir können uns vorstellen, dass die Institution der Azhar ein Beispiel dafür abgibt. Sie ist im Grunde eine wissenschaftliche und bekenntnisorientierte Institution und agiert dabei auf drei Ebenen.

Die Gelehrten sind Rechtsgelehrte, die das aufgezeichnete Recht studieren, die Allgemeinheit leiten, und ihnen $\mathrm{zu}$ ihren alläglichen Angelegenheiten Rechtsgutachten erstellen sowie Verwaltungsbeamte für ihre offiziellen Angelegenheiten, wenn sie bei ihnen Auskunft suchen.

Die Mudschtahidun erschließen die Gesetze selbstständig mittels ihrer Fähigkeit und ihrer Erwägung gemäß den Regeln der Deutung der Offenbarung und seiner Herabsendung unter den Voraussetzungen von Zeit und Raum. Ihre Arbeit hat im Grunde zwei Seiten: eine überlieferungstechnische Seite, die sich auf das Weitererzählen der Offenbarung bezieht, und eine verstandesmäßige Seite, die sich auf die Kenntnis der Gesellschaft bezieht. Und das sind diejenigen, die Rechtsgutachten zu modernen Fragen verfassen, welche das aufgeschriebene Recht auf dem Weg der direkten Herleitung aus der Offenbarung nicht umfasst. Dabei ziehen sie die Urteile der vorangegangenen Rechtsgelehrten heran, ohne dabei die Entwicklung des [eigenen] Verständnisses zu unterbrechen, wie einige sich einbilden, die in der Religion nicht fest gegründet sind.

Und die Gläubigen - da bin ich einer Meinung mit dem Imam an-Nawawi, die er im „Sharh“ äußert - pflegten eine vielgestaltige Gemeinschaft zu sein; unter den Gläubigen waren dabei mutige Kämpfer, Rechtsgelehrte, Überlieferer und Asketen, Leute, die das Gute befohlen und das Verwerfliche verboten haben (al-amr bil-ma'ruf wan-nahy 'an al-munkar) und noch weitere gute Arten [von Menschen]. Es ist nicht notwendig, dass sie vereint sind, wo sie doch bereits in allen Teilen der Welt verstreut waren. ${ }^{20}$ Keine Generation oder kaum eine verbleibt ohne solche Menschen, wie as-Suyuti in seinem Buch begründet hat: (Widerlegung dessen, der

\footnotetext{
${ }^{19}$ An-Nisa' (Die Frauen) 4:82f.

${ }^{20}$ AN-NAWAWI, Sharh 'ala sahih muslim, [Beirut, 1972], 13-65.
} 
ewig auf Erden bleibt und nicht weiß, dass der idschtihad in jedem Zeitalter eine Pflicht ist). Und auf dem Weg der Rechtsfindung, des idschtihad und der Erneuerung bleiben die Lehren der Propheten und die Rechtleitungen der Offenbarung bis zum Tag des Gerichts (Ein Zweig meiner Gemeinde wird immer die Wahrheit kennen und es werden sie nicht in die Irre führen, die nach ihnen kommen) ${ }^{21}$.

Hiermit mag ich etwas im Hinblick auf die Problematik gesagt haben, die Sie im Rahmen der Fragestellung dieses Treffens aufgeworfen haben. Das stammt jedoch nicht von mir. Ich habe nur Gedanken beigefügt, ${ }^{22}$ die von der Autorität der islamischen Offenbarung verbürgt sind. Ich habe mir keine andere Rede anstelle dieser erlaubt: „Und wir haben nur bezeugt, wovon wir Kenntnis hatten, und konnten das Verborgene nicht wenden.“ ${ }^{23}[12: 81]$

Friede sei mit euch und das Erbarmen Gottes und sein Segen.

\footnotetext{
${ }^{21}$ Von MUSLIM überliefert: 6-2766.

${ }^{22}$ Anm. des Übersetzers: Das ist ein Wortspiel mit dem Namen des Verfassers (shafa‘a, Shafii).

${ }^{23}$ Yusuf (Joseph) 12:81.
} 


\section{Offenbarung und Religion}

Ich möchte mit den Worten beginnen, die die Veranstalter diesem Treffen vorangestellt haben: Das Christentum und der Islam stützen sich auf die Norm einer göttlichen Offenbarung, repräsentiert durch den Koran oder durch die Person Jesu Christi und seine Bezeugung in der Heiligen Schrift. Diese Offenbarung ist eine ausreichende Autorität für Predigten und religiöse Praktiken sowie für alles, was im Namen der Religion gesetzlich eingeführt wird. Wir wollen im Folgenden eine Übersicht und eine Bewertung der kritischen und auf Neuerung drängenden Stimmen vornehmen, die wir als ein Phänomen der Kulturgeschichte betrachten, wie es im Zuge religiöser Reformbewegungen auftritt.

\section{Die Welle des Atheismus}

Es gab bereits eine Welle des Atheismus, und sie ist noch immer der Ton eines Sängers inmitten einer herrlichen Symphonie des Glaubens, die der Mensch zum Klingen bringt, so wie der Atheismus der missfällige Ton inmitten von Liedern des Glaubens ist, die der Gläubige singt und die die Menschen vortragen. Der Atheismus war - und ist noch immer - die neue Religion für diejenigen, die behaupten für Fortschrittlichkeit und gegen Reaktion zu kämpfen, den Modernismus für sich in Anspruch nehmen sowie die Fahnen des Säkularismus und der Tendenzen des wissenschaftlichen Sozialismus hochhalten.

Doch wuchs der Atheismus - überwiegend - mitten in jenen Gesellschaften, in denen die menschliche Erkenntnis auf die Wahrnehmung der den Sinnen offenkundigen Phänomene reduziert war. Und sie bestanden darauf, dass es überhaupt nichts vor jenen den Sinnen offenkundigen Phänomenen gebe und dass das Existierende nur das sinnlich Wahrnehmbare sei und für das, was die Sinne nicht in seinem Kern begreifen, bestimmten sie, dass es unmöglich existieren könne. So sind diese die Leute, die behaupten, dass jedes existierende Ding vielmehr ein Naturprodukt sei, dass die Welt ewig sei, keinen Anfang und keinen lenkenden Schöpfer habe und dass diese Welt dementsprechend ohne Endpunkt fortdauern werde.

Zur Widerlegung dieser materialistischen, atheistischen Tendenzen sagen wir:

Die Philosophen sind sich bereits mit den Vertretern einer logischen Haltung einig geworden, dass sich das Existierende in zwei Teile aufteilt:

1. Erster Teil: das notwendig Existierende, und das ist Gott, der Schöpfer allen Seins.

2. Zweiter Teil: das möglich Existierende, und das ist die Welt. 
Gott ist der ewige Seiende und der ewig Bestehende, während die Welt neu entsteht und ein einwirkendes Subjekt benötigt, das ihr die Existenz verleiht. So stellten diese Philosophen fest, dass die Welt eine materielle Existenz besitzt, die mit der Materie des Seins eng zusammenhängt, da all ihre Gesetze für sie wirksam sind. Zweitens besitzt sie eine geistige Existenz, die mit etwas anderem als dem Materiellen zusammenhängt und die einer anderen, höheren Existenz als der Welt der materiellen, existenziellen Gesetze unterworfen ist, und das ist Gott - Preis sei ihm und er ist erhaben.

Die Philosophen, Theologen und die Autoritäten im Islam haben bereits bemerkt, dass die existierenden irdischen Dinge zu ihren ursprünglichen Elementen zurückkehren, die da sind: Feuer, Luft, Wasser und Erde; und dass ihre gegenseitige Vermischung $\mathrm{zu}$ Bergen und Land werden, die nicht wachsen und sich nicht bewegen. Dann entstehen Pflanzen wie Holzgewächse und andere; sie sind auch Körper, nur dass sie wachsen ohne sich zu bewegen, und schließlich folgen die Tiere wie das Pferd, das Kamel, die Gazelle... usw., das heißt Körper, die wachsen, sich bewegen und materielle Empfindungen haben. Schließlich folgt an der Spitze der existierenden irdischen Dinge der Mensch. Er vereint in sich alles, was auf der Erdkugel an Elementen besteht, so ist er Körper, hat Wachstum und Empfindung, und unterscheidet sich außerdem dadurch, dass er vernunftbegabt ist, also logisch denkt und seinen Verstand gebraucht. So ist der Mensch entsprechend dieser Vorstellung - unter anderen - der Herr dieser Erde. Doch bestimmten die Denker des Islam, Philosophen und Theologen, dass derjenige, der dem Menschen dieses Merkmal verliehen hat, Gott ist, der Schöpfer dieser Erde. Sie waren bereits zu diesem Ergebnis vonseiten des Korans gekommen, in dem viele Verse über das Denken zu finden sind, wie seine Rede (t): „Und auch in euch selber. Könnt ihr denn nicht sehen?" ${ }^{\text {11 }}$ und seine Rede $(\mathrm{t})$ : „Wir werden ihnen unsere Zeichen zeigen, überall in der Welt und in ihnen selbst, bis ihnen klar geworden ist, dass er die Wahrheit ist.“2 Doch hatten bereits die Theologen und Philosophen bemerkt, dass die Fürsorge und der Schutz Gottes alle Geschöpfe umfassen und dass an der Spitze der Geschöpfe der Mensch steht, den Gott - er ist hoch und erhaben - geehrt hat. Denn Gott ( $t$ ) hat bereits gesagt: „Wir erwiesen den Kindern Adams Ehre.“3 Von daher sorgt sich Gott - er ist hoch und erhaben - um den Menschen. Er sandte bereits seine Propheten und Gesandten zu den Menschen insgesamt, angefangen bei Adam bis hin zum Siegel der Propheten, dem Gesandten Muhammad (sws), zur Leitung des Menschen in all seinen Gedanken und seinem Handeln, das mit seiner Person und den übrigen Menschen um ihn herum zusammenhängt. Die Botschaft dieser Propheten und Gesandten war die Religion Gottes, die dem Menschen auferlegt, sich ihm zuzuwenden und nach ihren Geboten und Verboten zu handeln, um für sich

\footnotetext{
${ }^{1}$ Adh-Dhariyat (Die Aufwirbelnden) 51:21.

${ }^{2}$ Fussilat (Erläutert wurde) 41:53.

${ }^{3}$ Al-Isra' (Die Nachtreise) 17:70.
} 
selbst die Glückseligkeit im Diesseits und im Jenseits zu verwirklichen. Die Gesamtheit der von Gott - Preis sei ihm und erhaben ist er- herabgesandten Regeln und Gesetze sorgt für Gerechtigkeit und Gleichheit unter den Menschen, wie sie erforderlich sind, um die Interessen der menschlichen Gattung nach ihrer Eigenart $\mathrm{zu}$ verwirklichen, um Sicherheit $\mathrm{zu}$ gewähren und damit Stabilität in der Gesellschaft herrscht.

Also, diejenige, die das umfassende Gesetz niederlegt, das die Regeln der Gerechtigkeit bewahrt, das ist die Religion Gottes ( $\mathrm{t}$ ). Sie ist es, die den Menschen ihre Verbindungen mit ihrem Schöpfer und ihre Beziehungen untereinander deutlich macht, damit ihre wichtigsten Interessen und ihr Glück im Diesseits und im Jenseits verwirklicht werden. Dadurch wird für uns klar, dass die Menschheit an den verschiedenen Flecken der Erde zum Zwecke der Fortdauer ihrer Existenz und ihres Lebens, für ihre Ordnung und Stabilität, für die wahrhafte Kenntnisnahme von ihrem Schöpfer und für die Hinwendung zu ihm allein in Gottesdienst und Heiligung einen hohen Bedarf an Religion hat, weitentfernt von der Abkehr einiger, und auch damit sie wissen, was Gott den Gläubigen im Jenseits an Lohn und dauerhaftem Glück und was er den Ungläubigen und Beigesellern an Strafe und schmerzlicher Pein bereitet hat, damit die Menschheit dem folgt, worin ihre Rettung, ihr Erfolg und ihr Glück im Diesseits und im Jenseits liegen.

\section{Hinwendung zum Pfad der Wahrheit und des Guten auf dem Pfad der Propheten Gottes und seiner Gesandten}

Die islamischen Philosophen und Theologen haben bemerkt, dass die menschlichen Bedürfnisse nicht auf Essen und Trinken beschränkt sind, die rein tierische Veranlagungen sind, sondern dass das Innere des Menschen nach mehr als diesem verlangt, dass es einer geistigen Nahrung bedarf, um den richtigen Weg zu kennen, um lauter, rein und gehorsam für seinen Schöpfer zu sein sowie den Weg der Wahrheit und des Guten durch die Schwierigkeiten des Lebens hindurch aufzudecken. Der Pfad, den Gott ( $\mathrm{t}$ ) gewählt hat, um die Menschen auf ihm zur Kenntnis der Wahrheit und des Guten zu leiten, ist bekannt unter dem Namen des Prophetentums: Die Propheten und Gesandten Gottes sind Männer der Führung und der Rechtleitung auf dem Weg der Wahrheit und der Aufrichtigkeit.

\section{Die Pflicht des Glaubens an die Propheten Gottes und seine Gesandten}

Es sind Verse des edlen Korans herabgekommen, die die Pflicht des Glaubens an alle Propheten Gottes und seine Gesandten festsetzen, die Gott zu den verschiedenen Völkern durch die menschlichen Zeitalter hindurch gesandt hat; Gott (t) sagte: „Die Frömmigkeit besteht nicht darin, dass ihr euer Angesicht gen Osten oder Westen wendet, vielmehr ist Frömmigkeit, an Gott zu glauben und an den jüngsten Tag und 
an die Engel, an das Buch und die Propheten.“4 Und er sagte (t): „O ihr, die ihr glaubt! Glaubt an Gott und seinen Gesandten und an das Buch, das er auf ihn herabgesandt. Denn wer an Gott nicht glaubt und seine Engel, seine Bücher, seine Gesandten und den Jüngsten Tag, der ist schon sehr weit abgeirrt. ${ }^{\text {“5 }}$ Als der Prophet Muhammad (sws) über den Glauben befragt wurde, sagte er: „Dass du an Gott glaubst, seine Engel, seine Bücher, seine Gesandten, den Jüngsten Tag und seinen Bescheid über sein Gutes und sein Schlechtes." Von daher wird uns deutlich, dass der Islam dem, der an ihn glaubt, zur Pflicht gemacht hat, an alle Propheten Gottes und seine Gesandten und an seine Bücher zu glauben - erhaben ist, der sie ihnen gesandt hat -, da sie alle zur Rechtleitung des Menschen und seinem Glück in diesem Leben und im nächsten Leben aufrufen.

Von daher erschienen die Propheten Gottes ( $\mathrm{t}$ ) als Leitung der Rechtgeleiteten für die Menschheit und sie gaben das höchste Beispiel für die Menschheit ab, damit die Menschen ihnen nacheiferten. Gott sagte ( $\mathrm{t}$ ): „Ihr habt ja im Gesandten Gottes ein schönes Vorbild.“6 Und der edle Koran bestätigte für die Menschheit die Gesandten in zahlreichen Versen, er sagte ( $\mathrm{t}$ ): „Oder erstaunt es euch, dass zu euch Mahnung kommt von eurem Herrn, durch einen Mann aus eurer Mitte, dass er euch warne und dass ihr Gott fürchten sollt? Vielleicht findet ihr ja Erbarmen. ${ }^{\text {"7 }}$ Und er sagte (t), als er zum Propheten Muhammad (sws) sprach: „Auch vor dir sandten wir nur solche Männer, denen wir eine Offenbarung gaben - sie waren aus ,den Städten“." ${ }^{8}$ Jeder einzelne dieser Propheten und Gesandten verkündete seiner Menschheit, er sagte (t): „Zu ihnen sprachen ihre Gesandten: ,Wir sind - wie ihr - nur Menschen; doch Gott erweiset, wem er will von seinen Knechten, Gnade.“" Der Koran verdeutlichte bereits, dass die Auserwählung der Propheten durch Gott ( $\mathrm{t}$ ) sie nicht aus dem Zustand des Menschseins heraushebt, und deshalb setzt der edle Koran fest, dass Gottes Gesandte und seine Propheten wie die anderen Menschen sind und sich von ihnen nicht unterscheiden außer durch das Prophetentum und die Gesandtschaft, so dass sie ein Vorbild für die Menschen seien, die ihnen in ihren Worten und in dem, was sie von Gott an Glaubensgrundsätzen, gottesdienstlichen Pflichten und Benimmweisen brachten, folgten. Der edle Koran bestimmt, dass die Rolle der Propheten und Gesandten - Gottes Segen und sein Heil sei auf ihnen - die Rolle der Führung und der Rechtleitung auf dem Wege der Wahrheit und des Guten sowie des Glücks des Menschen ist sowie die Warnung davor, vom rechten Weg abzukommen wie auch die Warnung vor dem Weg der Sünde, der zum Unglück der Menschheit führt und auch dahin, dass sie Gottes Strafe und Qual im diesseitigen Leben verdienen.

\footnotetext{
${ }^{4}$ Al-Baqara (Die Kuh) 2:177.

${ }^{5}$ An-Nisa' (Die Frauen) 4:136.

${ }^{6}$ Al-Ahzab (Die Gruppen) 33:21.

${ }^{7}$ Al-A'raf (Die Höhen) 7:63.

${ }^{8}$ Yusuf (Joseph) 12:109.

${ }^{9}$ Ibrahim (Abraham) 14:11.
} 
Der Koran legt fest, dass im Gehorsam des Menschen gegenüber den Propheten und Gesandten und in der reinen Absicht ihrerseits Gehorsam gegenüber Gott und reines Bekenntnis zu ihm liegt und dass im Ungehorsam der Menschen gegenüber den Propheten und Gesandten Ungehorsam ihm gegenüber $(t)$ ist, er sagte $(t)$ : „Sprich: „Wenn ihr Gott liebt, dann folgt mir nach, denn dann liebt euch auch Gott und vergibt euch eure Missetaten!" Siehe, Gott ist bereit $\mathrm{zu}$ vergeben und barmherzig. "

\section{Die Einheit der himmlischen Botschaften in ihren Grundlagen und Ursprüngen}

Da die Propheten und Gesandten eine auserwählte Auslese unter den Menschen darstellen und von dem einen Sender, nämlich Gott $(\mathrm{t})$, geschickt wurden, so hat bereits die göttliche Weisheit bestimmt, dass ihre Botschaft in ihren allgemeinen Grundlagen und Ursprüngen eine sein sollte - ohne Unterschied in den Glaubensgrundsätzen, zu denen sie aufriefen und ohne Unterschied im Geiste der gottesdienstlichen Pflichten, die sie geboten, wie auch in den materiellen und ethischen Prinzipien des Zusammenlebens, zu denen sie auffordern.

Wenn wir aber einige Unterschiede in den göttlichen gesetzlichen Bestimmungen von einer Botschaft zur nächsten im Erlaubten und Verbotenen erkennen und in den Formen der gottesdienstlichen Handlungen, die sich jeweils aus ihren Ursprüngen ergeben, so verweist dies auf eine Weisheit, die fein abgestimmt ist auf die Art und Weise der Erziehung und Förderung eines jeden Volkes, die Prüfung seines Gehorsams und seiner Gleichnisse für die Gebote und Verbote Gottes ( $t$ ). Dies geschieht mit Blick auf die Natur jener Völker und den Stand ihrer Bräuche und Traditionen, ihrer Kultur und ihres jeweiligen Gesellschaftsverständnisses sowie im Blick auf die Möglichkeit ihrer Entwicklung von einem Zustand zum nächsten nach Maß ihrer geistigen, gesellschaftlichen und ethischen Rückständigkeit. Die Botschaften Gottes ( $\mathrm{t}$ ), selbst wenn sie sich durch die Vielzahl der Propheten und Gesandten vervielfachten, waren hinsichtlich der Grundlagen und Regeln stets eine.

So ist die Religion eine: die Offenbarung Gottes an seine Propheten und Gesandten. Sie ist ein Ausdruck der Ursprünge, für die es keine Veränderung durch Abrogation gibt und in denen die göttlichen Botschaften, die eine ewige Rechtleitung sind, sich nicht voneinander unterscheiden. Nur die Botschaften der Propheten und Gesandten sind verschieden in den praktischen Bestimmungen, die sich unterscheiden, da Gott ( $\mathrm{t}$ ) die zur Situation jedes Volkes passenden Gesetze herabgesandt hat. So unterscheiden sich die Gesetze lediglich nach Maß der Unterschiedlichkeit der Umstände und Situationen. Gott (t) sprach: „Für einen jeden von euch haben wir Bahn und Weg gemacht. "“11 (Das heißt Weg und Sunna [....]

\footnotetext{
${ }^{10} \mathrm{Al}$ 'Imran (Das Haus 'Imran) 3:31.

${ }^{11}$ Al-Ma'ida (Der Tisch) 5:48.
} 
und verschiedene Sunnas, für die Tora gibt es eine Gesetzgebung, für das Evangelium eine Gesetzgebung, für den Koran gibt es eine Gesetzgebung, in der Gott erlaubt, was er will, und verbietet, was er will, als Prüfung, damit er weiß, wer ihm gehorcht und wer sich ihm widersetzt. Doch ist die Religion eine, keine andere als sie akzeptiert er und sie ist das Einheitsbekenntnis und die reine Absicht, mit der die Gesandten gekommen sind) $)^{12}$

Das Siegel der Propheten und Gesandten rief bereits zu demselben auf, zu dem alle vorhergehenden Propheten und Gesandten aufriefen, nämlich zu Gottesfurcht und zum Sich-Führen-Lassen durch seine Rechtleitung, so sagte Gott ( $t$ ), als er zu seinem besiegelnden Propheten (sws) sprach: „Dir wird nur das gesagt, was den Gesandten vor dir schon gesagt ward. “13

\section{Wahrlich, die Religion bei Gott ist der Islam}

Diese Religion, mit der Gott alle Propheten von Adam bis hin zu ihrem Siegel Muhammad (sws) sandte, ist der Islam. So sprach Gott ( $t$ ) über Noah - auf ihm sei Friede - aus seinem Munde: „Und mir ward befohlen, ein Gottergebener zu sein.“14 Er (t) sagte es auch mit Abraham, Jakob und Ismael: „Unser Herr! Mach uns beide zu dir Ergebenen, und mach auch aus unseren Kindeskindern eine Gemeinde, die dir ergeben ist!“15, und aus dem Munde des rechtschaffenen Josef - auf ihm sei Friede: „Du bist mein Schutzpatron im Diesseits wie im Jenseits. Nimm mich als Gottergebenen zu dir, und reihe mich bei den Rechtschaffenen ein! "16 Und über die Jünger Jesu - auf ihm sei Friede: „Als aber Jesus den Unglauben bei ihnen spürte, sprach er: „Wer sind denn meine Helfer hin zu Gott?“ Die Jünger sprachen: „Wir sind die Helfer Gottes. Wir glauben ja an Gott. Sei du dafür Zeuge, dass wir Gott ergeben sind!“17 Und aus dem Munde Muhammads (sws) sprach er (t): „Siehe, mir wurde befohlen, der Erste zu sein, der sich Gott ergibt!“"18, „Und: „Befohlen wurde mir, Erster der Gottergebenen zu sein. ${ }^{\text {"19 }}$ Und schließlich setzte Gott $(\mathrm{t})$ fest, dass die Religion des Wohlgefallens bei ihm der Islam ist, da er es ist, mit dem Gott seine Propheten und Gesandten schickte, Gott ( $\mathrm{t}$ ) sagte: „Siehe, die Religion bei Gott ist der Islam. “ ${ }^{20}$ Und er sagte $(\mathrm{t})$ : „Wer eine andere Religion begehrt als den Islam, so wird die von ihm nicht angenommen werden." ${ }^{21}$

\footnotetext{
12 ABU DSCHA'FAR MUHAMMAD IBN DSCHARIR AT-TABARI, Tafsir: Dschami'al-bayan fi ta'wil alqur'an [Kairo, 1955], Band 6, 174.

${ }^{13}$ Fussilat (Erläutert wurde) 41:43.

${ }^{14}$ Yunus (Jona) 10:72.

${ }^{15}$ Al-Baqara (Die Kuh) 2:128.

${ }^{16}$ Yusuf (Joseph) 12:101.

${ }^{17} \mathrm{Al}$ 'Imran (Das Haus Imran) 3:52.

${ }^{18}$ Al-An'am (Das Vieh) 6:14.

${ }^{19}$ Az-Zumar (Die Scharen) 39:12.

${ }^{20} \mathrm{Al}$ 'Imran (Das Haus Imran) 3:19.

${ }^{21} \mathrm{Al}$ 'Al s (Das Haus Imran) 3:85.
} 


\section{Die Vollendung der Botschaften durch ihr Siegel, durch Muhammad (sws)}

Die Botschaften Gottes ( $t$ ) folgten einander in ihrer Herabsendung auf die Propheten und Gesandten. Jeder einzelne von ihnen bewahrheitete, was ihm voranging, und bereitete für denjenigen vor, der nach ihm kam, er sagte ( $t$ ): „Und auf dich sandten wir herab das Buch mit der Wahrheit; es bestätigt, was von dem Buch schon vorher da war, und gibt darüber Gewissheit. So richte zwischen ihnen nach dem, was Gott herabgesandt hat.“22 Und er sagte: „Heute habe ich euch eure Religion vollständig gemacht und meine Gnade an euch vollendet und habe daran Gefallen, dass der Islam eure Religion ist. “" ${ }^{23}$ Und es überlieferte bereits at-Tabari von Ibn 'Abbas - Gott habe an ihnen Wohlgefallen - in seinem Kommentar zu diesem Vers: (Gott teilte seinem Propheten (sws) und den Gläubigen mit, dass Gott für sie bereits den Glauben vervollständigte und sie überhaupt nichts Zusätzliches benötigen). ${ }^{24}$ Es sind bereits zahlreiche Texte in den Büchern der vorangegangenen Propheten gekommen, die alle Prophezeiungen und Ankündigungen des Siegels der Propheten und Gesandten Muhammad (sws) sind, gleichermaßen in den Büchern des Alten Testaments wie in den Büchern des Neuen Testaments, insbesondere im Zusammenhang mit dem Parakleten, der Ahmad, Muhammad und Mahmud ist, die mit dem übereinstimmen, was im edlen Koran in seiner Rede ( $t$ ) herabgekommen ist: „Und einen Gesandten anzukündigen, der nach mir kommt und dessen Name Ahmad ist! “" Und es sind neue Untersuchungen erschienen, die bestätigen, dass das Wort Parakletos, das ins Englische übersetzt "Comforter" heißt, der „Tröster“ ist, den der Messias - auf ihm sei Friede - nennt. Aber das Wort Parakletos, das heißt: der Erhabene, Gepriesene, oder der Wohlbekannte, Berühmte, dessen Befehl die Leute preisen, stimmt in jeglicher Hinsicht mit dem arabischen Namen Ahmad und Muhammad überein; so haben einige ihn bereits ins Englische mit „the praised one“ übersetzt.

\section{Die Offenbarung}

Die Offenbarung ist der Kern und die Grundlage des Prophetentums. Viele derer, die es schmähten, haben dies durch die Verneinung der Offenbarung, sowohl ihrer Möglichkeit als auch ihres Eintretens, getan. Einige hielten es für unmöglich, dass die Menschheit mit dem Schöpfer - Preis sei ihm, er ist erhaben - in Verbindung tritt; eine Zustimmung zu dieser Meinung würde zum Zusammensturz der Grundlage des Prophetentums führen.

\footnotetext{
${ }^{22}$ Al-Ma'ida (Der Tisch) 5:48.

${ }^{23}$ Al-Ma'ida (Der Tisch) 5:3.

${ }^{24}$ AT-TABARI, Tafsir (s. Anm. 12), Band 9, 518.

${ }^{25}$ As-Saff (Die Reihe) 61:6.
} 
Die Offenbarung ist in der arabischen Sprache die Mitteilung (al-ilam) im Verborgenen. Es wird gesagt: Ich habe ihm eingegeben (wahaitu ilaihi; auhaitu ilaihi), wenn er ihn anspricht mit etwas, das er anderen verheimlicht; und in der Terminologie der Juristen: Die Mitteilung Gottes vollzieht sich entweder durch das Buch, durch die Sendung eines Engels, im Traum oder durch die Eingebung der Gesetzgebung.

So gibt es vier Arten der Eingebung:

Die erste: Das ist die Schau im Traum; so war die wahrhafte Schau das erste, womit die Offenbarung an unseren Propheten Muhammad (sws) begann; und diese Art der Eingebung mittels einer Schau im Traum ist unserem Herrn Abraham wiederfahren - auf ihm sei Friede -; er sagte (t) über Abraham, während Ismael bei ihm war: „Als er mit ihm den Lauf erreichte, sprach er: ,Mein Sohn! Ich sah im Traum, dass ich dich opfern soll. Nun sieh, was meinst du dazu?` Er sprach: ,Mein Vater, handle so, wie dir befohlen wird; du wirst mich, so Gott will, geduldig finden.' Als sich die beiden in ihr Geschick gegeben hatten und er ihn auf die Stirn geworfen hatte, da riefen wir ihm zu: ,o Abraham! Du hast den Traum für wahr gehalten.' Siehe, so belohnen wir die, die Gutes tun. Siehe, das war die klare Prüfung! Durch ein herrliches Schlachtopfer schafften wir Ersatz für ihn. “26

Die zweite Art: Das Sprechen ohne Vermittlung und das ist, wenn Gott - Preis sei ihm und er ist erhaben - seinen Propheten ohne Vermittlung unmittelbar anspricht. Das geschah Muhammad (sws) in der Nacht der Himmelsreise (mi'radsch), er sagte (t): „Da offenbart` er seinem Knechte, was er ihm offenbarte.“ ${ }^{27}$ Ebenso geschah diese Art Mose - auf ihm sei Friede - beim vertraulichen Gespräch, er sagte (t): „Und Gott sprach mit Mose unmittelbar.“ ${ }^{28}$

Die dritte Art: Die Eingebung mittels der Engel. Das ist, wenn der Engel kommt, dann mit dem Propheten spricht und ihm übermittelt, was Gott $(\mathrm{t})$ in seinem Auftrag befohlen hat. Bei dieser Art der Eingebung ist es meistens Gabriel - auf ihm sei Friede -, der eingibt und zum Propheten (sws) mit den Versen des edlen Koran herabkommt; er sagte (t): „Mit ihm herab kam der getreue Geist in dein Herz, damit du Warner seist, in klarer arabischer Sprache. ${ }^{\text {“29 }}$

Die vierte Art der Offenbarung ist die Eingebung. Das ist, wenn Gott $(\mathrm{t})$ in das Herz des Propheten all das legt, was Gott $(\mathrm{t})$ als Gewusstes will, und zwar mit der Gewissheit des Propheten, dass dies von Gott ( $\mathrm{t}$ ) kommt. Gott $(\mathrm{t})$ erwähnte bereits die Arten der Offenbarung in seiner Rede (t): „Keinem Menschen steht es an, dass Gott mit ihm spricht, es sei denn, durch Eingebung oder hinter einer Trennwand,

\footnotetext{
${ }^{26}$ As-Saffat (Die sich Reihenden) 37:102-107.

${ }^{27}$ An-Nadschm (Der Stern) 53:10.

${ }^{28}$ An-Nisa' (Die Frauen) 4:164.

${ }^{29}$ Ash-Shu'ara' (Die Dichter) 26:193-195.
} 
oder aber er sendet einen Gesandten, dass der mit seiner Erlaubnis offenbart, was er will. Siehe, er ist erhaben, weise. “"

So kam die Offenbarung entsprechend dieser vier Arten auf die Propheten und Gesandten von Adam bis zu Muhammad (sws), ihrem Siegel, herab. So ist also die Offenbarung der Kern und die Grundlage des Prophetentums. Wer also an das Prophetentum und die Propheten Gottes und seine Gesandten sowie seine Bücher, die er auf die Gesandten herabsandte, glaubt, der glaubt zweifellos an die Offenbarung, durch die sich diese Propheten von dem Rest der menschlichen Individuen unterscheiden. Diese Offenbarung verlieh allem, was sie brachte und was offenbart wurde, Erhabenheit und Heiligkeit. Diese Erhabenheit und Heiligkeit nun gilt für die Texte der von Gott offenbarten Bücher, die auf die Propheten und Gesandten herab gesandt wurden. Sie sind im Hinblick auf die Tatsache, dass sie den religiösen Text überbringen, unverbrüchlich miteinander verbunden. Was aber die Bedeutungen angeht, so mag sich hier das menschliche Denken in die Interpretation der Texte einschalten, je nachdem, wie die Texte durch Wahrheit und Metapher bestimmt sind. So kann der religiöse Text definitiv sein, was seine Endgültigkeit und seine Bedeutung angeht, oder er kann nur hinsichtlich seiner Endgültigkeit definitiv sein und damit in seiner Bedeutung ungewiss bleiben.

${ }^{30}$ Ash-Shura (Die Beratung) 42:51. 
Reinhold Bernhardt

Religion und Offenbarung

\section{Religion und Säkularisierung (Weltbezug)}

Ich beginne mit der Erzählung einer kleinen Begebenheit, die sich in den 1950er Jahren in der sowjetisch besetzten Zone Deutschlands zutrug. Der Präsident einer deutschen evangelischen Landeskirche, Martin Niemöller, begegnete einem General der sowjetischen Armee. Im Verlauf des Gesprächs zwischen beiden sagte der General: „Mit der Religion geht es ja nun bald zu Ende“. Und der Kirchenpräsident antwortete: "Ja, das glaube ich auch“. Der General glaubte nicht richtig gehört zu haben und fragte nach. Niemöller erklärte ihm, dass er das ganz ernst meine. Die Religion sei nur ein Gewand der Offenbarung, noch dazu ein Gewand, das die Offenbarung mehr verhülle als enthülle. Und wenn dieses Gewand im Prozess der neuzeitlichen Säkularisierung absterbe, dann sei das nur gut, weil dann das Licht der Offenbarung umso heller leuchten könne.

Niemöller brachte mit dieser Haltung eine Überzeugung zum Ausdruck, die seit dem Ersten Weltkrieg unter den evangelischen Theologen weit verbreitet war. Der Begriff "Religion“ war negativ besetzt und wurde abgelehnt. Ich will dieses Verständnis an Dietrich Bonhoeffer, einem der bedeutendsten evangelischen Theologen des 20. Jahrhunderts, kurz herausarbeiten.

Auch Bonhoeffer ging davon aus, dass wir einer vollkommen religionslosen Zeit entgegengehen, und er begrüßte diese Entwicklung hin zur Säkularisierung. Für ihn bedeutete Religion die Domestizierung Gottes. Die Religion weist Gott einen bestimmten Bereich der Wirklichkeit zu, sei es die Innerlichkeit des Menschen, sei es die sakrale Sphäre der Kirche, sei es das Jenseits. Im ersten Fall wird Gott in der Frömmigkeit des Menschen gesucht, im religiösen Bewusstsein, in der spirituellen Erfahrung oder - wie die Mystiker gesagt haben - auf dem Seelengrund des Menschen. Diese Suche kann zu einer Abwendung von der Welt führen. Im zweiten Fall wird Gott hinter der Welt gesucht. Das Leben des Menschen ist eine beschwerliche Wanderung durch ein dunkles Jammertal. Wenn er sich darin bewährt hat, tritt er nach seinem Tod in die Lichtsphäre Gottes ein. Diese Vertröstung auf ein Jenseits hatte besonders die Religionskritik des 19. Jahrhunderts kritisiert. Karl Marx sah in der Religion bekanntlich „Opium für das Volk“, das den Widerstand gegen ungerechte Lebensverhältnisse unterdrückt. Im dritten Fall wird Gott in einem sakralen Bezirk gesucht, in der Kirche mit allem, was ihre Lehre und ihre Praxisformen ausmacht. In allen drei Fällen wird Gott ein bestimmtes Refugium zugewiesen - im ersten Fall die Innenwelt des Menschen, im zweiten Fall die Hinterwelt des Jenseits und im dritten Fall die Sonderwelt der Kirche. Alle diese drei Platzanweisungen führen aus der Welt heraus und machen Gott den Anspruch streitig, dass die gesamte Wirklichkeit der Raum seiner machtvollen Gegenwart ist. 
Bonhoeffers Kritik richtet sich also gegen die Zurückdrängung Gottes auf eine abgrenzbare Sphäre der Wirklichkeit, der gegenüber dann die Lebenswelt des Menschen religiös abgewertet wird. Diese Abwertung kann verschiedene Formen annehmen: In der milderen Form stellt sie die Welt als einen Ort der Fremde und Heimatlosigkeit für den Glaubenden dar. In der radikaleren Form verteufelt sie die Welt als Herrschaftsbereich der Sünde. Auf jeden Fall erscheint die Welt gegenüber der religiösen Sphäre als gottferne oder gottlose Wirklichkeit. Weil Gott in einer der genannten Sphären ,wohnt', wird die Welt als mehr oder weniger gottfreier Raum angesehen. So kann gerade die religiöse Weltsicht zu einem Säkularismus führen.

Gegenüber einem solchen religiösen Säkularismus fordert Bonhoeffer eine wohlverstandene Säkularität des christlichen Glaubens. „Gott ist mitten im Diesseits jenseitig“, schreibt er in einem Brief aus dem Gefängnis. Damit betont er den Weltbezug des christlichen Glaubens. Gott ist mitten in der Welt, in der wir leben, präsent, geht aber darin nicht auf. Er nimmt die Welt in Anspruch und ruft Menschen in Verantwortung für eine Weltgestaltung im Sinne der christlichen Ethik. Das ist das Thema der Ethikfragmente, die Bonhoeffer vor seiner Inhaftierung geschrieben hat.

Für das Gespräch mit dem Islam scheint mir dieser Ansatz interessant zu sein. Der Islam unterscheidet zwischen „Islam“ als einer grundlegenden Haltung des Menschen und „Islam“ als einer geschichtlichen Religion, die mit der Offenbarung des Korans entstanden ist. Die Haltung der gehorsamen Hingabe an Gott kann und soll sich im Alltag der Welt realisieren. Sie soll das ganze Handeln des Menschen bestimmen.

Aber gibt es nicht auch im Islam Ansätze zur Unterscheidung zwischen den weltlichen Dingen und den Dingen, die Gott betreffen; und dementsprechend zwischen der alltäglichen Lebenswelt und bestimmten ,heiligen' Wirklichkeitsbereichen, in denen Gott besonders intensiv erfahren wird. Ich denke dabei an die Koranrezitation oder das Gebet, an den Dschihad als besondere Glaubensanstrengung, an die umma als beste aller menschlichen Gemeinschaften, an die Hoffnung auf das Jenseits als Vollkommenheitsform des Lebens. Weisen diese Sphären nicht in eine ähnliche Richtung wie die von Bonhoeffer genannten Bereiche?

Ganz grundsätzlich kann man fragen: Liegt in der Religion nicht immer die Tendenz, besondere Heiligkeitsbereiche auszuweisen und sie der Alltäglichkeit des Lebens gegenüberzustellen? Ist es nicht geradezu ein Wesenszug der Religion, auf solche Inseln der besonderen Gottesgegenwart hinzuweisen und diese Inseln kultisch zu kultivieren? Dabei kann es aber immer auch geschehen, dass die Religion die Deuteund Vollzugshoheit über die dort angebotene Gottesvermittlung in Anspruch nimmt, dass sie sich also zur Hüterin dieser Inseln aufspielt. Und genau an diesem Punkt kann es dann zum Konflikt zwischen Offenbarung und Religion kommen. Es 
kommt $\mathrm{zu}$ diesem Konflikt, wenn einerseits die Offenbarung einen Universalanspruch geltend macht, wenn sie also die gesamte Wirklichkeit als Herrschaftsbereich Gottes beansprucht, und wenn andererseits die Religion ihre eigenen Medien als privilegierte Wege der Gottesvermittlung deklariert.

Als ein solcher Konflikt lässt sich die Reformation im 16. Jahrhundert deuten. Die römisch-katholische Kirche hatte die Vermittlung der Gnade Gottes an kirchliche Vollzüge gebunden: an die von der Kirche gewährte Schuldvergebung, die auch mit Geld erkauft werden konnte; an das Amt des Bischofs und des von ihm geweihten Priesters, der in der Eucharistie das substantiell verstandene Heil austeilen konnte; an die Institution der Kirche selbst, die allein die Gemeinschaft der voll verwirklichten Heiligkeit darstellt. Dagegen haben die Reformatoren protestiert. Sie kritisierten die kirchliche Religion im Namen der Christusoffenbarung. Die gesamte kirchliche Praxis und das theologische Denken wurden im Lichte dieser Kritik umgestaltet. Nicht die Kirche, sondern Christus wurde als Gottesmittler wieder in den Mittelpunkt gerückt.

Bonhoeffers Religionskritik nimmt diesen Impuls auf und fragt nun auch die evangelische Kirche und das reformatorische Christentumsverständnis, wo es seinerseits der Tendenz der Religion erlegen ist, die in Christus offenbarte universale Gottesgegenwart $\mathrm{zu}$ domestizieren, das heißt: sie an bestimmte Wirklichkeitsbereiche $\mathrm{zu}$ binden und damit in die Verfügung von Menschen $\mathrm{zu}$ geben, die für diese Wirklichkeitsbereiche Autorität beanspruchen.

Das führt uns vor die Grundfrage, ob Religion nicht immer in der Gefahr steht, die Offenbarung Gottes verfügbar zu machen. Einerseits bedarf es der autorisierten Auslegung der Offenbarung, und dazu bedarf es autorisierter Ausleger. Es bedarf Praxisformen, in denen die Offenbarung im Leben der Menschen Gestalt gewinnt: Im Islam sind das vor allem die fünf Säulen, im Christentum ist es das gesamte kirchliche Leben mit dem Gottesdienst als Zentrum. Andererseits kann es aber immer passieren, dass sich die damit verbundenen religiösen Autoritäten und Regelwerke verhärten, indem sie Gehorsam für sich selbst und nicht mehr für die Offenbarung beanspruchen. Wenn das geschieht, wird es über kurz oder lang zu einer theologischen Religionskritik im Namen der Offenbarung kommen. In allen Offenbarungsreligionen liegt diese Gefahr der relativen Verselbständigung der Religion gegenüber der offenbarung begründet, und deshalb kam es in der Geschichte dieser Religionen auch immer wieder $\mathrm{zu}$ Reform- und Erneuerungsbewegungen. In solchen Bewegungen wird die Spannung zwischen offenbarung und Religion manifest.

\section{Religion als Selbstherrlichkeit des Menschen?}

In einem zweiten Teil meines Vortrags will ich nach dem Religionsverständnis fragen, in dem die theologische Religionskritik verwurzelt ist, die bei vielen 
Theologen zur Zeit Bonhoeffers weit verbreitet war. Um dieses Verständnis von „Religion“ herauszuarbeiten, unterscheide ich grob zwischen drei Bedeutungen dieses Begriffs in der abendländischen Geistesgeschichte.

In der ersten der drei Bedeutungen meint „Religion“ die Verehrung Gottes (cultus Dei / cultus Deorum). Wir finden diese Bedeutung in der Antike, im Mittelalter bis in die frühe Neuzeit hinein. Es war nicht eigentlich ein theologischer, sondern eher ein - wie man heute sagen würde - soziologisch-praktischer und auch ein rechtlicher Begriff. Er bezeichnete eine bestimmte Praxis, also kultische Handlungen, mit denen die Gott geschuldete Verehrung praktiziert wurde.

Nach diesem Verständnis konnte es keinen Konflikt zwischen Offenbarung und Religion geben. Offenbarung war der Grund der Religion als kultischer Praxis. Religion führte aus, was sich aus der Offenbarung als Forderung ergab.

In der zweiten der drei Bedeutungen ist „Religion“ ein Allgemein- oder Gattungsbegriff, der die verschiedenen geschichtlichen Religionen - die jüdische, christliche, islamische Religion - als spezifische Exemplare der Gattung „Religion“ zusammenordnet. Dieses Verständnis, das sich in der Aufklärung entwickelt hat, ist bis heute im Abendland vorherrschend. „Religion“ bezeichnet demnach eine historisch greifbare Religionsgemeinschaft und das mit ihr verbundene System von Überzeugungen, Praxisformen und sozialen Institutionen. Weil es aber diese Gemeinschaften im Plural gibt, ist mit dem so verstandenen Religionsbegriff (als Oberbegriff) immer auch eine doppelte Beziehungsbestimmung thematisiert: zum einen die Beziehung zwischen dem Einzelnen und dem Allgemeinen, also zwischen der konkreten einzelnen Religion (dem Judentum, Christentum und Islam) und dem Wesen der Religion. Diese Frage war im ganzen 19. Jh. bis über die Mitte des 20. Jhs. hinaus - von Schleiermacher bis Tillich - das vorherrschende Thema der Theologie und Religionsphilosophie. Zum anderen die Beziehung zwischen den einzelnen Religionen. Diese Frage ist schon in Lessings Ringparabel aufgeworfen worden. Damals stellte sie sich noch eher als philosophisches Problem, heute ist sie von drängender Aktualität.

Die Beziehung von Religion und Offenbarung kommt dabei im Rahmen einer Deutung der religiösen Vielfalt zur Sprache. Es gibt mehrere Offenbarungen als grundlegende Bezugspunkte mehrerer Religionen. Wie verhalten sie sich zueinander? Können sie nebeneinander bestehen? Überbieten sie sich? Schließen sie sich aus? Von „Offenbarung" und „Religion“ ist dabei in einer religionsphänomenologischen Perspektive die Rede, also nicht aus der Sicht einer bestimmten Religion, so wie es beim ersten Modell der Fall war und wie es beim jetzt vorzustellenden dritten Modell wieder der Fall sein wird.

In der dritten der drei Bedeutungen ist „Religion“ nicht kultisch und nicht religionsgeschichtlich, sondern anthropologisch bestimmt: als eine Anlage in der Psyche des Menschen und als die daraus erwachsenen intellektuellen und 
praktischen, individuellen und kollektiven Vollzüge. Der Gedanke, dass der Mensch von Natur aus religiös ist, dass ihm also die Begabung mit einem religiösen Bewusstsein in die Wiege gelegt ist, hat eine lange Geschichte. In Röm 2,14f ist davon die Rede, dass Gott den Völkern - also allen Menschen - das Gesetz (gemeint ist das Sittengesetz) ins Herz geschrieben habe. Und in Apg 14,15-17 heißt es, Gott habe sich den Völkern nicht unbezeugt gelassen. In jedem Menschen findet sich also die Anlage zur Erkenntnis des Willens Gottes - und sei sie auch nur rudimentär ausgeprägt. Tertullian postulierte dann, dass die Seele des Menschen von Natur aus christlich sei. Sie habe also die Befähigung, die (offenbarte) Wahrheit des christlichen Glaubens einzusehen. Die Linie dieser natürlichen Theologie zieht sich dann bis ins 20. Jh., wo Ernst Troeltsch von einem „religiösen apriori“ sprach.

Auch die islamische Überzeugung, dass jeder Mensch als Muslim geboren ist, schließt ein, dass auch jeder den im Koran geoffenbarten Willen Gottes erkennen kann. Jeder Mensch ist ansprechbar auf das Wort Gottes und zur Antwort in seinem Reden und Handeln gerufen. Deshalb ist er auch unentschuldbar, wenn er diese Antwort verweigert. Ähnlich argumentiert Paulus im Röm 1,20.

Wenn nun der Mensch diese Begabung zur Gotteserkenntnis nicht im Sinne einer vernehmenden bzw. hörenden bzw. rezeptiven Vernunft, sondern im Sinne einer aktiven bzw. entwerfenden bzw. produktiven Vernunft anwendet, wenn er sich also nicht unter, sondern über das zu Erkennende stellt, dann schlägt die Offenheit für Gott in religiöse Selbstherrlichkeit um. Diese ist die Gefahr, die im biblischen Verbot, sich ein Bild von Gott zu machen, angezeigt ist: die Gefahr der Projektion menschlicher Vorstellungen und Bilder auf Gott. Wo solche Gottesbilder erzeugt werden, wird die Gottheit Gottes zur Projektionsfläche des religiösen Bewusstseins des Menschen. Dass Gottes Wirklichkeit allen diesen Bildern voraus liegt und sie durchkreuzt, tritt dabei in den Hintergrund.

Liegt diese Projektionsgefahr nicht in aller Religion, wobei „Religion“ hier verstanden ist als menschliches religiöses Bewusstsein, also als Religiosität? Wenn Offenbarung kritisch der Religion entgegengestellt wird, dann ist damit die Aufforderung verbunden, Gott nicht von den menschlichen Gottesvorstellungen aus, sondern von der Offenbarung Gottes her zu erkennen - so, wie er seinen Willen und darin auch sich selbst zu erkennen gibt. Für Muslime ist das im Koran geschehen, für Christen in Jesus Christus.

Die Gegenüberstellung von Religionen und Offenbarung kann man nach diesem Religionsverständnis also als idealtypisch entgegengesetzte Erkenntniswege deuten: Im einen Fall geht die Erkenntnis vom Menschen aus und versucht Gott zu erreichen. Im anderen Fall geht sie von der Kundgabe Gottes aus und will vom Menschen entgegengenommen werden.

Der Versuch des Menschen, auf Grund seiner religiösen Begabung Gott zu erkennen, verfehlt Gott, wie es besonders Karl Barth, der vielleicht bedeutendste Theologe des 
20. Jhs. betont hat. Denn Gott kann nur so erkannt werden, wie er sich selbst zu erkennen gibt: in seiner Offenbarung. Alle Versuche des Menschen, sich von sich aus $\mathrm{zu}$ Gott in Beziehung zu setzen, sind zum Scheitern verurteilt, weil sie einer unangemessenen Bewegungsrichtung folgen. Indem sie vom Menschen ausgehen, bleiben sie Selbstentfaltungen des religiösen Bewusstseins des Menschen. Im Grunde umkreist der gottsuchende Mensch hier sich selbst.

Von diesem Verständnis her prägte Barth den scharfen Satz: „Religion ist Unglaube“. Man versteht den Satz nur, wenn man sich bewusst macht, dass Barth den Begriff „Religion“ in der dritten der unterschiedenen drei Bedeutungen auffasst: als Streben des Menschen, von sich aus den Weg zu Gott zu bahnen. Das heißt zum einen, sich durch gottwohlgefälliges Handeln Gottes gnadenhafte Zuwendung erwerben zu wollen, und zum anderen, durch Vernunft und Erfahrung Gotteserkenntnis erlangen zu wollen. Diese Hybris des Menschen versteht Barth unter Religion. Religion ist also der Versuch des Menschen, sich durch Handeln und Erkennen zu Gott aufzuschwingen - und damit Sünde.

Offenbarung und Glaube sind die Gegenbegriffe zu „Religion“. Sie müssen nach Barth die Leitbegriffe des Christseins und der Theologie sein. Das Christentum ist eine Religion, die sich auf der phänomenologischen Ebene von anderen Religionen nicht grundlegend unterscheidet. Das Unterscheidende ist der Glaube, also die von Gott in Jesus grundgelegte Gottesbeziehung, nicht aber die Dimension des Religiösen.

Christlicher Glaube soll sich nach Barth gerade nicht als Religion verstehen, sondern als Antwort auf das Wort Gottes, also auf die Offenbarung in Christus. Dieses Wort ist der entscheidende Grund des christlichen Glaubens, aber auch das kritische Gegenüber der christlichen Religion.

Und wieder frage ich, ob diese Kritik der religiösen Urteilskraft nicht anschlussfähig an islamisches Denken ist. Dort wird ja auch dem Menschen jedes Recht bestritten, sich ein Bild von Gott zu machen, also seine eigenen Bilder und Konzepte auf Gott zu übertragen. Gott soll einzig aus der Quelle seiner Offenbarung erkannt werden. Das religiöse Bewusstsein muss sich immer wieder dieser Quelle zuwenden. Wo es sich auf sich selbst bezieht, kann es geschehen, dass es diese Quelle verschüttet und durch eigene Gedanken ersetzt.

\section{Die Dialektik von Offenbarung und Religion}

In den beiden ersten Teilen meines Vortrags habe ich gezeigt, wie sich die Gegenüberstellung von Religion und Offenbarung auf ein ganz bestimmtes Verständnis von Religion bezog. Religion wurde anthropologisch und psychologisch verstanden. Jetzt im dritten Teil lasse ich diese Frontstellung hinter mir, frage nach 
der Bedeutung von Offenbarung und will zeigen, dass zwischen Religion und Offenbarung eine dialektische Beziehung besteht.

In der evangelischen Theologie wird der Religionsbegriff heute nicht mehr dem Offenbarungsbegriff so scharf entgegensetzt. Er wird zum einen auf das religiöse Bewusstsein des Menschen bezogen, zum anderen auf die geschichtlichen Erscheinungsformen, in denen sich das religiöse Bewusstsein manifestiert. Es ist dies die zweite der vorhin unterschiedenen Bedeutungen des Religionsbegriffs. Dieses mehr empirische Verständnis des Begriffs ist eher beschreibend als wertend. Die theologisch-kritische Aufladung spielt in der Regel keine Rolle mehr. Der Religionsbegriff hat eine starke Aufwertung erfahren. Er steht für die geschichtlichen Gestalten des Glaubens und gibt der Theologie damit Bodenhaftung, das heißt einen Bezug zur Kultur und zur Gesellschaft.

Der Heidelberger Neutestamentler Gerd Theißen definierte Religion als „ein kulturelles Zeichensystem, das Lebensgewinn durch Entsprechung zu einer letzten Wirklichkeit verheißt“. ${ }^{1}$ Es ist dies eine allgemeine funktionale Beschreibung, wie sie sich auch außerhalb der Theologie in den Religionswissenschaften oder auch in der Jurisprudenz findet. So wird „Religion“ im Schweizerischen Bundesstaatsrechts definiert als „Überzeugungen, die sich auf das Verhältnis des Menschen zum Göttlichen, zum Transzendenten beziehen und weltanschauliche Dimensionen haben“2.

In dieser religionswissenschaftlichen Außenperspektive, in der Religion als menschliches, weltliches, kulturelles Sinnsystem verstanden wird, kann die Rede von Offenbarung nur noch als eine Ausdrucksform der Religion bzw. Religiosität verstanden werden. In ihr artikuliert sich der von Theißen angesprochene Transzendenzbezug des religiösen Subjekts. Glaube wird in eine Theorie der Religion eingezeichnet, und wenn in diesem Bezugsrahmen dann von „Offenbarung“ die Rede ist, dann ist damit zuweilen nur ein religiöses Interpretament gemeint, mit dem sich das religiöse Bewusstsein selbst auslegt.

Gegenüber der bei Offenbarung und Glauben ansetzenden Theologie war es wichtig, in Erinnerung zu rufen, dass es Offenbarung und Glaube immer nur im Modus und in den Medien der Religion gibt. Gegenüber einer beim Religionsbegriff ansetzenden Theologie scheint es andererseits wichtig zu sein, Offenbarung nicht nur als Ausdruck des religiösen Bewusstseins, sondern als ein Ereignis zu beschreiben, das zu den Erscheinungsformen der Religion immer auch in Spannung steht und damit auch religionskritisch zur Geltung kommt.

Im Folgenden will ich einige Überlegungen zum Verständnis des Offenbarungsbegriffs anstellen. Ich ziehe dazu fünf Unterscheidungen heran.

\footnotetext{
${ }^{1}$ GERD THEIßEN, Die Religion der ersten Christen, Gütersloh 2003, 28.

${ }^{2}$ ULRICH HÄFELIN und WALTER HALLER, Schweizer Bundesstaatsrecht, Zürich 2005, 124.
} 
Der Begriff „Offenbarung“ hat erstens eine subjektive und eine objektive Bedeutung. Der objektive Aspekt verweist auf ein Geschehen in der Vergangenheit: auf die Herabsendung des Koran oder auf die Vergegenwärtigung Gottes in Jesus Christus. Daraus haben sich Offenbarungsschriften als Objektivierungen der Offenbarung ergeben. Der subjektive Aspekt verweist auf die Erkenntnis des Offenbarungsinhalts durch einen Rezipienten. Sie ist also als ein Erkenntnisvorgang zu beschreiben, der dem Menschen widerfährt, sein religiöses Vorverständnis herausfordert und über sich hinausführt. Im einen Fall meint „Offenbarung“ das, was dem Menschen zu erkennen gegeben wurde. Im anderen Fall meint sie die Erkenntnis des Mitgeteilten.

Zweitens kann man unterscheiden zwischen einer dynamischen und einer statischen Bedeutung des Begriffs „Offenbarung“. Der dynamische Aspekt bezeichnet den Vorgang der Mitteilung: das Geschehen der Herabsendung bzw. das Christusereignis. Der statische Aspekt bezieht sich auf das Resultat dieses Vorgangs, auf das, was offenbart worden ist und ggf. auf das Dokument, in dem diese Offenbarung bezeugt ist. So kann man vom Koran als Offenbarung sprechen oder von der Bibel als Zeugnis der Christusoffenbarung.

Drittens kann man unterscheiden zwischen verbaler und nonverbaler Offenbarung, also zwischen Wortoffenbarung und Tatoffenbarung. Unter Tat- oder Werkoffenbarung versteht man das Handeln Gottes in der Geschichte, in dem er sich nach dem Zeugnis der Bibel zu erkennen gibt. Besonders in den geschichtlichen Büchern des Alten Testaments ist davon die Rede. Einen verdichteten Ausdruck findet die Offenbarung Gottes in der Geschichte in dem Wort aus Ex 3,14, das man übersetzen kann als: „Ich bin der, als der ich mich erweisen werde“. An seinen Werken gibt sich Gott demnach zu erkennen.

Eine vierte Unterscheidung ist die zwischen der Selbst- oder Wesensoffenbarung Gottes einerseits und der Offenbarung seines Willens andererseits. Der Islam spricht nicht von einer Selbstmitteilung Gottes, während diese Vorstellung für die Deutung der Christusbotschaft zentral ist. Christus gilt nach christlichem Verständnis als Selbstoffenbarung Gottes. Dort gibt sich das Wesen Gottes als unbedingte und universale Gnade zu erkennen.

Die fünfte Unterscheidung ist die zwischen dem sog. Instruktionsmodell und dem Kommunikationsmodell der Offenbarung. Das Instruktionsmodell versteht Offenbarung als Mitteilung einer Information, die von Gott gesandt und vom Menschen empfangen wurde. Das Kommunikationsmodell versteht Offenbarung dagegen als personale Selbstmitteilung Gottes. Es ist ein Beziehungsgeschehen zwischen Gott und Mensch. Offenbarung meint die Selbstentäußerung Gottes, mit der er sich in eine Beziehung zum Menschen setzt und damit diese Gottesbeziehung des Menschen konstituiert. Gott ist Urheber und Inhalt dieser Offenbarung zugleich. Nach christlichem Verständnis ist diese beziehungskonstituierende Vergegenwärtigung Gottes in der Schöpfung maßgeblich in Jesus Christus 
geschehen, von dem es in Hebr 1,3a heißt, er sei der „Abglanz seiner [Gottes, R.B.] Herrlichkeit und Ebenbild seines Wesens" und den Luther als "Spiegel des väterlichen Herzens Gottes “3 bezeichnete.

In meinem Verständnis von Offenbarung steht die subjektive, die dynamische und die relational-kommunikative Dimension im Vordergrund. „Offenbarung" ist ein Erkenntnisvorgang, bei dem sich der davon Betroffene in das Licht Gottes gestellt erfährt. Er sieht Gott, die Welt und sich selbst mit anderen Augen.

Nach christlichem Verständnis scheint dieses Licht Gottes in der Person Jesu Christi auf. In dieser Person haben die Anhänger Jesu und die Christen aller Zeiten die Gegenwart Gottes erfahren. Sie haben ihr Selbstverständnis daran ausgerichtet und ihr Leben daran orientiert. Weil sie sich als Nachfolger Jesu Christi verstanden haben, haben sie sich nach ihm benannt und sich als „Christen“ bezeichnet.

Offenbarung ist ein dreistelliger Geschehenszusammenhang: erstens die Begegnung mit der Gegenwart Gottes in einem dafür absolut offenen Menschen, zweitens die Erkenntnis dieser Gegenwart und drittens die Konsequenzen, die diese Erkenntnis für die Einstellung zur Welt, zu den Mitmenschen und zu sich selbst hat. Man kann daher nicht sagen: Die Person Jesu ist an sich und als solche Offenbarung Gottes. Sie ist es für die, denen diese Person zur Offenbarung wurde und wird.

Es gibt Offenbarung nicht an sich - als unerkannte Mitteilung Gottes. Es ist eine empfangene Mitteilung Gottes - empfangen von Menschen, die mit Jesus zu tun hatten und die die Bedeutung, die er für sie hatte, für die späteren Generationen mündlich und schriftlich bezeugten. Auch dieses Zeugnis, wie es in der Bibel niedergelegt ist, ist nicht an sich offenbarung. Es kann aber zur Offenbarung werden, wo sich Menschen im Zentrum ihrer Person davon betroffen erfahren, wo sie also darin eine Botschaft hören, die sie „unbedingt angeht“" (Tillich).

Offenbarung ist ein lebendiger Akt, ein Ereignis, ein Wahrnehmungsgeschehen, in dem das eigene Leben und die Welterfahrung in das Licht Gottes gestellt und so mit anderen Augen gesehen werden. Es gibt Offenbarung also immer nur im Modus ihrer Vergewisserung. Und diese Vergewisserung erfolgt durch die Medien der Religion im religiösen Bewusstsein des Menschen. Deshalb gibt es keine Offenbarung ohne Religion. Aber Offenbarung ist immer mehr als Religion. Sie ist das Zentrum der Religion, das aber nicht in dieser selbst liegt, sondern über sie hinausweist. Sie ist daher ein exzentrisches Zentrum, das Religion auch kritisch entgegentreten kann, wo sie das Licht Gottes eher verdunkelt als leuchten lässt.

\footnotetext{
${ }^{3}$ MARTIN LUTHER, Großer Katechismus, Auslegung des Glaubensbekenntnisses, in: Weimarer Ausgabe (WA) 30/1, 192,5; Bekenntnisschriften der evangelisch-lutherischen Kirche (BSLK), Gütersloh $2000^{4}, 750$.
} 
Deshalb darf man die Unterscheidung von Offenbarung und Religion nicht nach einer Seite hin auflösen. 


\section{Bileam: Die wandernde Prophezeiung}

Mit meinen Überlegungen möchte ich anknüpfen an die Ausführungen, die Joachim Kügler bei unserem ersten Treffen in Wittenberg vorgetragen hat. Ich zitiere dazu aus der Zusammenfassung seines Beitrages, wie sie uns von Dr. Abd-Elsalam und Prof. Leder übersandt worden ist:

„Die Bibel ist deshalb Heilige Schrift, weil sie die Offenbarung Gottes in Jesus und in der Geschichte Israels bezeugt, aber sie ist nicht selbst Offenbarung. Deshalb gilt von der Heiligen Schrift, dass sie menschliches Zeugnis der göttlichen Offenbarung ist. Wer sich um dieses Zeugnis bemüht, muss sich um den menschlichen Text mühen."

In der Diskussion über Herrn Küglers Beitrag war zudem darauf hingewiesen worden, dass besonders im Bereich der wissenschaftlichen Forschung am Alten Testament auch die Erkenntnisse der Archäologie eine wichtige Rolle spielen. Denn menschliche Texte, um diesen Ausdruck aufzunehmen, haben je für sich eigene Aussageabsichten, wollen eine bestimmte Sicht der Geschichte oder einzelner Ereignisse konstruieren, andere Sichtweisen dadurch zurückdrängen oder destruieren. Doch in vielen Fällen ist es durch archäologische Erkenntnisse möglich, zumindest einen Teil der Geschichte hinter den Geschichten zu rekonstruieren. Zwar wird das in manchen Kreisen der christlichen Glaubensgemeinschaften als Angriff auf die Autorität der Heiligen Schrift verstanden, die dann mit mühsamen Hilfskonstruktionen im Sinne von „Die Bibel hat doch Recht“ gerettet werden soll . Doch es ist meine feste Überzeugung, dass - ganz im Sinne dessen, was Herr Kügler „Aufklärungsexegese“ genannt hat - wir das Profil der biblischen Texte viel genauer fassen können, wenn uns ihre historischen und materialen Verstehensvoraussetzungen deutlich sind. Das möchte ich in diesem Beitrag darstellen, wobei ich mit Bileam ein Beispiel gewählt habe, das das Oberthema „Offenbarung“ aufnimmt. Doch zunächst der derzeitige Forschungshintergrund:

\section{Das neue Bild der Religionsgeschichte Israels durch die Archäologie}

Zwei klassische Beispiele mögen illustrieren, was die Archäologie zum Verständnis biblischer Texte beitragen kann: $\mathrm{Zu}$ den frühen wichtigen Ergebnissen der älteren Palästina-Archäologie gehörte die Erkenntnis, dass es eine militärische

\footnotetext{
${ }^{1}$ Zur Diskussion um diese Fragen vgl. z.B. SABINE HÜTTIG, Archäologie versus Textforschung? Einige grundsätzliche Überlegungen zum Verhältnis von Archäologie und Text am Beispiel der Erforschung von Khirbet Qumran. In: JÖRG FREY (Hg.): Qumran und die Archäologie. Texte und Kontexte. Tübingen 2011 (WUNT II, 278), 101-118, auch: DIETER VIEWEGER, Text und (Be-)Fund. Archäologie und Exegese als Geschichtswissenschaften. In: ebd., 73-99.
} 
„Landnahme“ Israels, wie sie das Buch Josua beschreibt, nicht gegeben haben kann. So ist festgestellt worden, dass die Städte Jericho und Ai zu der Zeit, in der die Landnahme stattgefunden haben soll (13./12. Jh.) gar nicht besiedelt waren. Ausgrabungen anderer Städte, die angeblich zerstört worden sein sollen, zeigen für diese Zeit keine Merkmale einer Eroberung. „Israel“ hat also Palästina nicht erobert, sondern ist im Land Israel/Kanaan in einem vielschichtigen Prozess entstanden. Mit dieser Erkenntnis wird aber auch das Buch der Richter viel besser verständlich, das genau diese Situation voraussetzt: Einzelne Stämme formieren sich zu größeren Einheiten und setzen sich mit der kanaanäischen Bevölkerung auseinander. Und es wird deutlicher, dass es sich um eine Glaubensgeschichte handelt: In der Rückschau auf die Frühzeit bekennen die Israeliten erzählerisch, dass ihr Gott es war, der ihnen das Land gegeben hat. Daraus resultiert die Verpflichtung Israels, sich an diesen einen Gott zu halten ${ }^{2}$.

Das zweite Beispiel ist brisanter. Das Alte Testament behauptet in den meisten seiner Teile die Einzigkeit und Identität des Gottes JHWH von der Schöpfung der Welt an. Zwar gab es mehrere Phasen des Abfalls vom rechten Glauben, in denen sich die Israeliten fremden Göttinnen und Göttern zuwendeten, doch mit Heilstaten und Strafen schafften es Gott und die von ihm gesandten Propheten, die Menschen zur wahren Gottesverehrung zurückzubringen.

Dieses Bild ist durch archäologische Funde erschüttert worden. Deren wichtigste sind die Ausgrabung von Kuntillet Adjrud im nördlichen Negev und ein Grab aus Chirbet el-Qom ${ }^{3}$. Hier wird, datierbar auf das 8./7. Jahrhundert, eindeutig von „JHWH und seiner Aschera“ gesprochen; der Gott Israels wurde also mit einer Partnergöttin zusammengeordnet. Von daher bekamen die verschiedenen Stellen des AT, in denen von einer Aschera die Rede ist (als Göttin oder Kultgegenstand), ein neues Gewicht. Es war nun deutlich, dass in den früheren Phasen der Geschichte Israels JHWH nicht allein im Sinne eines Monotheismus verehrt wurde, sondern in einer polytheistischen bzw. später monolatrischen Religiosität. Erst in der exilischnachexilischen Zeit hat sich, vor allem durch die Theologie des „zweiten Jesaja“ (Jes 40-55), der Glaube durchgesetzt, dass es nur den einen Gott als Schöpfer der Welt

\footnotetext{
${ }^{2}$ Besonders deutlich für diese Sichtweise ist die Darstellung des „Landtages zu Sichem“ in Jos 24, vgl. v.a. V. 14+15, wo nach der geschichtlichen Rückschau die Konsequenz für das gegenwärtige Israel gezogen wird. Die komplexen Fragen nach Literar- und Redaktionskritik des Josuabuches können hier ausgeklammert bleiben, eindeutig ist jedenfalls, dass Jos 24 eine nachträgliche, deuteronomistisch beeinflusste Geschichtsdeutung darstellt, die die Zerstörung Jerusalems voraussetzt (V. 20).

3 Textedition bei: JOHANNES RENZ und WOLFGANG RÖLLIG, Handbuch der Althebräischen Epigraphik (HAE), Bd. I, II/1, III, Darmstadt 1995. Aus der nahezu uferlosen Literatur vgl. zusammenfassend v.a. OTHMAR KEEL und CHRISTOPH UEHLINGER, Götter, Göttinnen und Gottessymbole. Neue Erkenntnisse zur Religionsgeschichte Kanaans und Israels aufgrund bislang unerschlossener ikonographischer Quellen, Freiburg, Basel, Wien 1998, § 129-147; 237-282; s. auch MARTIN RÖSEL, Inscriptional Evidence and the Question of Genre, in: MARVIN A. SWEENEY und EHUD BEN ZVI (Hrsg.), The Changing Face of Form Criticism for the Twenty-First Century, Grand Rapids 2003, 107-121.
} 
und Herrscher der Geschichte geben kann ${ }^{4}$. Wieder bereichert diese aus archäologischen Daten gewonnene Einsicht unser Bild von der Religion Israels erheblich. Denn es wird die immense Transformationsleistung deutlich, durch die sich die polytheistischen Nationalreligionen der Bruderstaaten Israel und Juda im Gespräch mit und in Abgrenzung von den sie umgebenden Kulturen zur monotheistischen, universal ausgerichteten Religion Israels entwickelt haben.

\section{Bileam: Offenbarung im Ostjordanland I: Deir Alla}

Israel gehört zwar heute zu den archäologisch am besten erforschten Gebieten der Welt. Doch es gibt ein schmerzliches Manko, denn bisher wurden kaum Texte aus alttestamentlicher Zeit gefunden. Das unterscheidet Israel von Nordsyrien oder Mesopotamien, wo mit Keilschrift beschriebene Tontafeln auch feuchtes Klima überdauerten, oder von Ägypten, wo das trockene Wüstenklima Papyri und Inschriften konservierte. Einige kreative Ansätze, dieses Problem zu lösen und biblische Berichte durch angeblich gefundene Texte zu bestätigen, wurden in den letzten Jahren als Fälschung entlarvt ${ }^{5}$. In der alttestamentlichen Forschung hat dieser Negativbefund bei manchen Exegeten zu der Annahme geführt, dass die biblischen Texte sämtlich spät entstanden sind, zumeist erst nach dem babylonischen Exil als Identifikationstexte des sich neu formierenden Israels. Extrempositionen gehen gar davon aus, dass das gesamte AT als im Wesentlichen hellenistisches Produkt zu verstehen sei ${ }^{6}$.

$\mathrm{Zu}$ den Glücksfällen der Archäologie gehört nun aber ein Fund, der dieses Bild nachhaltig in Frage stellt. Denn auf einer 1967 im jordanischen Tell Deir Alla (biblisch: Sukkot) gefundenen Inschrift wird eine "Schrift (sefer) Bileams, des Sohnes Beors, des Sehers der Götter" erwähnt ${ }^{7}$. Diese Schrift war auf den Wandverputz eines Gebäudes geschrieben, das später eingestürzt ist, so dass die Inschrift konserviert wurde. Die Funktion des Gebäudes ist nicht mehr ganz klar; es diente vielleicht als Versammlungsstätte oder Schulraum ${ }^{8}$. Die Inschrift ist in einem frühen

\footnotetext{
${ }^{4}$ Dazu MATTHIAS ALBANI, Der eine Gott und die himmlischen Heerscharen. Zur Begründung des Monotheismus bei Deuterojesaja im Horizont der Astralisierung des Gottesverständnisses im Alten Orient (ABG 1), Leipzig 2000.

${ }^{5}$ So etwa der Granatapfel mit dem Hinweis auf den Tempel in Jerusalem, die sog. Joasch-Inschrift oder das Ossuar des Herrenbruders.

${ }^{6}$ Aus der weiten Literatur zum Thema sei nur erwähnt: NIELS PETER LEMCHE, Die Vorgeschichte Israels. Von den Anfängen bis zum Ausgang des 13. Jahrhunderts v. Chr. (Biblische Enzyklopädie 1), Stuttgart 1996.

${ }^{7}$ TUAT II, 138-148; J. HOFTIJZER und G. VAN DER KOOIJ, Aramaic Texts from Deir Alla, DMOA 19, Leiden 1976. Zur Interpretation vgl. etwa HANS-PETER MÜLLER, Einige alttestamentliche Probleme zur aramäischen Inschrift von Dēr 'Allā, ZDPV 94 (1978), 56-67; ders., Die aramäische Inschrift von Deir 'Allā und die älteren Bileamsprüche, ZAW 94 (1982), 214-244.

8 So RUDOLF WENNING und ERICH ZENGER, Heiligtum ohne Stadt - Stadt ohne Heiligtum? Anmerkungen zum archäologischen Befund des Tell Dēr 'Allā ", ZAH 4 (1991) 171-193. Deutlich ist, dass in dem Gebäude typische Elemente von Sakralarchitektur und -ausstattung fehlen, vgl. auch ERHARD BLUM, Die Kombination I der Wandinschrift vom Tell Deir 'Alla. Vorschläge zur Rekonstruktion mit
} 
Aramäisch abgefasst ${ }^{9}$, aus stratigraphischen und paläographischen Gründen ist sie in das 9./8. Jh. v.Chr. datiert worden, was durch C-14 Messungen bestätigt wurde. ${ }^{10}$ Interessant ist, dass die Inschrift in zwei Farben ausgeführt wurde (schwarz und rot für Überschriften / Rubrum) und durch Linien gerahmt war. Offensichtlich ist die Repräsentationsform als Wandinschrift sekundär, ihr ging wohl eine Version auf Papyrus etc. voraus, deren Gliederung bei der Wandinschrift nachgezeichnet wird. ${ }^{11}$

Leider sind nur Fragmente der Inschrift erhalten, deren Lesung und Zuordnung untereinander nicht immer sicher sind ${ }^{12}$. Üblicherweise werden die Bruchstücke zu zwei Textkombinationen zusammengeordnet. Bei allen Fragen im einzelnen ist jedenfalls deutlich, dass die sogenannte 1. Kombination der Inschrift von einer Gestalt Balaam, masoretisch: Bileam, erzählt. Er wurde nachts visionär in eine Versammlung der Götter versetzt und erfährt dort Dinge, die er seinem Volk kundtun soll. Am nächsten Morgen erwacht er, weint bitterlich und tut dann dem Volk kund, was die Schadajin-Götter tun wollen (Z. 1-7). Dann wird eine ,verkehrte Welt" beschrieben, die Sonnengöttin wird nicht mehr scheinen, und die bekannte Ordnung der Dinge wird zusammenbrechen: „Hyänen hören auf die Worte der Fuchswelpen, Hochgestellte gingen als Getriebene aus der Stadt, Taugenichtse machen sich über Weise lustig“ (Z. 11; Übersetzung orientiert an Blum). Es liegt auf der Hand, an eine Parallele zu biblischen Visionsschilderungen wie 1.Kön 22 oder Jes $6 \mathrm{zu}$ denken, in denen sich die Gottheit einzelnen Propheten offenbart und ihnen bevorstehendes Unheil ankündigt. Unklar ist dabei, ob die „verkehrte Welt“ Inhalt dessen ist, was Bileam gezeigt wird, oder umgekehrt die

historisch-kritischen Anmerkungen. In: INGO KOTTSIEPER u.a. (Hrsg.), Berührungspunkte. Studien zur Sozial- und Religionsgeschichte Israels und seiner Umwelt (FS R. Albertz), Münster 2008 (AOAT 350), 573-601: 596f.

${ }^{9}$ Dazu ÉMILE PUECH, Bala'am and Deir 'Alla, in: GEORGE H. VAN KOOTEN und JACQUES VAN RUITEN (Hrsg.), The Prestige of the Pagan Prophet Balaam in Judaism, Early Christianity and Islam, Leiden 2008 (Themes in Biblical Narrative, 11), 25-47.

10 WENNING und ZENGER, Stadt (siehe Anm. 8), 193, fassen die jüngsten archäologischen Untersuchungen dahingehend zusammen, dass i.E. eine Datierung in die 2. Hälfte des 9. Jh. anzunehmen ist. Dazu passen auch die sprachgeschichtlichen Überlegungen von HANS-PETER MÜLLER, Die Sprache der Texte von Tell Deir 'Allā im Kontext der nordwest-semitischen Sprachen mit einigen Erwägungen zum Zusammenhang der schwachen Verbklassen, ZAH 4 (1991), 1-31. Zu den C-14 Ergebnissen s. MEINDERT DIJKSTRA, Is Balaam also among the Prophets?, JBL 114 (1995), 43-64, hier: 45.

${ }^{11}$ Vgl. MANFRED WEIPPERT, Der „Bileam“-Text von Tell Der “Alla und das Alte Testament. In: Ders., Jahwe und die anderen Götter (FAT 18), Tübingen 1997, 163-188, hier: 185f., vgl. auch JAN CHRISTIAN GERTZ, Die unbedingte Gerichtsankündigung des Amos, in: FRANZ SEDLMEIER (Hg.), Gottes Wege suchend (FS R. Mosis), Würzburg 2003, 153-170, hier: 162.

${ }^{12}$ Vgl. dazu die beiden wichtigen Aufsätze von Erhard Blum, der eine ganze Reihe plausibler neuer Lesungen vorschlägt (hier auch umfassende Hinweise $\mathrm{zu}$ früherer Literatur), neben BLUM, Kombination I (siehe Anm. 8), auch ders., "Verstehst du dich nicht auf die Schreibkunst...?". Ein weisheitlicher Dialog über Vergänglichkeit und Verantwortung: Kombination II der Wandinschrift vom Tell Deir 'Alla. In: MICHAELA BAUKS u.a. (Hrsg.), Was ist der Mensch, dass du seiner gedenkst? (Psalm 8,5). Aspekte einer theologischen Anthropologie, (FS B. Janowski), Neukirchen-Vluyn 2008, 33-53. 
geschilderten heillosen Zustände auf der Welt Grund für das Eingreifen der Götter sind (so Blum).

Die zweite Kombination ist deutlich schwieriger zu verstehen. Nach der neuesten Untersuchung von Erhard Blum ist sie als weisheitlicher Text zu lesen, als Gespräch zwischen Lehrer und Schüler, in dem es u.a. um Fragen der Vergänglichkeit und der ethischen Orientierung (Vergreifen von Mächtigen an Häusern, Bestechungsannahme) geht. Das kann mit inhaltlich parallelen Vorwürfen etwa im Amosbuch verglichen werden; der sozialgeschichtliche Hintergrund wäre also ähnlich. Der Name Bileam begegnet hier nicht (es sei denn, man rekonstruiert ihn), und der Zusammenhang mit Kombination 1 ist unklar. Erneut muss man davon ausgehen, dass die Wandinschrift nicht die erste Verschriftungsversion des Textes ist, sondern dass sie eine literarische Vorgeschichte hat. Das aber bedeutet, dass es in einer vergleichsweise unbedeutenden Siedlung im östlichen Teil des Jordangrabens bereits im 9. Jh. Hinweise auf eine umfangreiche und differenzierte literarische Tätigkeit gab. Eine solche wird man folglich auch für wichtigere Residenzorte wie Jesreel oder Sichem annehmen können, ebenso auch für das weiter entfernte Jerusalem. (Hier sind ohnehin durch die diplomatischen Tontafel-Archive aus Tell Amarna (Ägypten) Schreiber schon im 14. Jh. v. Chr. nachgewiesen.) Ein prinzipieller Ausschluss der Möglichkeit so früher schriftlicher Überlieferung in Israel/Juda, wie es manche Kollegen tun, ist daher m.E. nicht zu rechtfertigen ${ }^{13}$.

Für das Thema unseres Symposions ist nun aber entscheidend, dass wir durch den Fund aus Deir Alla den ältesten Beleg aus Israel/Palästina ${ }^{14}$ für ein Schema haben, das sich später im Alten Testament aber auch im Koran findet ${ }^{15}$ : Durch göttliche Offenbarung erhält ein Prophet eine Einsicht in die bedrängende Zukunft, die er dem Volk mitzuteilen hat.

Anders als im AT und den späteren Überlieferungen ist in Deir Alla aber nicht erhalten, wie das Volk im Land Gilead auf die Mitteilungen Bileams reagiert hat. Doch allein die Tatsache, dass seine Vision aufgeschrieben wurde, in einem späteren Schritt sogar zu Lehrzwecken auf einer Wand, zeigt die Wertschätzung, die diesem Orakel entgegengebracht wurde.

\footnotetext{
${ }^{13} \mathrm{Zu}$ diesem grundsätzlichen Problem s. ERHARD BLUM, Israels Prophetie im altorientalischen Kontext. Anmerkung zu neueren religionsgeschichtlichen Thesen. In: IZAK CORNELIUS und LOUIS JONKER (Hrsg.): From Ebla to Stellenbosch: Syro-Palestinian Religions and the Hebrew Bible, Wiesbaden 2008 (ADPV, 37), 81-115; vorher bereits mit ähnlicher Argumentationsrichtung ANDREAS SCHERER, Vom Sinn prophetischer Gerichtsverkündung bei Amos und Hosea, Biblica 86 (2005), 1-19. Anders etwa: HERMANN MICHAEL NIEMANN, Kein Ende des Büchermachens in Israel und Juda (Koh 12,12). Wann begann es? BiKi 53 (1998), 127-134.

${ }^{14}$ Für die Zwecke der vorliegenden Überlegungen kann das Problem der in Mari oder Assyrien belegten Prophetie ausgeblendet bleiben, dazu übersichtsweise BLUM, Israels Prophetie (siehe Anm. 13).

${ }^{15}$ Vgl. ROBERT TOTTOLI, Biblical prophets in the Qur'ān and Muslim literature, Richmond 2002, 4-11.
} 


\section{Bileam: Offenbarung im Ostjordanland II: Altes Testament}

Die Wertschätzung Bileams zeigt sich nun auch in der jüdisch-christlichen Bibel. ${ }^{16}$ Denn an einer kompositionell wichtigen Stelle der Erzählung von Exodusgeschehen, Sinai-Offenbarung und Zug nach Kanaan begegnet ausgerechnet dieser Seher. Das Geschehen ist im Land Moab lokalisiert, gegenüber von Jericho, keine 100km südlich des späteren Deir Alla. Dem Gang der Erzählung nach fürchtet sich der moabitische König Balak vor den Israeliten. Er schickt Boten zu einem Seher namens Bileam ben Beor, der am Euphrat lebte, damit er komme und Israel verfluche. Bileams Fluch gilt als wirkmächtig: „Wen du segnest, der ist gesegnet, und wen du verfluchst, der ist verflucht." (Num 22,6). Der Konsonantenbestand des Eigennamens בִּלָעם בִּן (bil'am ben be'or) stimmt mit dem des Textes aus Deir Alla überein, mit Ausnahme des Wechsels vom aramäischen בר (bar) zum hebräischen). Es ist also offensichtlich die gleiche Person gemeint.

Bileam teilt den Boten mit, dass er in der Nacht erst den Herrn befragen müsse, bevor er ihnen Antwort geben könne. Interessanterweise steht hier (Num 22,8) im hebräischen Text der Eigenname des Gottes Israels, JHWH; es wird vorausgesetzt, dass der fremde Prophet ihn kennt. Gott aber (hier steht nun das Appellativum elohim, 22,12) verbietet Bileam, mit nach Moab zu gehen, denn Israel sei ein gesegnetes Volk. Ein zweites Mal werden Boten geschickt, wieder sagt Bileam, dass er nichts tun könne ohne einen Auftrag JHWHs, des Herrn $(22,19)$. Diesmal jedoch wird ihm erlaubt, mit den Boten zu gehen.

Im Ablauf des Geschehens wird aber nun derselbe Gott, der eben noch erlaubt hat, dass der Seher mit den Boten zieht, zornig und schickt seinen Engel, um Bileams Weg zu verstellen (22,22 ff.). Doch nur Bileams Eselin erkennt den Engel und scheut. Bileam, der von Gott gesandte Prophet, erkennt den Boten des Herrn nicht, bis der Herr selbst ihm die Augen öffnet (V. 31) und ein weiteres Mal mit ihm redet. Er schärft dem Propheten ein - was bereits gesagt war -, dass er nichts weissagen möge außer dem, was Gott ihm eingegeben habe. Diese Unterbrechung im Geschehensablauf wird von den meisten Forschern, m. E. zu Recht, als sekundäre Einfügung betrachtet, die das positive Bild des fremden Propheten nachhaltig verändert ${ }^{17}$, denn Bileam kann eigentlich nicht JHWHs Prophet sein, wenn er seinen Boten nicht erkennt.

\footnotetext{
${ }^{16}$ Vgl. dazu auch MARTIN RÖSEL, Wie einer vom Propheten zum Verführer wird. Tradition und Rezeption der Bileamgestalt, Biblica 80 (1999), 506-524; HERBERT DONNER, Balaam pseudopropheta. In: ders. u.a., (Hrsg.), Beiträge zur alttestamentlichen Theologie (FS W. Zimmerli), Göttingen 1977, 112-123.

${ }_{17}$ Anders, aber nicht überzeugend und methodisch wenig klar z.B. ULRIKE SALS, Bileam - der lächerliche Falschprophet. Eine Widerlegung. In: EGBERT BALLHORN und GEORG STEINS (Hrsg.): Der Bibelkanon in der Bibelauslegung. Methodenreflexionen und Beispielexegesen, Stuttgart 2007, 163188 (mit Literatur). S. auch JOHN VAN SETERS, From Faithful Prophet to Villain: Observations on the Tradition History of the Balaam Story. In: EUGENE E. CARPENTER (Hg.), A Biblical Itinerary - in Search of Method, Form and Content (FS G.W. Coats), Sheffield 1997, 126-132.
} 
Nach der Begegnung mit dem Engel des Herrn zieht Bileam zum Moabiterkönig Balak und dann Israel entgegen. Nach feierlichen Opfern soll nun der Seher sein Werk ausführen (23,1ff). Doch statt die Israeliten zu verfluchen, gibt Gott Bileam Segensworte ein. Dies geschieht in vier poetischen Spruchreden. In der ersten wird Israel als Volk bezeichnet, das abgesondert von den anderen Völkern wohnt $(23,9)$. Der zweite Spruch preist Israel als Volk, das einem Löwen gleich ist $(23,24$, vgl. Gen 49,9). Diese Prädikation steht auch im dritten Spruch, der mit dem Ruhm des Wohnlandes Israels einsetzt $(24,5.9)$. Der vierte Spruch schließlich, der sogar gegen den ausdrücklichen Befehl des Königs Balak gesprochen war, weissagt das Kommen einer mächtigen Gestalt, die Moab schlagen werde $(24,17)$. Nach diesen vier Segenssprüchen zieht Bileam wieder nach Hause. Kurz vor dem Einzug in das gelobte Land (zuerst: Inbesitznahme des Ostjordanlandes, Num 32ff., dann: Zug nach Israel, Jos 1ff.) wird also erzählt, dass Gott sich mehrfach einem fremden Propheten offenbart habe, der Israel segnen musste. Der Fluch, den der Moabiter Balak - nicht Bileam - erbeten hatte, wurde von Gott in Segen gewandelt.

Die Erzählung ist, wie bereits angedeutet, literarisch sicher nicht aus einem Guss; ihr Wachstum war kompliziert und seine Rekonstruktion ist strittig ${ }^{18}$. Erkennbar ist: Die vier poetischen Segensreden sind wohl eingefügte Traditionsstücke unterschiedlichen Alters ${ }^{19}$, die später noch erweitert wurden, auch die EselinPerikope ist sicher ein Zusatz. Die Datierung der Geschichte ist ebenfalls strittig. Doch die Grundschicht der Erzählung ist nur sinnvoll, wenn es noch eine lebendige Tradition gab, die Bileam ben Beor als mächtigen Propheten oder Mantiker kannte. Das wird nicht zu lange nach dem 8. Jh. gewesen sein, zumal es einige Merkmale in den Segenssprüchen gibt, die auf die Texte aus Deir Alla zurückweisen, so vor allem die Erwähnung der Schaddaj-Götter. ${ }^{20}$ Gottes Offenbarung kann folglich nach dieser Geschichte auch an einen Fremden ergehen. Fraglich ist allerdings, ob es sich hier tatsächlich um eine offenbarung handelt. Viel eher haben wir es mit einer

\footnotetext{
${ }^{18} \mathrm{Vgl}$. etwa den Forschungsüberblick und den eigenen redaktionsgeschichtlichen Versuch von MARKUS WITTE, Der Segen Bileams - eine redaktionsgeschichtliche Problemanzeige zum „Jahwisten“ in Num 22-24, in: JAN CHRISTIAN GERTZ u.a. (Hrsg.), Abschied vom Jahwisten. Die Komposition des Hexateuch in der jüngsten Diskussion, Berlin 2002 (BZAW 315), 191-213. Aber vgl. auch UWE WEISE, Vom Segnen Israels. Eine textpragmatische Untersuchung der Bileam-Erzählung Num 22-24, Gütersloh 2006, 200-208, der die literarische Einheitlichkeit von 22,5-24,25 zu begründen sucht.

${ }^{19}$ Sinnvoll erscheint mir die Annahme, dass zunächst ein Grundbestand des 3. und 4. Orakels als selbständige Stücke überliefert wurde. Nur diese haben eine eigene Einleitung ("Es sagt Bileam, der Sohn Beors...", Num 24,3f.+15f.), wie man sie von anderen Prophezeiungen her kennt. Sie sind also nicht auf den Kontext angewiesen. In diesen beiden Stücken finden sich zudem die deutlichsten Parallelen zu den in Deir Alla gefundenen Bileam-Texten.

${ }^{20}$ Num 24,4+16. Vgl. MÜLLER, Aramäische Inschrift (siehe Anm. 7); HORST SEEBASS, Numeri 22,236,13 (BKAT 4,3), Neukirchen-Vluyn 2007. Weitere Überlegungen sind, dass am Ende des 8./Beginn des 7. Jh. mit der Niederschrift von Prophetensprüchen begonnen wurde und dass nach dem syrischefraimitischen Krieg und dem Untergang des Nordreichs die Frage nach dem Verhältnis von Israel zu den umgebenden Völkern besonders virulent war. Aber es ist zugegeben, dass das keine sicheren Anhaltspunkte sind.
} 
literarischen Nachbildung zu tun, die die - aus Deir Alla bekannte - Offenbarung der fremden Götter an den ursprünglich moabitischen Bal'am bar Beor in ihren Dienst nimmt.

\section{Korrektur des Offenbarungsträgers}

Folgt man dem weiteren Verlauf der Erzählung, so geht im nächsten Kapitel, Num 25, der Blick wieder zu Israel selbst. Und die Israeliten, denen eben durch Bileam geweissagt worden war, dass sie die Moabiter schlagen werden, treiben stattdessen mit deren Töchtern Unzucht und beten sogar ihre Götter an (25,1.2). Das wäre heute zwar im Sinne von „make love, not war“, geht aber im Alten Testament als „Sünde vom Baal Peor" in die Geschichte ein; es ist für die Nachgeschichte der BileamGestalt von großer Bedeutung.

Das Problem deutet sich bereits im näheren Kontext unserer Erzählung an: Nur wenig später, in Num 31, ist wieder von Bileam die Rede. Dort heißt es nun aber, dass die Israeliten nicht nur die Midianiter getötet haben, sondern auch Bileam, den Sohn Beors $(31,8)$. Der habe nämlich die Frauen der Midianiter beraten, dass sie die Israeliten abwendig machten und sich am Baal Peor versündigten $(31,16)$. Nach Num 25 waren es allerdings die Töchter der Moabiter, nicht der Midianiter, und die Israeliten hatten ihrerseits damit angefangen, sich mit ihnen zu verbinden. ${ }^{21}$ Hinzu kommt: Bileam war längst nach Hause gegangen.

Die Absicht und die Entstehungszeit von Num 31 sind andere: Die Darstellung von der Auslöschung eines ganzen Volkes steht direkt vor der Verteilung des Ostjordanlandes an drei der Stämme Israels. Mit dieser Anordnung soll der Eindruck erweckt werden, als wäre das Land leer gewesen, ohne Gefährdungen oder Versuchungen wie fremde Götter. Das passt gut zur Entstehungszeit dieses Textes, die sicher im nachexilischen Israel anzusetzen ist, als man nach der Exilserfahrung von der unbedingten Reinheit des Volkes als theologischer Notwendigkeit für das Heil ausging. Entscheidend ist nun, dass in Num 31 hier ein deutlich anderes Bileam-Bild dokumentiert wird. Dieses ist - mit einer Ausnahme, Micha 6,5 $5^{22}$ dann in allen

\footnotetext{
${ }^{21}$ Dies nimmt Num 25,16-18 auf, wo erstmals die Midianiter für die Ereignisse in Baal Peor verantwortlich gemacht werden. Für MARTIN NOTH, Das 4. Buch Mose. Numeri (ATD 7); Göttingen $1977^{3}$, 198f. ist Num 31 daher als sehr späte Zufügung zum Gesamtpentateuch anzusehen, ähnlich WALTER GROSS, Bileam (SAINT 38), München 1974, 114.

${ }^{22}$ In Mi 6 wird eine Kurzfassung der Geschichte Num 22-24 gegeben: Balak hatte Böses mit Israel vor, aber Bileam hat ihm passend darauf geantwortet und das Volk bewahrt. Bileam steht hier in einer Reihe mit Mose, Aaron und Mirjam (6,4); gewiss nicht zufällig, waren diese doch mit Abraham die einzigen als Propheten bezeichneten Gestalten vor Bileam. Interessanterweise ist hier die Perspektive gegen Israel gerichtet, mit dem der Herr einen Rechtsstreit hat. Im Zuge dieser Auseinandersetzung wird an die Werkzeuge Gottes zum Heil Israels erinnert. Die Mosezeit bis zur Landnahme erscheint hier als goldenes Zeitalter; der Fremde Bileam gehört zu den substantiell wichtigen Heilstaten JHWHs.
} 
anderen Stellen des AT zu erkennen, an denen von Bileam die Rede ist ${ }^{23}$ : Es mag hier reichen, einen dieser Texte zu zitieren; ich wähle Dtn 23,4-6:

Kein Ammoniter oder Moabiter darf in die Versammlung des HERRN kommen, niemals darf einer ihrer Nachkommen in die Versammlung des HERRN kommen, auch nicht in der zehnten Generation, denn sie sind euch nicht mit Brot und Wasser entgegengekommen auf dem Weg, als ihr ausgezogen seid aus Ägypten, und er hat Bileam, den Sohn Beors, von Petor in Syrien am Eufrat, gegen dich gedungen, damit er dich verfluche. Aber der HERR, dein Gott, wollte nicht auf Bileam hören, sondern der HERR, dein Gott, hat dir den Fluch in Segen verwandelt, weil der HERR, dein Gott, dich liebte. (Zürcher Bibel)

Bileam gilt nun als einer, der mit den Fremden im Bunde war und gegen Israel gehandelt hat; weshalb Gott gegen Bileam eingreifen musste. Es ist nicht mehr der Fluch des Moabiterkönigs, der in Segen verwandelt wurde, sondern der des fremden Propheten. Von einer Erscheinung oder Offenbarung Gottes an Bileam ist keine Rede mehr.

Dieses negative Bild Bileams als heidnischer Mantiker ${ }^{24}$ oder Verführer ${ }^{25}$ ist nun in der Rezeptionsgeschichte das vorherrschende Bild geworden. Schon in Qumran ist sein Name in einer Liste der falschen Propheten zu finden (4Q339), auch das Neue Testament bestätigt die negative Sichtweise, Bileam gilt nun als Typos der Irrlehrer, die die christliche Gemeinde vom rechten Weg ableiten. ${ }^{26}$ Wahrscheinlich hält sich diese negative Bewertung auch bis in den Koran hinein, denn nach einigen Kommentatoren (u.a. Ibn 'Abbas, Ibn Mas'ud, Mudschahid) spielt Sure 7:175-6 auf Bileam an, auch wenn sein Name nicht genannt ist ${ }^{27}$ :

„Trage ihnen die Geschichte von dem vor, dem wir unsere Zeichen gaben, der sich dann aber von ihnen lossagte! Da holte ihn der Satan in sein Gefolge und er irrte ab. Hätten wir gewollt, so hätten wir ihn durch sie erhoben. Er aber blieb der Erde zugewandt und folgte seiner Neigung. So ist er dem Hund zu vergleichen: $\mathrm{Ob} d u$ ihn angreifst oder in Ruhe lässt, er lässt die Zunge hängen.“"28

Der weitere Kontext der Stelle ist die Nacherzählung der Mosegeschichte, wobei das murrende Volk der Wüstenwanderung als Typos der Frevler und Gottesgegner gilt. Die gegen sie von Gott gesandten Strafgerichte sind als Hinweise zur Umkehr zu verstehen; Vers 174: „So erklären wir die Zeichen, vielleicht kehren sie um.“

\footnotetext{
${ }^{23}$ Jos 24,9f; Jos 13,22; Neh 13,3.

${ }^{24}$ Vgl. Jos 13.

${ }^{25}$ Vgl. Num 31.

${ }^{26}$ Vgl. 2.Petr 2,15; Jud 11; Apk 2,14.

${ }^{27}$ TOTTOLI (siehe Anm. 15), 59, Anm. 45, vgl. al-Qur'an: arabisch deutsch, übersetzt und kommentiert von ADEL THEODOR KHOURY, Bd. 7, Gütersloh 1996, 170f.; G. VAJDA, Art. Bal'am. In: Encyclopaedia of Islam, Vol. 1, Leiden 1960, 984: „perhaps in an allusion“. S. auch RUDI PARET, Der Koran, Kommentar und Konkordanz, Stuttgart 1980, 179: „es lässt sich nicht ausmachen, wer wirklich gemeint ist“; auch Khoury nennt eine Reihe weiterer Optionen, ohne zu einem Urteil zu kommen.

${ }^{28}$ Übersetzung von HARTMUT BOBZIN, Der Koran, München 2010.
} 
Interessant ist nun - wenn Bileam wirklich gemeint ist - dass hier im Koran Bileam ursprünglich als von Gott gesandt gilt, „dem wir unsere Zeichen gaben“, der sich dann aber abkehrte bzw. vom Satan in die Irre geleitet wurde. Es ist also noch die positive Sicht auf Bileam bekannt, doch die negative Tradition übermalt das Bild. Es wäre natürlich interessant und reizvoll, hier gemeinsam weiterzuarbeiten, denn spätere Kommentatoren tragen einiges Wissen über Bileam zusammen. Dabei diskutieren sie vor allem die Frage, wie es sein kann, dass ein Prophet, der Gottes Namen kannte, von Gott abfallen konnte ${ }^{29}$.

An dieser Entwicklung der Bileamfigur wird besonders deutlich, was in der biblischen Textüberlieferung vor sich gehen kann, die ja eingangs als „menschlicher Text" bezeichnet worden war. Frühe Tradenten konnten offensichtlich problemlos die Überlieferung eines „heidnischen“ Propheten aufnehmen ${ }^{30}$ und erzählerisch darstellen, dass Gott sich auch Fremden offenbart, dies zum Wohle seines auserwählten Volkes. Spätere Überlieferer nahmen daran Anstoß und korrigierten die Darstellung; Bileam ist nun ein Verführer oder falscher Mantiker. Die Offenbarung Gottes an ihn wird also erzählerisch zurückgenommen; die Bibel korrigiert sich selbst. Die Gründe dafür kann man nur vermuten; wahrscheinlich ist m. E. eine in verschiedenen Schriften zu beobachtende Tendenz, sich von den andern Völkern abzugrenzen. Eine Offenbarung Gottes außerhalb Israels schien dann nicht länger hinnehmbar zu sein.

\section{Offenbarung im Alten Testament}

Damit komme ich zum Schluss, indem ich die Ergebnisse der Beschäftigung mit Bileam an unser Konferenzthema zurückbinde - zugegeben in sehr groben Strichen. „Diese Offenbarung ist der Bezugspunkt aller religiösen Verkündigung und Praxis und als solche der Legitimationsgrund der Religion“, so heißt es in der Einladung zu unserer Tagung. Für die Religion des Alten Testaments kann dieser Satz nicht gelten. Die Hebräische Bibel hat keinen Begriff für „Offenbarung“, aber sie kennt unterschiedliche Formen der Selbstmitteilung Gottes, in Träumen, Visionen, Auditionen, Naturereignissen, geschichtlichen Machttaten - bis hin zur großen Theophanie am Sinai. Doch es gibt auch Texte wie 1. Könige 19, die frühere Erzählungen von Offenbarungen in Frage stellen können: Der Herr war nicht im Sturmwind, nicht im Erdbeben, nicht im Feuer. ${ }^{31}$ Und selbst die normativ gemeinten Inhalte dessen, was dem Mose auf dem Sinai als ewiger Wille Gottes offenbart wurde $^{32}$, kann erzählerisch in den darauf folgenden Kapiteln korrigiert oder

\footnotetext{
${ }^{29}$ S. FRED LEEMHUIS, Bal'am in Early Koranic Commentaries, in: GEURT HENDRIK VAN KOOTEN, The prestige of the pagan prophet Balaam in Judaism, early Christianity and Islam, Leiden 2003 , 303-308. 30 BARUCH A. LEVINE, Numbers 21-36, AB 4, New York 2000, 207-237, nimmt etwa eine transjordanisches Archiv als mögliche Quelle an.

${ }^{31}$ Vgl. 1. Kön 19,11f.

${ }^{32}$ Vgl. Ex 19-Num 10.
} 
schriftgelehrt erweitert werden; die zwei Versionen der Zehn Gebote in Ex 20 und Dtn 5 sind nur die Spitze des Eisbergs. Einig sind sich die Texte allerdings darin, dass Gott sich offenbart hat, dass er Israel zu seinem Eigentumsvolk erwählt hat, ihm Rettung erwiesen, Weisung gegeben und Gericht angekündigt hat. Im Anschluss an Otto Kaiser und Rolf Rendtorff lässt sich formulieren, dass diese Gottesgewissheit das Eigentliche der Offenbarungsvorstellung Israels ist ${ }^{33}$. Die konkret in den biblischen Texten beschriebenen Offenbarungsakte werden demgegenüber erst durch nachträgliche Deutungen erlebter Ereignisse als Offenbarung Gottes verstanden. So konnte wohl auch der aus Mesopotamien stammende Seher Bileam als Offenbarungsträger Gottes verstanden werden, zu Zeiten, als Israel gesegnet und im Schalom mit seinen Nachbarn lebte. Und dem Seher konnte diese Deutung auch wieder entzogen werden, als man das Zusammenleben mit den Völkern anders empfand und deutete. Die Bibel ist menschliches Zeugnis der göttlichen Offenbarung; das wird an der Wanderung der Bileam-Gestalt durch verschiedene Religionen besonders deutlich.

${ }^{33}$ ROLF RENDTORFF, Partikularismus und Universalismus im Offenbarungsverständnis Israels. In: ders., Kanon und Theologie. Vorarbeiten zu einer Theologie des Alten Testaments, NeukirchenVluyn 1991, 113-122; OTTO KAISER, Art. Offenbarung III. AT, Religion in Geschichte und Gegenwart ${ }^{4}$, 6, 2003, 467-470. 


\section{Joachim Kügler \\ Religion ist ein Angebot Gottes, sich ihm zu entziehen, ohne ihn zu vergessen}

Thesen zum Verhältnis von Religion und Offenbarung aus der Perspektive eines katholischen Bibelwissenschaftlers

\section{Einleitung: Die Unterscheidung von Religion und Offenbarung}

Die Unterscheidung von Religion und Offenbarung ist keinesfalls selbstverständlich. Im europäischen Kontext setzt sie eine bestimmte Form der Religionskritik voraus. Die Grundlage lieferte Feuerbach ${ }^{1}$ (1804-1872) mit seiner These, Religion sei nur eine menschliche Projektion ohne jeden Realitätsgehalt. Wenn Religion aber nur ein Produkt menschlicher Phantasie ist, dann machen religiöse Aussagen keine Aussage über eine Wirklichkeit. Sie sagen allenfalls noch etwas über die Bedürfnisse, Wünsche und Träume der Menschen. Ihre Aussagen über Gott sind Aussagen über etwas, was es nicht gibt, so die Position dieses Stranges der Religionskritik. Die naheliegende Form, das Christentum gegen diese Kritik zu verteidigen, lag darin, das Christentum als etwas Besonderes zu sehen. Die Grundthese ist dabei: Alle anderen Religionen mögen nur Gebilde menschlicher Phantasie sein, für die christliche Religion kann das natürlich nicht gelten.

Sie ist nämlich überhaupt keine Religion, so die Behauptung z.B. der Dialektischen Thologie zu Beginn des zwanzigsten Jahrhunderts. Das Christentum, so die These, unterscheidet sich von allen anderen Religionen dadurch, dass es keine Phantasie des Menschen über Gott ist, sondern die Offenbarung Gottes an die Menschen.

Im Christentum träumt nicht der Mensch von Gott, sondern Gott spricht zum Menschen. Diese Reaktion auf Feuerbachs Kritik beruht auf einer weitgehenden Zustimmung zu seiner Einschätzung der Religion. Religion, so wird angenommen, ist in der Tat in der Regel nur menschliche Projektion, nicht mehr als ein Produkt menschlicher Phantasie. Sie redet von Dingen, die es nicht gibt, und zeigt uns nur, wovon Menschen träumen, worauf sie hoffen, wonach sie sich sehnen und wovor sie Angst haben. Feuerbachs Kritik stimmt für alle Religionen, aber sie kann das Christentum nicht betreffen, weil dieses eben gar keine Religion ist!

Diese geschickte Verteidigungsstrategie lässt sich sehr schön graphisch verdeutlichen:

${ }^{1}$ LUDWIG ANDREAS FEUERBACH, * 28. Juli 1804 in Landshut; † 13. September 1872 in Rechenberg bei Nürnberg, deutscher Philosoph, Hauptwerk: Das Wesen des Christenthums, Leipzig 1841. 
Verteidigung gegen die Feuerbach-These: Das Christentum ist keine Religion!

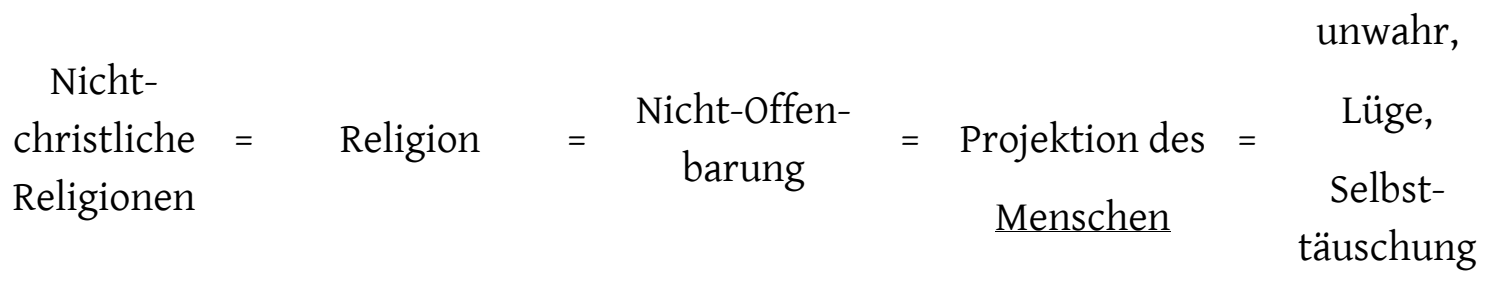

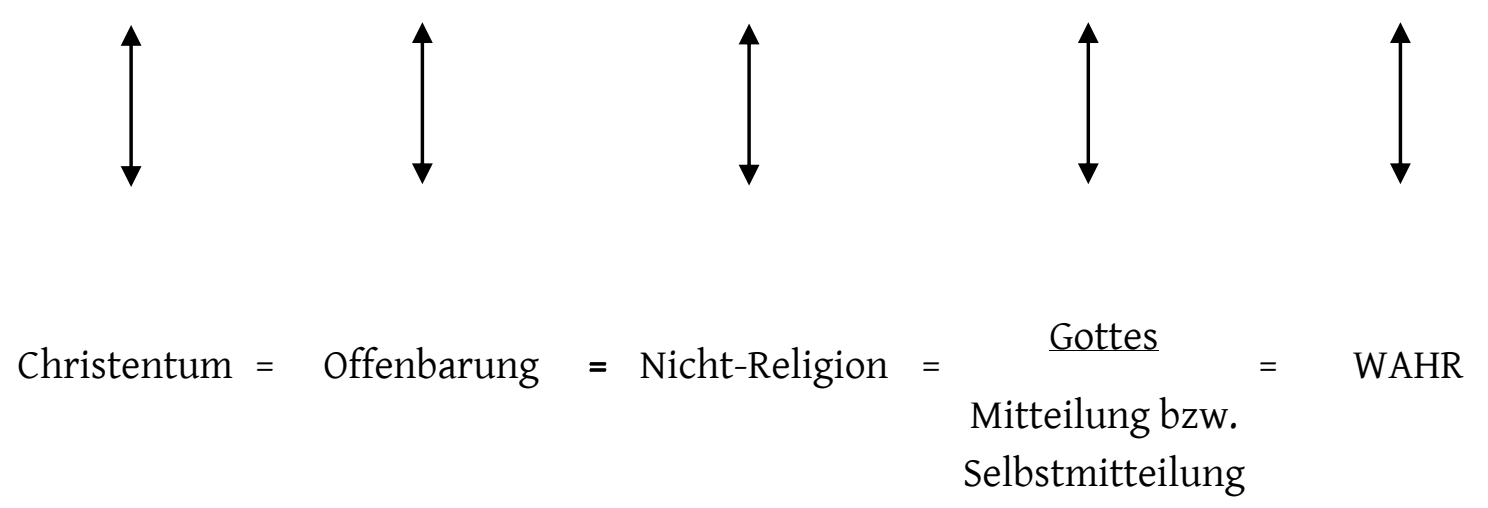

Diese trickreiche Verteidigung des Christentums, die Feuerbach Recht gibt und den eigenen Glauben dadurch rettet, dass sie ihn für Nicht-Religion, also für Offenbarung, erklärt, hat freilich einen entscheidenden Nachteil: Der Offenbarungsbegriff kommt natürlich nicht nur im Christentum vor, sondern auch in unzähligen anderen Religionen. Natürlich kann man die Offenbarungen der pharaonischen Religion, der Maya-Religion, der Schona-Religion usw. als Projektionen erklären. Natürlich kann man sagen: Menschen sehnen sich eben danach, dass es einen Gott gibt, der zu ihnen spricht. Wenn aber Offenbarung in den anderen Religionen nur Teil der Projektion ist, warum sollte es dann in der eigenen Religion anders sein? Warum sollte dann ausgerechnet in der eigenen Religion die Offenbarung keine menschliche Einbildung, sondern göttliches Handeln sein? Ist eine Theologie, die das Christentum zur Offenbarung erklärt, nicht auch einfach nur Teil eines großen menschlichen Phantasiegebildes?

Diese Frage scheint mir unvermeidbar und führt dann zur Notwendigkeit der Fundamentaltheologie, also der Begründung, warum das Christentum wahr (= Offenbarung = Nichtreligion $)$ ist und andere unwahr (= Religion $=$ Projektion $)$ sind . 
Die Unterscheidung von Religion = Projektion = unwahr und Christentum = Offenbarung = wahr löst also kein Problem, aber sie führt zu einem Problem hin, nämlich zur Begründungspflichtigkeit der eigenen Wahrheit. Außerdem enthält die Behauptung, das Christentum sei keine Religion und deshalb wahr, eine massive Abwertung aller anderen Religionen, die einen interreligiösen Dialog sehr schwer macht, wenn nicht sogar unmöglich. Will man diese Abwertung der nichtchristlichen Religionen vermeiden, dann muss man auch das Verhältnis von Projektion und Offenbarung untersuchen. Feuerbach - und dann später die skizzierte Verteidigung gegen ihn setzen ja voraus, dass es einen direkten Gegensatz zwischen Projektion und Offenbarung gibt. Feuerbach und seine Gegner behaupten: ENTWEDER Offenbarung ODER Projektion.

So will ich hier einen anderen Weg gehen, der letztlich zwar auch nicht ohne Fundamentaltheologie auskommt, aber zumindest auf die generelle Abwertung nichtchristlicher Religionen verzichten kann. Zunächst aber muss die Frage geklärt werden, wie denn im biblischen Bereich mit der Beziehung „Offenbarung Religion" umgegangen wird.

\section{Biblische Varianten der Projektionsthese}

\subsection{Im Frühjudentum: Das Weisheitsbuch}

Die Frage nach dem Verhältnis von Religion und Offenbarung stellt sich im alten Israel zunächst nicht richtig. Offenbarung ist ein selbstverständlicher Bestandteil der Religion, und zwar im Plural! Man muss nämlich von vielen Offenbarungen reden: Gott zeigt sich in Träumen, Visionen und Auditionen. Immer wieder spricht er zu seinem Volk oder zu auserwählten Einzelnen. Propheten vor allem sind hier zu nennen. Sie vermitteln das, was Gott sagen will, seinem Volk. Sie sind so etwas wie seine Lautsprecher. Sie werden aber selbst auch schon durch eine Offenbarung von Gott in Dienst genommen, nämlich durch die Berufungsvision. Das gilt für Mose ebenso wie für Jesaja oder Jeremia. Eine Unterscheidung von Religion und Offenbarung liegt hier nicht nahe. Und solange Israel polytheistisch denkt, ist es nicht einmal nötig, zu bestreiten, dass auch andere Völker Offenbarungen haben. Natürlich müssen auch deren Götter mit ihrem Volk sprechen. Selbstverständlich müssen auch die ägyptischen Götter in Offenbarungen, vor allem in bestimmten Orakeln, dem König und dem Volk ihren Willen mitteilen. Ähnliches gilt für die Götter der anderen Nachbarvölker Israels.

Ein Problem entsteht erst, als Israel überzeugt ist, das Jahwe nicht nur der höchste Gott ist, nicht nur der einzige, den man verehren darf, sondern der einzige überhaupt! Der einzige, der existiert! Von da an müssen die offenbarungen der anderen abgewertet werden, weil die Götter, die da angeblich sprechen, ja gar nicht existieren. 
Dieses Problem verschärft sich zusätzlich im Diasporajudentum, das nicht nur mit der Existenz anderer Religionen zurechtkommen muss, sondern darüber hinaus auch noch als Minderheit in Gesellschaften überleben muss, die ganz und gar von diesen anderen Religionen geprägt sind. Das gilt für die Kultur ebenso wie für die Politik und das Recht. Die gesamte Lebenswelt, in der sich das Diasporajudentum bewegt, ist von Göttern geprägt, die es aus jüdischer Sicht gar nicht gibt.

Ich möchte nur zwei Beispiele für den biblischen Umgang mit diesem Problem darstellen.

Das erste Beispiel stammt aus dem „Buch der Weisheit“ (auch: „Weisheit Salomos“; lateinisch: „Sapientia Salomonis“). Diese Schrift ist das jüngste Buch des Alten Testaments und vermutlich in Alexandrien entstanden. Die Datierung ist unsicher, aber es muss jedenfalls in hellenistischer Zeit entstanden sein, grob gesprochen eben nach 300 v. Chr. Die genauere Datierung ist viel schwieriger, aber in jüngster Zeit haben viele Forscher dafür plädiert, es eher in die frühe Römerzeit zu datieren. Diese beginnt für Ägypten mit dem Sieg Octavians über Kleopatra VII. und Marcus Antonius in der Seeschlacht bei Actium, also $31 \mathrm{v}$. Chr. Das Weisheitsbuch ist ursprünglich griechisch geschrieben, also keine Übersetzung aus dem Hebräischen oder Aramäischen. Es ist deswegen nicht Bestandteil der Jüdischen Bibel, sondern nur der griechischen Fassung des Alten Testaments („Septuaginta“), weswegen es dann später Martin Luther nicht zum eigentlichen Bestand des Alten Testaments rechnete, während katholische und orthodoxe Christen es bis heute als Bestandteil ihrer Bibel lesen. Ganz unabhängig davon aber, wie der Status des Weisheitsbuches in den jeweiligen christlichen Konfessionen gesehen wird, ist das Buch in jedem Fall ein wichtiger Zeuge dafür, wie das frühe Judentum in Ägypten die Religionen seiner Umwelt wahrgenommen hat.

Ich möchte hier nur einen kurzen Textausschnitt präsentieren, der aber zeigt, dass das frühe Judentum, das diesen Text schuf, den Religionen der Mehrheitskultur sehr kritisch gegenüberstand, auch wenn man sich generell um ein gutes Verhältnis zur Mehrheitsgesellschaft bemühte.

Das Weisheitsbuch erklärt die Entstehung von Religion 1:

$13^{10}$ Unselig aber sind jene, die auf Totes ihre Hoffnung setzen und Werke von Menschenhand als Götter bezeichnen, Gold und Silber, kunstvolle Gebilde und Tiergestalten oder einen nutzlosen Stein, ein Werk uralter Herkunft. ${ }^{11}$ Da sägte ein Holzschnitzer einen geeigneten Baum ab, entrindete ihn ringsum geschickt, bearbeitete ihn sorgfältig und machte daraus ein nützliches Gerät für den täglichen Gebrauch. ${ }^{12}$ Die Abfälle seiner Arbeit verwendete er, um sich die Nahrung zu bereiten, und $a ß$ sich satt. ${ }^{13}$ Was dann noch übrig blieb und zu nichts brauchbar war, ein krummes, knotiges Stück Holz, das nahm er, schnitzte daran so eifrig und fachgemäß, wie man es tut, wenn man am Abend von der Arbeit 
abgespannt ist, formte es zum Bild eines Menschen ${ }^{14}$ oder machte es einem armseligen Tier ähnlich, beschmierte es mit Mennig und roter Schminke, überstrich alle schadhaften Stellen, ${ }^{15}$ machte ihm eine würdige Wohnstatt, stellte es an der Wand auf und befestigte es mit Eisen.

${ }^{16}$ So sorgte er dafür, dass es nicht herunterfiel, wusste er doch, dass es sich nicht helfen kann; es ist ein Bild und braucht Hilfe.

${ }^{17}$ Aber wenn er um Besitz, Ehe und Kinder betet, dann schämt er sich nicht, das Leblose anzureden. Um Gesundheit ruft er das Kraftlose an, ${ }^{18}$ Leben begehrt er vom Toten. [....]

\section{Das Weisheitsbuch erklärt die Entstehung von Religion 2:}

$14^{15}$ Bedrückt durch allzu frühe Trauer ließ ein Vater von seinem Kind, das gar schnell hinweggerafft wurde, ein Bildnis machen; so ehrte er einen toten Menschen als Gott und führte bei seinen Leuten geheime Kulte und festliche Bräuche ein.

${ }^{16}$ Im Lauf der Zeit verfestigte sich die frevelhafte Sitte und wurde schließlich als Gesetz befolgt; ${ }^{17}$ die Standbilder erhielten auf Anordnung der Herrscher göttliche Verehrung. Konnten die Menschen einen König nicht unmittelbar ehren, weil er weit weg wohnte, dann vergegenwärtigten sie den Fernen; sie machten von dem verehrten König ein Bildnis, das allen sichtbar war, um dem Abwesenden, als ob er gegenwärtig wäre, mit Eifer zu huldigen. ${ }^{18}$ Der Ehrgeiz des Künstlers führte dazu, dass auch jene, die den König gar nicht kannten, ihm göttliche Verehrung erwiesen. ${ }^{19}$ Wohl um dem Herrscher zu gefallen, bot er seine ganze Kunst auf, um ihn schöner darzustellen, als er war. ${ }^{20}$ Von der Anmut des Bildes hingerissen, betete die Menge den, der noch kurz zuvor nur als Mensch geehrt wurde, jetzt wie einen Gott an.

${ }^{21}$ Der Welt ist dies zum Verhängnis geworden: Die Menschen haben, unter dem Druck von Unglück oder Herrschermacht, Stein und Holz den Namen beigelegt, der mit niemand geteilt werden kann. ${ }^{2}$

Ich denke, der Text macht sehr schön klar, dass die Projektionsthese nicht erst von Feuerbach entwickelt wurde. Sie wird allerdings im Weisheitsbuch eben nicht auf alle Religionen angewendet, sondern gilt nur für die Religionen der anderen, nicht für die eigene. Besonders kritikwürdig ist aus jüdischer Sicht dabei die Verehrung von Kultbildern. Dass sie menschliche Produkte sind, liegt auf der Hand. Deshalb sind sie auch der schönste und beste Angriffspunkt für die antike Form der Projektionsthese. In gnadenloser Polemik wird etwa in Weish 13,16 die Hilflosigkeit

${ }^{2}$ Weish 14:15-21 (EÜ), Hervorhebungen J.K. 
und Schutzbedürftigkeit eines Götterbildes dargelegt. Es kann sich selbst nicht helfen, also muss man es gut an der Wand befestigen, damit es nicht herunterfällt.

Diese Polemik funktioniert freilich nur, weil man ignoriert, dass die alten Ägypter oder die Griechen und Römer, natürlich nicht das Kultbild anbeteten, sondern die Gottheit, die dieses Bild gegenwärtig machte. Die feine, aber deutliche Unterscheidung, die die antike Theologie zwischen Bild und Gottheit macht, wird völlig ignoriert. Das geschieht nicht nur aus Unwissenheit, sondern auch aus der Überzeugung, dass es die Götter und Göttinnen, die die Anderen anbeten, gar nicht gibt. Wenn man aber davon überzeugt ist, dass die Gottheit, die in einem Kultbild gegenwärtig sein soll, gar nicht existiert, dann ist klar, dass die anderen das Kultbild anbeten. Da die Götter der Anderen nicht existieren, muss man sich natürlich erklären, wo dann die Verehrung dieser Gottheiten herkommt. Dabei geht das Weisheitsbuch einen ganz ähnlichen Weg wie Feuerbach. Es geht von den Sehnsüchten, Träumen und Nöten der Menschen aus. Trauer, Schmerz über Verlust und Angst, aber auch sekundäre Motive wie Karrierestreben, Gefallsucht und Anpassung an die Massen - das sind die Triebkräfte, die das Weisheitsbuch für die Entstehung der heidnischen Religionen nennt.

Im Neuen Testament sieht der Befund ganz ähnlich aus. Auch im frühen Christentum finden wir eine Argumentation, die der Projektionsthese des frühen Judentums entspricht.

\subsection{Im Neuen Testament: das Beispiel Paulus}

Auch Paulus interessiert sich nicht für Details der antiken Religionen. Für ihn sind die Religionen der anderen ein Zeichen dafür, dass die ganze Welt der Sünde und dem Zorn Gottes verfallen ist.

\section{Die Religion der anderen ist Sünde}

${ }^{18}$ Der Zorn Gottes wird vom Himmel herab offenbart wider alle Gottlosigkeit und Ungerechtigkeit der Menschen, die die Wahrheit durch Ungerechtigkeit niederhalten.

${ }^{19}$ Denn was man von Gott erkennen kann, ist ihnen offenbar; Gott hat es ihnen offenbart.

${ }^{20}$ Seit Erschaffung der Welt wird seine unsichtbare Wirklichkeit an den Werken der Schöpfung mit der Vernunft wahrgenommen, seine ewige Macht und Gottheit. Daher sind sie unentschuldbar.

${ }^{21}$ Denn sie haben Gott erkannt, ihn aber nicht als Gott geehrt und ihm nicht gedankt. Sie verfielen in ihrem Denken der Nichtigkeit, und ihr unverständiges Herz wurde verfinstert. 
${ }^{22}$ Sie behaupteten, weise zu sein, und wurden zu Toren.

${ }^{23}$ Sie vertauschten die Herrlichkeit des unvergänglichen Gottes mit Bildern, die einen vergänglichen Menschen und fliegende, vierfüßige und kriechende Tiere darstellen. ${ }^{3}$

\section{Versuch einer Neubestimmung von Religion und Offenbarung}

3.1 Kritik an der eigenen Religion in der Bibel

Man würde die Bibel unterschätzen, wenn man meinte, es werde nur billige Kritik an fremden Religionen getrieben. Stattdessen ist die Bibel voll von Kritik an der eigenen Religion mit ihren von Menschen gemachten Projektionen.

Man kann sogar so weit gehen, dass es in der Bibel eine Gedankenlinie gibt, die versucht, die Identifizierung von Glaube und Religion aufzubrechen und dabei auch eine Neufassung des Heiligkeitsbegriffes zu versuchen. In dieser - nennen wir sie prophetischen - Linie wird betont, dass Heiligkeit etwas Anderes bedeuten kann als üblicherweise in den Religionen. Dabei wird deutlich, dass Gott sich nicht im heiligen Raum einsperren lässt. Der Gott Israels sprengt den kultischen Rahmen. Er ist nicht nur ein Gott der Priester, sondern einer der Witwen und Waisen, der Ausgebeuteten und Unterdrückten. Ja, Gott lehnt den Kult sogar ab, wenn er auf Kosten der Armen geschieht:

${ }^{23}$ Kein Gefallen hat der Höchste an den Gaben der Sünder, auch für eine Menge Brandopfer vergibt er die Sünden nicht.

${ }^{24}$ Man schlachtet den Sohn vor den Augen des Vaters, wenn man ein Opfer darbringt vom Gut der Armen.

${ }^{25}$ Kärgliches Brot ist der Lebensunterhalt der Armen, wer es ihnen vorenthält, ist ein Blutsauger.

${ }^{26}$ Den Nächsten mordet, wer ihm den Unterhalt nimmt,

${ }^{27}$ Blut vergießt, wer dem Arbeiter den Lohn vorenthält ${ }^{4}$

${ }^{1}$ Viele Opfer bringt dar, wer das Gesetz befolgt;

${ }^{2}$ Heilsopfer spendet, wer die Gebote hält;

${ }^{3}$ Speiseopfer bringt dar, wer Liebe erweist;

${ }^{4}$ Dankopfer spendet, wer Almosen gibt ${ }^{5}$

${ }^{3}$ Röm 1:18-23 EÜ.

${ }^{4}$ Sir 34:23-27 EÜ. 
An dieser und an zahlreichen anderen Stellen des Alten Testaments wird deutlich, dass Gott nicht nur ein Gott des Kultes ist. Er interessiert sich für das Auskommen der Armen und für den Lohn der Arbeiter sogar mehr als für das Fett der Opfertiere. Die Heiligkeit Gottes lässt sich nicht im Tempel einsperren, sondern greift auf das Leben aus, und zwar auf alle Bereiche des Alltags.

Deshalb ist es nicht verwunderlich, wenn die Laienbewegung der Pharisäer versucht, das ganze Leben als Dienst an Gott zu gestalten. Diese Bewegung entsteht vermutlich um etwa $100 \mathrm{v}$. Chr. und setzt sich zum Ziel, die priesterlichen Ideale des Tempelkultes auf die normalen Israeliten zu übertragen: Das ganze Volk Israel soll gottgemäß leben, und zwar immer und überall. Das Mittel, mit dem das erreicht werden soll, besteht im absoluten Gehorsam gegen Gottes Gebote, wie sie in der Bibel festgelegt sind. Das ganze Leben soll durchdrungen werden von dieser Ehrfurcht vor der göttlichen Weisung. In dem Konzept der Pharisäer wird ganz deutlich, dass die Heiligkeit Gottes sich nicht auf den Tempelbezirk beschränkt, sondern die gesamte Lebenswirklichkeit der Menschen erfassen und umgestalten will.

Die Pharisäer kommen im Neuen Testament schlecht weg. Ihr Name wurde in der christlichen Tradition zum Inbegriff für Heuchelei, äußerliche Gesetzesfrömmigkeit und Scheinheiligkeit. Das trübt den Blick dafür, dass die pharisäische Bewegung mit der Jesusbewegung vieles gemeinsam hat. Die Gruppe, die sich um Jesus schart, ist ebenfalls eine Laienbewegung. Kein einziger Priester wird erwähnt. Und die Botschaft Jesu richtet sich ebenfalls an die normalen Leute. Die Landbevölkerung Galiläas, Männer, Frauen und Kinder spricht er an. Diese Gemeinsamkeiten sind beachtlich, weil sie zeigen, dass Jesus eine Grundüberzeugung der Pharisäer teilt: Gott will nicht nur im Tempel beräuchert werden, seine Heiligkeit beansprucht die ganze Welt und das ganze Leben.

Jesus setzt freilich nicht auf den Gesetzesgehorsam. Vermutlich sieht er die Menschen so tief in Sünde und Schuld verstrickt, dass er es für unrealistisch hält, die vollkommene Erfüllung des Gesetzes anzustreben. Deshalb muss Gott den ersten Schritt machen. Er kommt den Sündern entgegen, bietet ihnen seine Barmherzigkeit an und realisiert so seine Königsherrschaft.

Konsequenterweise verwirklicht sich die königliche Heiligkeit Gottes im Staub der galiläischen Landstraße: Nicht das prachtvolle Haus des Kaisers in Rom, nicht der Palast eines Königs und nicht der gewaltige Tempel in Jerusalem bilden den Raum, in dem sich für Jesus die Herrschaft Gottes realisiert. Jesus entdeckt die Königsherrschaft Gottes in der ländlichen Welt der galiläischen Fischer, Bauern und Hausfrauen. Er findet Gott dort, wo Häuser gefegt werden, um verlorenes Geld zu

${ }^{5}$ Sir 35:1-4 EÜ. 
finden, wo man Brot backt, Felder bestellt und verirrte Schafe sucht. Die staubige Welt des Alltags auf dem Land ist für Jesus der Ort, wo die Königsherrschaft Gottes anbricht.

Jesus behauptet gerade nicht, dass die religiöse Elite im Tempel Gott am nächsten ist, sondern er zeigt Gott in einer Welt, die aus der Sicht der Reichen und Mächtigen ganz nebensächlich ist, weil sie eine Welt der Armen und Machtlosen ist.

Das Heilige vermittelt sich nicht mehr in der kultischen Reinheit des Tempels. Jesus behauptet, dass die Gegenwart Gottes erkennbar wird im mühsamen, schmutzigen Leben der Bauern und sogar im Leben derer, die von ihnen verachtet werden. Seine heilsame „Liturgie“ ist das Berühren der Kranken und das Vertreiben des Bösen. Seine „Sakramente“ des Gottesreiches finden auf den Straßen und Plätzen Galiläas statt. Sein heiliges Mahl besteht im Essen mit Zöllnern und anderen Schuldbeladenen. Dieses Essen wird nicht dadurch zum heiligen Mahl, dass es in einem besonderen Raum und nach einem besonderen Ritual mit besonderen Geräten zelebriert wird, sondern dadurch, dass es die Integrationsbewegung Gottes, der die „verlorenen Schafe“ sucht, abbildet und vollzieht.

\subsection{Religion - Projektion - Offenbarung}

Es gibt also eine gute Basis für die Behauptung, dass man Heiligkeit biblisch ganz neu definieren kann. Im Alten und im Neuen Testament gibt es eine starke Tradition, die uns sagt: Das Heilige lässt sich nicht einsperren in Gotteshäuser und heilige Bezirke. Die Heiligkeit Gottes ist damit zugleich eine deutliche Kritik an den religiösen Projektionen, die es auch in der biblischen Religion gibt.

Wenn wir diese Tradition ernst nehmen, dann könnte man zu einer Neubestimmung von Religion und offenbarung gelangen, wie ich sie in meiner Titel-These formuliert habe: Religion ist ein Angebot Gottes, sich ihm zu entziehen, ohne ihn zu vergessen.

Diese These nimmt den Projektionscharakter von Religion ernst. Sie sieht, dass nicht nur andere Religionen, sondern auch die eigene von menschlichen Projektionen durchsetzt sind. Ich versuche aber nicht, Religion und Offenbarung komplett zu trennen, deshalb verstehe ich Religion als Angebot Gottes.

Religion und Offenbarung sind aber auch nicht einfach identisch. Die vielen Irrungen der biblischen Religion, gegen die die Propheten immer wieder aufstehen, zeigen, dass Menschen immer wieder dazu neigen, sich ihren eigenen Gott zu basteln. Die Gottheit Gottes wird dann ersetzt durch die menschlichen Vorstellungen von Gott. Man könnte also sagen: Religion ist wie ein Denkmal Gottes. Sie zeigt Gott nicht unbedingt, wie er ist, aber Religion hält doch auch immer die Erinnerung wach, so dass wir ihn nicht vergessen. 
Die Offenbarung und ihr gegenüber vorgebrachte Anzweifelungen

\section{Die Offenbarung: Ihre Bedeutung und ihre Arten}

In der Sprache gilt Offenbarung (wahy) als die besondere Mitteilung im Verborgenen an jemanden, dem offenbart wird, insofern als dass sie anderen verborgen ist.

In diesem Sinne wird die Bezeichnung Offenbarung (im Arabischen) verwendet für:

1. Die der Veranlagung des Menschen entsprechende Eingebung oder die Eingebung in Form von Einfällen; das ist, was Gott - Preis sei ihm - in das Herz des Menschen mit unbeschadeter Veranlagung gibt, so wie er zur Mutter Moses sprach und zu den Jüngern unter den Leuten Jesu. Darüber sagt er - Preis sei ihm!: „Wir gaben Moses Mutter ein: 'Nähre ihn an deiner Brust! Wenn du aber um ihn fürchtest, dann wirf ihn in den Strom! Und fürchte dich nicht, und sei nicht traurig! Siehe, wir werden ihn dir wiedergeben und ihn zu einem der Gesandten machen!'“1 Und er sagt: „Und damals, als ich den Jüngern eingab: 'Glaubt an mich und meine Gesandten!' Da sprachen sie: 'Wir glauben! Bezeuge, dass wir gottergeben sind!'“

2. Die instinktive Eingebung, wie die Eingebung an die Biene, zu der Gott spricht: „Dein Herr gab der Biene ein: 'Mach dir in den Bergen etwas zu Häusern, dazu von den Bäumen und dem, was sie errichten!“3

3. Die Einflüsterung des Teufels, der das Hässliche schön erscheinen lässt, die Einfälle des Bösen, die den Menschen befallen; darüber sagt er - er ist groß und erhaben: „Ja, die Satane reden ihren Vertrauten etwas ein, um mit euch zu streiten. Wenn ihr auf sie hört, dann seid ihr Beigeseller.“4 Und er sagt: „So machten wir jedem Propheten einen Feind, die Satane der Menschen und der Dschinne. Der eine von ihnen flüstert dem anderen $\mathrm{zu}$, blendende Rede und Täuschung. ${ }^{\text {"5 }}$

4. Das Zeichengeben in Form des Symbols und der Gebärde; darüber sagt er - Preis sei ihm!: „Da trat er aus dem Tempel vor seine Leute und machte ihnen kund: ,Sprecht das Lob in der Morgenfrühe und am Abend! ${ }^{\circ 6}$ Es ist bekannt: Zacharias Friede sei auf ihm - hielt seine Zunge drei Tage vor dem Reden mit den Leuten zurück, aber er hielt sich nicht vor dem Gedenken Gottes zurück. Dieser Vers betraf die Schwangerschaft seiner Frau. So sprach er mit den Leuten während dieser Zeit mittels Zeichen und Symbolen, so wie er sagte - Preis sei ihm!: „Er sprach: ,Mein Herr, gib mir ein Zeichen!' Er sprach: ,Dein Zeichen sei, dass du drei Tage lang nur

\footnotetext{
${ }^{1}$ Al-Qasas (Die Geschichte) 28:7.

${ }^{2}$ Al-Ma'ida (Der Tisch) 5:111.

${ }^{3}$ An-Nakhl (Die Biene) 16:68.

${ }^{4}$ Al-An‘ām (Das Vieh) 6:121.

${ }^{5}$ Al-An'ām (Das Vieh) 6:112.

${ }^{6}$ Maryam (Maria) 19:11.
} 
deutend zu den Menschen sprichst. Gedenke häufig deines Herrn! Preise ihn am Abend und am Morgen! “"

Die Offenbarung ist also in all diesen Verwendungsweisen die Mitteilung im Verborgenen. Die Offenbarung nach dem Gesetz der offenbarten Religion ist das, was den Propheten - auf ihnen sei Friede - von Gott eingegeben wird - Preis sei ihm!

Der edle Koran hat bereits die Arten der Offenbarung an die Gesandten in seiner Rede - Preis sei ihm! - festgelegt: „Keinem Menschen steht es an, dass Gott mit ihm spricht, es sei denn, durch Offenbarung oder hinter einer Trennwand. Oder er sendet einen Gesandten, dass der mit seiner Erlaubnis offenbart, was er will. Siehe, er ist erhaben, weise." ${ }^{\text {" }}$ So hat Gott an diesem Vers bereits verdeutlicht, dass seine Offenbarung an seine Gesandten auf drei Arten erfolgt:

1. Die Eingebung des Sinninhalts in das Herz; das ist, was der Vers mit „Offenbarung“ bezeichnet, obwohl auch die restlichen Arten Offenbarung sind; doch ist diese Art noch mehr im Verborgenen als die restlichen Arten: So hört der, dem eingegeben wird, keine Stimme und sieht keinen Engel, vielmehr gibt Gott in sein Herz ein, was er ihm eingeben will. Hier weiß der, dem eingegeben wird, in tiefster Seele, dass das, was ihm eingegeben wird, eine Offenbarung von Gott ist.

2. Das Reden hinter der Trennwand; das bedeutet, dass der Gesandte die Rede Gottes hört, ihn aber nicht sieht. So hört er die Rede, sieht aber nicht den Sprecher.

Die Rede Gottes, die der Gesandte hört, kommt also aus irgendeiner Sache oder irgendeinem Ort hervor. Der Koran äußert sich bereits darüber in der Geschichte Moses - Friede sei auf ihm - so sagte er - Friede sei auf ihm: „Als Mose die Frist erfüllt hatte und mit den Seinen fortgezogen war, nahm er ein Feuer an der Seite des Berges wahr. Er sagte zu den Seinen: 'Bleibt! Siehe, ich nahm ein Feuer wahr. Vielleicht bringe ich euch von ihm Kunde oder ein brennendes Scheit. Vielleicht könnt ihr euch wärmen. Als er zu ihm kam, wurde er gerufen vom rechten Rand des Tales aus, auf dem gesegneten Platz, aus dem Gesträuch: 'Mose! Siehe, ich bin Gott, der Herr der Weltbewohner!'“9

3. Die Rede mit dem Propheten durch die Vermittlung Gabriels. Diese Art ist die Offenbarung aufgrund der Vermittlung Gabriels ohne dies zu verbergen, während die ersten beiden Arten Offenbarung ohne Vermittlung waren. Wir finden weder im Koran noch in der prophetischen Sunna, wie die vorhergehenden Gesandten - auf ihnen sei Friede - von Gabriel unterwiesen worden sind. Doch wir finden dies hinsichtlich des Gesandten Gottes (sws) aus der prophetischen Sunna. Wir finden dort, dass Gabriel zum Gesandten Gottes (sws) in zwei Zuständen herabkam:

\footnotetext{
${ }^{7} \mathrm{Al}$ 'Imran (Das Haus 'Imran) 3:41.

${ }^{8}$ Ash-Shura (Die Beratung) 42:51.

${ }^{9}$ Al-Qasas (Die Geschichte) 28:29f.
} 
Der erste Zustand: dass er zu ihm wie der Klang einer Glocke kommt, vielleicht ist der Glockenklang die Stimme des Engels selbst, als der Gesandte (sws) das erste Mal hingehört hat.

Der zweite Zustand: dass für ihn der Engel die Gestalt eines Mannes annimmt, d.h. er kommt in menschlicher Gestalt $\mathrm{zu}$ ihm und passt sich der menschlichen Natur des Gesandten Gottes (sws) an. Und dieser Zustand ist leichter als der vorhergehende, insofern als er eine Anpassung zwischen dem Sprecher und dem Hörer ist. Die Gestalt, in der sich Gabriel als Mensch zeigt, erfordert nicht, dass er seiner Geistlichkeit beraubt ist, und heißt auch nicht, dass sein Wesen sich in einen Mann verwandelt hat, sondern dass er sich in jener Gestalt dem Gesandten Gottes (sws) mit dem Zweck der Annäherung und Erleichterung zeigt. Was den ersten Zustand betrifft, so ist er schwer für den Gesandten Gottes (sws), da er eine geistige Erhöhung vom Gesandten Gottes erfordert, indem er sich der Geistigkeit des Engels anpasst. Das hat Ibn Khaldun so beschrieben:

Der erste Zustand ist ein Abstreifen der körperlichen Menschlichkeit und ein Erreichen der geistigen Engelhaftigkeit, der andere Zustand jedoch sein Gegenteil, $\mathrm{da}$ es sich um ein Herabsteigen des Engels von der reinen Geistigkeit zur körperlichen Menschlichkeit handelt. Wir haben bereits die Beschaffenheit des Herabsteigens Gabriels zum Gesandten Gottes (sws) der prophetischen Sunna entnommen:

Es wurde bereits von Aischa überliefert - Gott sei mit ihr zufrieden -, dass al-Harith b. Hischam - Gott sei mit ihm zufrieden - den Gesandten Gottes (sws) fragte: „Wie kommt die Offenbarung zu dir?“ Da sagte der Gesandte Gottes: „Manchmal kommt er wie der Klang einer Glocke zu mir, und das ist schwerer für mich: So verlässt er mich, wenn ich alles, was er sagte, im Gedächtnis behalten habe. Und manchmal nimmt für mich der Engel die Gestalt eines Mannes an und spricht zu mir, und ich behalte, was er sagt." ${ }^{\text {"10 }}$

\section{Auf welche Art der Offenbarung der Koran herabkam:}

Der ganze edle Koran kam auf Muhammad (sws) durch die Vermittlung Gabriels herab, nämlich in seinem ersten Zustand ${ }^{11}$, bei dem er herabstieg und ihn nicht sah, und in dem der Prophet (sws) Mühe und Schwierigkeit fand.

Es wurde auch gesagt, dass die Sure al-Kauthar (Die Fülle) im Schlaf herabkam. Man schlussfolgerte dies aus dem, was von Anas überliefert wurde, der sagte: Als der Gesandte Gottes (sws) an dem Tag, an dem wir uns in der Moschee zeigten, kurz einnickte und dann seinen Kopf lächelnd hob, da sagte ich: „Warum lachst du, Gesandter Gottes?“ Da sagte er: Es kam auf mich die obenstehende Sure herab, so

\footnotetext{
${ }^{10}$ Aus dem Sahih al-BUKHARI entnommen.

${ }^{11}$ Das heißt, er kam herab wie der Klang einer Glocke.
} 
trug er vor: „Siehe, wir verliehen dir die Fülle, so bete für deinen Herrn und opfere! Siehe, dein Hasser ist der Kinderlose. “" ${ }^{12}$ Vielleicht ist dieser Schlummer einer von den Stadien der Veränderung, die den Gesandten Gottes (sws) bei der Herabkunft Gabriels in Form eines Glockenklangs überkamen. ${ }^{13}$ Muhammad (sws) war kein Neuerer unter den Gesandten hinsichtlich des Phänomens der Offenbarung, und er war nicht der erste Prophet, der den Menschen die himmlische Rede überbrachte. Den Gesandten Gottes (sws) überkamen verschiedene Veränderungen während einiger Offenbarungszustände. Wir können einen Blick auf manche dieser Veränderungen mithilfe einiger Überlieferungen werfen:

Aischa sagt: „Ich sah ihn - d.h. den Gesandten Gottes - während auf ihn die Offenbarung an einem sehr kalten Tag herabkam. Sie verließ ihn und wahrlich, der Schweiß rann ihm von der Stirn." Und Zaid b. Thabit beschreibt das Gewicht des Oberschenkels des Gesandten Gottes (sws): Sein Oberschenkel war auf mir, als die Offenbarung herabkam, weiter heißt es wörtlich: „Bei Gott, ich habe nichts Schwereres als den Oberschenkel des Gesandten Gottes gesehen (sws).“

Und Ya'la b. Ummaya sagt, dass er den Gesandten Gottes (sws) einmal während der Herabkunft einer Offenbarung sah: Der Gesandte Gottes (sws) wurde rot im Gesicht, versank deshalb eine Stunde lang in tiefem Schlaf und erholte sich dann wieder davon." Von daher war die Offenbarung manchmal schwer für ihn. Darüber sagt Asma' bint 'Umais: So war das Empfinden des Propheten jedes Mal bei der Herabkunft einer Offenbarung an ihn, als würde ihn etwas bedrücken wollen.

Die Bedeutung dessen ist nicht, dass der Gesandte Gottes (sws) seine Persönlichkeit und seinen Verstand oder seine Sinne und sein Empfinden verlor. Diese Wahrheit bestätigt der Gesandte Gottes (sws) und sagt in einer Beschreibung der Art und Weise der Herabkunft der Offenbarung: „Manchmal kommt er zu mir wie ein Glockenklang $^{14}$, und das ist schwerer für mich. So verlässt er mich, wenn ich im Gedächtnis behalten habe, was er sagte. Und manchmal nimmt er für mich die Gestalt eines Mannes an, spricht zu mir und ich merke mir, was er sagt." Die beiden Ausdrücke, „ich habe im Gedächtnis behalten“ und „ich merke mir“, sollten doch klarmachen, dass der Gesandte Gottes (sws) während der Offenbarung und nach ihrem Ende in einem im Hinblick auf Verstand und Wahrnehmung ganz und gar wachem Zustand war, obwohl die Schwierigkeit der Offenbarung leichter oder schwerer zu ertragen war und ihm Veränderungen widerfuhren.

\footnotetext{
${ }^{12}$ Al-Kauthar (Die Fülle) 108.

${ }^{13}$ Die Veränderungen: Sie haben den Gesandten Gottes (sws) überkommen, als Gabriel zu ihm in Form eines Glockenklangs herabkam.

${ }^{14}$ Der Gesandte (sws) hörte eine ununterbrochene Stimme wie das Geräusch eines Glockenklangs.
} 


\section{Der Koran ist ein Zeugnis der Offenbarung}

Die Ungläubigen versuchten den Koran als ein Zeugnis von den Zeugnissen der Offenbarung in Zweifel zu ziehen und behaupteten, dass er ein Erzeugnis und eine Erfindung Muhammads sei (sws) und nicht das Ergebnis einer Offenbarung, die von Gott - Preis sei ihm! - ausgeht. Dies ist eine falsche Behauptung, deren Ungültigkeit viele Zusammenhänge und Indizien bezeugen:

a) Im Koran gibt es viele Verse, die zu Beginn den Gesandten Gottes (sws) mit dem Ausdruck „Sprich!“ ansprechen. (Die Einleitung dieser Verse mit diesem Ausdruck ist feinsinnig und wird von den des Arabischen Kundigen unmittelbar verstanden. Er drückt die Ausrichtung der Rede an den Gesandten (sws) aus und seine Unterrichtung über das, was gesagt werden muss. Der Gesandte spricht dabei nicht aus seinem Inneren heraus, sondern folgt dem, was ihm eingegeben wird. Deswegen wiederholt sich der Ausdruck „Sprich!“ mehr als 300 Mal im Koran, auf dass sich die Leute daran erinnern, dass Muhammad (sws) sich nicht in die Eingebung einmischt. Es wird weder in seiner Ausdrucksweise formuliert noch in seiner Rede geformt, vielmehr wird ihm die Rede eingegeben. Er ist somit ein Angesprochener und kein Sprecher, er gibt weiter, was er hört und äußert sich nicht darüber, was ihn innerlich beschäftigt. ${ }^{15}$

b) Die Heuchler beschuldigten Aischa, eine Hure zu sein, und verbreiteten über sie schändliche Dinge. Als die Nachricht dem Gesandten Gottes (sws) zu Ohren kam, litt er sehr. Die Offenbarung blieb einen ganzen Monat aus, während er sich des wahren Sachverhalts nicht sicher war, und die Sache unentschieden blieb, bis im Herzen des Gesandten sich der Zweifel regte und er zu seiner Frau, der Mutter der Gläubigen, sprach: „Oh Aischa, was das und das betrifft, was ich hörte: Wenn du unschuldig bist, wird dich Gott freisprechen und wenn du dich mit der Sünde eingelassen hast, dann bitte Gott um Verzeihung!"

Es ist unübersehbar, dass dieser Monat, nach dem der Vorfall ablief, ohne dass der Prophet eine Offenbarung erhalten hätte, schwerer auf ihm lastete als viele Jahre, da die Heuchler sich gegen die reine Rechtschaffene (Aischa) ereifert hatten. Wie kommt es, dass der Prophet, der Opfer von Zweifel und Besorgnis war, einen ganzen Monat schweigend wartete und niedergeschlagen harrte, bis die Verse der Sure anNur (das Licht) herabkamen und die Mutter der Gläubigen entlastete? Warum sollte er sich nicht beeilen, sich in den Befehl des Himmels einzumischen, in die Wollkutten der Mönche zu schlüpfen, gereimte Sprüche anzufertigen, Weihrauch verströmen zu lassen und die Rechtschaffenen von der Verleumdung der Schmäher zu befreien?

c) [Das Herz] des Propheten (sws) brannte vor Sehnsucht nach der Veränderung der Gebetsrichtung (Kibla) zur Kaaba hin und er wandte sein Gesicht immer wieder,

\footnotetext{
${ }^{15}$ SUBHI SALIH, Mabahith fi 'ulum al-qur'an [Beirut, 1977], 30.
} 
sechzehn oder siebzehn Monate lang zum Himmel, ob vielleicht eine Offenbarung zur Veränderung der Kibla in die Richtung des Hauses ${ }^{16}$ hin auf ihn herabkäme. Doch der Herr des Korans sandte keinen Offenbarungstext (qur'an) zu dieser Veränderung herab, obwohl sich sein edler Gesandter fast eineinhalb Jahre lang grämte. Warum hat er dann den Prophet (sws) nicht mit einer schnellen Offenbarung unterstützt, die verwirklicht, wonach er gestrebt und was er erwünscht hat? ${ }^{17}$

Es wurde auch behauptet dass der Koran in seinem mekkanischen Teil von Indizien und Beweisen frei wäre, im Unterschied zum medinensischen Teil, der voll wäre von Indizien und sich auf die Beweisführung stützte.

Dies soll eine Erklärung dafür sein, dass der Koran ein Werk Muhammads sei und daher von dem Milieu beeinflusst worden sei, in dem er lebte. In Mekka, als der Koran frei von Indizien und Beweisführungen herabkam, sei Muhammad unter Analphabeten gewesen. Erst als er nach Medina unter die kultivierten Leute der Buchreligionen kam, sei der Koran dann voll von Indizien und Beweisführungen.

Das ist aber reine Lüge und glatte Verleumdung. Der mekkanische Koran ist nämlich reich an Hinweisen und Argumenten für das Bekenntnis des Islam, in Theologumena, Prophezeiungen und Traditionen...

Lasst uns diese Verse betrachten:

1. Er sagt - Preis sei ihm! - in der mekkanischen Sure al-Anbiya' (Die Propheten): „Gäbe es in beiden Götter außer Gott, dann würden beide verfallen. Lobpreis sei Gott, dem Herrn des Thrones! Er ist erhaben über das, was sie da behaupten. Er wird nicht gefragt nach dem, was er tut. Sie aber werden gefragt. Oder nehmen sie sich Götter neben ihm? Sprich: „Bringt euren Beweis herbei! Das hier ist Mahnung derer, die mit mir und die vor mir lebten." Die meisten von ihnen aber kennen die Wahrheit nicht. Sie wenden sich von ihm ab.“18 Und diese Verse stellen Grundsätze für das Einheitsbekenntnis auf und vollziehen dabei die Beweisführung kraft der Logik und nicht kraft einer anderen Sache. So entnahmen die Theologen aus dem ersten Vers einen Beweis für die Einheit Gottes und nannten ihn „Beweis der gegenseitigen Ausschließung“, so sagten sie: Der Vers lehrt, dass die Welt, würde sie zwei Erschaffer haben, nicht nach einer Ordnung von ihnen beiden gelenkt werden könnte; vielmehr würde das Unvermögen beide oder einen von ihnen unvermeidbar befallen, zum Beispiel: Wenn einer von beiden die Belebung eines Körpers wollte, und der andere sein Sterben, würde sich - vorausgesetzt sie einigten sich - beider Wille durchsetzen, wobei hier ein unauflösbarer Widerspruch entstünde. Denn diese Tat kann nicht geteilt werden, bzw. vorausgesetzt, sie verblieben im Dissens, wäre

\footnotetext{
${ }^{16}$ Die Ka'ba (Übers.).

${ }^{17}$ S.o. 37.

${ }^{18}$ Al-Anbiya' (Die Propheten) 21:22-24.
} 
es auch unmöglich, beide Gegensätze zusammenzuführen. Entweder würde also ihr beider Wille nicht ausgeführt, und das führte zu ihrer beider Unvermögen, oder es würde keiner der beiden ausgeführt, was zu Seinem Unvermögen führte. Gott ist aber nicht unvermögend.

2. Er - Preis sei ihm - sagt in der Sure al-'Ankabut (Die Spinne): „Nie vorher trugst du aus einem Buche vor und schriebst es nicht mit deiner Rechten ab. Sonst würden die daran zweifeln, die es für Trug erklären. Nein, er stellt klare Zeichen dar in den Herzen derer, denen das Wissen gegeben wurde. Allein die Frevler bestreiten unsere Zeichen. Sie sprechen: „Warum wurden keine Zeichen von seinem Herrn auf ihn herabgesandt?" Sprich: „Die Zeichen sind allein bei Gott, und ich bin nur ein klarer Warner." Genügt es ihnen nicht, dass wir auf dich das Buch herniedersandten, damit es vorgetragen werde? Siehe, darin liegt fürwahr Barmherzigkeit und eine Mahnung für Menschen, die glauben." ${ }^{19}$ So sehen wir in diesen Versen den Beweis für das Prophetentum Muhammads (sws): klar, ohne Zweifel und ohne Verkehrtheit... und wir sehen eine friedliche Diskussion, die versucht, diese Verleumdung, für die es kein Argument und keinen Hinweis gibt, auszuräumen.

3. Er sagt - Preis sei ihm! - in der mekkanischen Sure Ya Sin: „Sah der Mensch denn nicht, dass wir ihn aus einem Tropfen erschaffen haben? Und schon ist er ein klarer Gegner! Ein Gleichnis prägte er für uns, vergaß dabei jedoch, dass er geschaffen ist. Er sprach: „Wer kann die Gebeine lebendig machen, wenn sie schon zerfallen sind?“ Sprich: „Der macht sie lebendig, der sie ein erstes Mal erschuf. Wissen hat er von allem, was erschaffen ist. “20 In diesen Versen sehen wir, wie der edle Koran einen Beweis aufstellt für das Problem der Wiederbelebung am Beispiel des Neubeginnens. Vielleicht verstärkt die Erwähnung der Gründe für die Herabsendung die Klarheit der beiden Verse. Al-Hakim wählte aus und bestätigte von Ibn 'Abbas, dass er sagte: „Es kam Al-'As b. Wa'il zum Gesandten Gottes (sws) mit einem verwesten Knochen, er zerbröckelte ihn und sagte höhnend: ,Oh Muhammad, erweckt Gott diesen wieder, nachdem ich ihn wegwerfe?' Er sagte: Ja, Gott erweckt diesen wieder, dann lässt er dich sterben, dann erweckt er dich wieder zum Leben und lässt dich schließlich ins Höllenfeuer eingehen. Dann kamen die Verse herab. Von dieser Art ist auch seine Rede - Preis sei ihm! - in der mekkanischen Sure Al-Mu'minun (Die Gläubigen): „Den Menschen schufen wir aus einem Extrakt aus Lehm und machten ihn zu einem Samentropfen an einem sicheren Platz. Dann formten wir den Samentropfen um zu einem Klumpen, dann formten wir den Fötus um zu Knochen, um dann die Knochen mit Fleisch zu umkleiden. Dann ließen wir ihn als andere Schöpfung erstehen. Voller Segen ist Gott, der beste Schöpfer! Und siehe, danach

\footnotetext{
${ }^{19}$ Al-'Ankabut (Die Spinne) 29:48-51.

${ }^{20}$ Ya Sin (Ya Sin) 36:77-79.
} 
müsst ihr dann sterben und werdet dann, am Tag der Auferstehung, wieder auferweckt.“21

4. Er - Preis sei ihm! - sagte in der mekkanischen Sure al-An'am (Das Vieh): „Acht paarweise, von den Schafen ein Paar und von den Ziegen ein Paar. Sprich: „Hat er die Männchen für verboten erklärt oder die Weibchen oder was die Weibchen im Leibe tragen? Teilt es mir mit aufgrund von Wissen, wenn ihr die Wahrheit sprecht!“ Und von den Kamelen ein Paar und von den Rindern ein Paar. Sprich: „Hat er die Männchen für verboten erklärt oder die Weibchen oder was die Weibchen im Leibe tragen? Oder wart ihr selbst dabei, als euch Gott das aufgetragen hat?" Wer ist frevelhafter wohl als jener, der Lügen gegen Gott ersinnt, um die Menschen, ohne über Wissen zu verfügen, irrezuleiten? Siehe, Gott leitet das frevlerische Volk nicht recht."22

Diese Verse richten sich gegen die Ungläubigen in ihrem Verbot, mal der männlichen Tiere, mal der weiblichen Tiere. Der Text zeigt ihnen den Beweis für den Irrtum dieses Verbots durch die Erklärung, dass es keine Ursache dafür gibt und keinen Hinweis darauf außer der Begierde, der Verleumdung und des Unrechts.

Die Theologen haben aus diesen Versen einen Beweis hergeleitet, den sie „Erkundung und Klassifizierung“ nennen. Er beschränkt sich auf das Beschreiben, aber meint nicht, dass einer von diesen als Grund aufgeführt wird; die Anwendung auf die Verse ist folgende:

Als die Ungläubigen einmal die männlichen Tiere und dann die weiblichen verbaten, widerlegte Gott ( $\mathrm{t}$ ) dies ihnen auf dem Weg der Erkundung und Klassifizierung und sagte (sinngemäß): „Gottes ( $t$ ) Schöpfung beinhaltet von allen ein $\operatorname{Paar}^{23}$, von dem Männliches und Weibliches Erwähnung finden. Woher also kommt das Verbot, das ihr erwähntet? Was ist seine Ursache?

Eine Begründung kann nicht ganz ohne Bezug auf entweder das Männliche oder das Weibliche auskommen, oder darauf dass der Fötus beide Geschlechter enthält. Eine andere Möglichkeit ist, dass man für das Verbot keinen Grund weiß und es als ein gottesdienstliches Gebot versteht, das von Gott $(\mathrm{t})$ empfangen wird. Das Empfangen [einer Offenbarung] von Gott $(\mathrm{t})$ geschieht entweder durch die Offenbarung und das Senden von Gesandten oder das Hören seines Wortes und die Bezeugung der Entgegennahme dessen. Darauf bezieht sich Seine ( $\mathrm{t}$ ) Rede: „Oder wart ihr selbst dabei, als euch Gott das aufgetragen hat?... Doch diese Arten des Verbots stammen nicht aus einem von diesen." ${ }^{24}$

\footnotetext{
${ }^{21}$ Al-Mu’minun (Die Gläubigen) 23:12-16.

${ }^{22}$ Al-An'am (Das Vieh) 6:143f.

23 "Von jedem Paar" ist ein Ausdruck, der im Koran mehrfach in der Bedeutung "von allen" steht.

${ }^{24}$ Al-An'am (Das Vieh) 6:144.
} 
Das erste, was notwendig wäre, ist, dass alles Männliche verboten wäre, und das zweite, dass alles Weibliche verboten wäre, und das dritte, dass beide Arten verboten wären. Unschlüssig ist, was sie an Verboten für einige in einem Zustand und andere in einem anderen Zustand vorschrieben, da der Grund dafür, nach dem, was er erwähnte, ein generelles Verbot erfordern würde. Sich nun auf das Empfangen einer Offenbarung zu berufen, wäre nichtig, und ist in diesem Fall auch nicht erfolgt. Die Berufung auf eine Offenbarung ohne Vermittlung wäre nichtig, und sie haben sich darauf auch nicht berufen. Ebenso nichtig wäre es, sich auf die Vermittlung des Gesandten zu berufen, denn zu ihnen ist kein Gesandter vor den Propheten (sws) gekommen. Wenn aber all dies falsch ist, dann ist die Behauptung bewiesen, dass das, was sie sagten, Verleumdung Gottes und ein Irrtum ist.

Was an Skepsis gegenüber dem Koran angeführt wird, dass er ein Erzeugnis Muhammads und eine Folge der Epilepsie sei, und deswegen an Muhammad physiologische Veränderungen während der offenbarung auftraten und er deswegen Schweißausbrüche hatte und unter der Schwere seines Körpers gelitten habe, so ist dies Unsinn und wertlos. Denn die Epilepsie ist eine Krankheit und der Epileptiker weiß nichts von sich selbst während seiner Epilepsie. War denn der Gesandte Gottes (sws) dem Wachzustand verborgen und wusste er nichts über sich selbst, nachdem der Anfall der Epilepsie von ihm gegangen war? Wahrlich, der Gesandte Gottes (sws) kannte alles, was ihm eingegeben wurde, während die Offenbarung an ihn ging oder Gabriel kam. Er hat sich darüber bereits wie folgt geäußert: Er trennte sich von mir und ich behielt das, was er sagte, im Gedächtnis.

Zweitens: Wenn man sich ernsthaft vorstellen wollte, der Koran wäre die Rede des Gesandten Gottes (sws) in Zuständen der Epilepsie, also in einem Zustand des Unvermögens, der den Menschen wehrlos macht und davon ausschließt, klare Sprache und kunstvolle Beredsamkeit $\mathrm{zu}$ entwickeln und das Niveau der Prophetenworte zu erreichen, die vom Gesandten Gottes im Zustand der Wachheit stammen, dann verweist dies nur auf die Nichtigkeit solcher Skepsis und ihre Oberflächlichkeit. 


\section{Karlheinz Ruhstorfer \\ Offenbarung und Religion in christlicher Perspektive}

Meine Aufgabe ist es, das Verhältnis von Offenbarung und Religion aus christlicher Perspektive zu beschreiben. Dabei geht es um ein Verhältnis von Geben und Nehmen. Der Geber ist Gott, der Empfänger, der die Gabe vernimmt, ist der Mensch. Das Organ des Menschen, das vernimmt, ist sein Denken, das wir als Glaube und als Vernunft bestimmen können. So zeichnet sich bereits jetzt ab, dass es um eine lebendige Beziehung geht, deren Mitte der Geist darstellt, der sich freilich nicht auf eine Innerlichkeit beschränkt, sondern sich auch in einem Tun manifestiert und letztlich den ganzen Menschen betrifft. Offenbarung kann auch als das Kommunikationsgeschehen zwischen Gott und Mensch bezeichnet werden, das den Menschen und seinem ganzen Denken, Wollen und Tun eine neue Bestimmung gibt. Wodurch aber unterscheidet sich offenbarung von einer sonstigen Kommunikation? Der Sender der Botschaft ist Gott, der die gewöhnliche Erfahrung ebenso übersteigt wie das gewöhnliche Denken des Menschen. Deshalb meint offenbarung immer auch das Offenbarwerden einer verborgenen Wirklichkeit oder Wahrheit. Die Transzendenz, die Erhabenheit, die Unendlichkeit Gottes vermitteln sich in die Immanenz, die Gewöhnlichkeit und die Endlichkeit des Menschen. Das Geheimnis Gottes wird offenbar, doch nicht in der Weise, dass damit das Geheimnis gelüftet würde, sondern dass es als Geheimnis in neuer und überwältigender Weise überhaupt erst vor uns steht.

Das bisher Gesagte betrifft gleichermaßen alle monotheistischen Religionen, die von einem sowohl persönlichen als auch transzendenten Schöpfer der Welt ausgehen und sich mit diesem eben durch seine offenbarung verbunden wissen. Das besondere der christlichen Offenbarung besteht nun darin, dass Gott nicht etwas mitteilt, wie in Judentum und Islam, sondern sich selbst. Die Offenbarung besteht nicht in einer Botschaft, sondern in Gott selbst. Wir sprechen deshalb auch von Selbstmitteilung Gottes. Das Mitgeteilte im Judentum ist zuhöchst die Tora. Die Tora aber ist nicht Gott, sondern nur sein Wissen, eine Weisung für die Menschen, die den göttlichen Willen offenbart. Ebenso ist im Islam das Mitgeteilte nicht Gott selbst, sondern der Koran, verstanden als das an Mohammed durch den Engel Gabriel ergangene Wort Gottes. Doch auch dieses Wort ist nicht selbst Gott. Selbst der Gedanke von der Unerschaffenheit des Korans, will nicht die Göttlichkeit des Offenbarungswortes implizieren. Wie verhält es sich nun mit dem Christentum?

Bevor wir zum konkreten Inhalt der christlichen Offenbarung kommen, möchte ich abstrakt den Grundgedanken der christlichen Religion erläutern. Gott ist der Eine. Dies ist der erste Grundsatz des Christentums. Im Credo heißt es: „Wir glauben an den einen Gott". Doch ist die Einheit Gottes nach christlichem Verständnis nur die halbe Wahrheit. Gott ist auch der Andere. Die Einheit Gottes zeichnet sich dadurch 
aus, dass sie den Gedanken der Differenz noch umfasst. Deshalb ist es nach christlicher Überzeugung auch wahr, dass Gott der Eine, das zu ihm Andere einschließt, und durch die Kraft seiner Einheit die Differenz in sich aufhebt. Ja, die Einheit Gottes eröffnet nicht nur den Raum für die Differenzen, sondern er birgt letztlich alle Unterschiede in sich. Wir nennen nun die Einheit Gottes vor aller Differenz den Vater. Die innere Differenz Gottes zu sich selbst nennen wir den Sohn, der ebenso Gott ist wie der Vater und doch nicht als Vater, sondern als Sohn gedacht werden will. Und schließlich meint die Differenz von Vater und Sohn nicht, dass es zwei Götter gibt, sondern, dass der Eine Gott nicht gegen die Andersheit begrenzt ist, sondern, dass er sich selbst ein Anderer sein kann und doch er selbst bleibt. Die darin liegende Einheit des in sich differenten Gottes nennen wird den Heiligen Geist. Der Geist der Liebe verbindet das Verschiedene so sehr, dass das Eine und das Andere in Liebe eins sind. Was nun auf abstrakte Weise gesagt wurde, meint nichts anderes als "Gott ist Liebe “. ${ }^{1}$ Liebe ist Beziehung und mehr noch Vereinigung des Verschiedenen. Göttliche Liebe ist absolute Einheit. Wir Christen nennen diese in sich differente Einheit Trinität. Die Rede von der Trinität meint aber nichts anderes als die christliche Fassung Gottes als Geheimnis. Denn das Geheimnis der Trinität ist jedem menschlichen Vorstellen und jedem Verstehen entzogen. Der Verstand, dessen Prinzip der Satz vom Widerspruch ist, kommt hier an seine Grenze. Am deutlichsten ist das Geheimnis der Trinität wohl im Prolog des Johannesevangeliums ausgesprochen: „Im Prinzip ist der Logos, und der Logos ist bei Gott und ein Gott ist der Logos. Dieser ist im Prinzip bei Gott, und ohne ihn wurde nichts von dem, was geworden ist."

Woher aber wissen wir von diesem Geheimnis? Wir wissen es, weil Gott sich selbst mittgeteilt hat. Im anderen zu sich hat er sich als er selbst mitgeteilt. Die Empfänger der Botschaft sind die Menschen. Die größtmögliche Nähe zu den Menschen unter allem Geschaffenen kommt dem Menschen selbst zu. Der Mensch ist sich selbst das Nächste. So lesen wir im Johannesevangelium weiter: „Und der Logos wurde Fleisch." Gemeint ist damit, dass Gott selbst, nicht der Vater, wohl aber der Sohn, Mensch geworden ist, dass er unter uns gewohnt hat, um uns selbst so nahe wie möglich zu kommen. Die eigentliche offenbarung nach christlichem Verständnis ist also das Wort Gottes, das einerseits selbst Gott und andererseits auch Mensch ist. Deshalb gilt Jesus von Nazaret als die Selbstmitteilung Gottes. Jesus Christus vermittelt also zwischen Gott und Mensch. Mit Gott ist er ganz Gott und mit uns Menschen ist er ganz Mensch. Und auch hier zeigt sich wieder jene Grundfigur christlichen Denkens, die die Einheit in einer Differenz annimmt. Der Mensch ist das Andere zu Gott, und doch ist Gott nicht gegen das Andere begrenzt, da er selbst auch Mensch wurde. Und wie er selbst absolut einer ist, so wird er auch nur einmal

\footnotetext{
${ }^{1}$ 1. Joh 4,8 .
} 
Mensch, ein für allemal. Einer für Alle. Wie aber können wir erkennen, dass das Offenbarte, der Mensch Jesus selbst das offenbarende Wort Gottes ist?

Der bloße Verstand des Menschen kann dies genauso wenig erkennen, wie der Mensch das Geheimnis der Trinität erfassen kann. Deshalb bedarf es einer zweiten Gabe, die nun aber nicht ein Gegenstand ist, sondern eine Erkenntnis. Diese Erkenntnis, die es ermöglicht, die Einheit von Jesus und Gott anzunehmen, nennen wir den Heiligen Geist: „Und keiner kann sagen: Jesus ist der Herr!, wenn er nicht aus dem Heiligen Geist redet“. ${ }^{2}$ Das vom Geist Gottes erfüllte Denken, das dieser Gabe entspricht, nennen die Christen Glaube. Der Geist setzt am subjektiven Pol an und ermöglicht, dass der objektive Pol in seiner Wahrheit erkannt werden kann. Aber wie wir noch sehen werden, ist dieser Glaube durchaus nicht irrational. Ebenso wenig darf die Offenbarung nach christlicher Überzeugung willkürlich angenommen werden, vielmehr entspricht dem Glauben auch eine neue Einsicht, denn die Botschaft will vernommen werden. Das entsprechende Vernehmen nennen wir auch Vernunft. Dies ist aber nicht die natürliche Vernunft, sondern ein erneuertes Denken. Dazu sagt Paulus:

„Gleicht euch nicht dieser Welt an, sondern wandelt euch und erneuert euer Denken, damit ihr prüfen und erkennen könnt, was der Wille Gottes ist: was ihm gefällt, was gut und vollkommen ist.“3

Wie wir noch sehen werden, wird gerade das neuzeitliche Christentum die Vernunft als die andere Seite des Glaubens aufweisen. Vernunft und Glaube sind ein weiteres Beispiel für die in sich differente Einheit, die die christliche Logik kennzeichnet. Die gegebene Einsicht ist aber auch nicht notwendig im Sinne von zwingend, sondern sie ist frei. Die Zustimmung des Glaubens versteht sich als ein Akt der Freiheit, ebenso wie die Erneuerung der Vernunft. Die neue Vernunft weiß sich frei, befreit das Wort Gottes anzunehmen.

Das Wort Gottes, das nach christlichem Verständnis auch so viel bedeutet wie der Logos Gottes oder man könnte auch sagen: die Vernunft Gottes, offenbart sich aber, wie wir gesehen haben, in Jesus von Nazaret. Darin liegt in der Tat auch ein Skandal, dessen sich die Christen seit frühester Zeit bewusst waren. Wer ist Jesus? Wir müssen hier unterscheiden, was ein nicht vom göttlichen Geist erleuchtetes Denken hier wahrnimmt und der Wahrnehmung des Glaubens oder der erneuerten Vernunft. Die historisch-kritische Denkart, wie es sie erst seit dem 19. Jahrhundert gibt, wie sie aber mittlerweile ein fester Bestandteil theologischer Forschung ist, gibt folgende Auskunft: Jesus war ein jüdischer Wanderprediger und Wunderheiler. Das Besondere an ihm ist seine Gottesbeziehung. Er schien sich in einem besonders innigen Verhältnis zum Gott Israels gewusst zu haben. Dies jedenfalls lässt sich an

\footnotetext{
${ }^{2} 1$. Kor 12,3 .

${ }^{3}$ Röm 12,2.
} 
der für ihn signifikanten Anrede Gottes als Vater entnehmen. Er nannte JHWH seinen Vater und verwendete dafür das familiäre aramäische Wort „Abba“ - „lieber Vater", „Pappa“. Zudem war er davon überzeugt, dass mit seinem Wirken die Herrschaft Gottes anbrechen würde. Er sagte: „Wenn ich mit dem Finger Gottes die Dämonen austreibe, dann ist das Reich Gottes schon zu euch gekommen". ${ }^{4}$ Seine Botschaft war: Kehrt um, solange es noch Zeit ist. Bald kommt das Reich Gottes, dann ist es zu spät. ${ }^{5}$ Es ergibt sich eine Spannung zwischen der gegenwärtigen Heilszeit und der zukünftigen Vollendung des Heils. Seine Absicht war es jedenfalls, Israel vor dem Ende neu zu sammeln, und zur Umkehr zu Gott zu bewegen. Vermutlich kam es durch seine Kritik am Tempelkult zum Konflikt mit der Tempelaristokratie, den so genannten Sadduzäern, der ihm zum Verhängnis wurde. Jedenfalls wurde er durch Pontius Pilatus, dem römischen Statthalter, zum Tod verurteilt und hingerichtet. Erstaunlich ist nun, dass seine Schülerinnen und Schüler kurz nach seinem Tod zur Überzeugung kamen, dass Jesus nicht tot sei, sondern lebe. Das Kreuz, das zunächst Zeichen seines Scheiterns war, wurde plötzlich anders verstanden. Seine Anhängerinnen und Anhänger betrachteten nun den Tod selbst als Teil und mehr noch als Vollendung seiner Sendung. Vor allem mit den Gottesknechtliedern aus dem Buch Jesaja wird nun sein Sterben als ein Tod für uns verstanden. Gerade in der Spannung von der Unsterblichkeit des ewigen Gottes und der Sterblichkeit des Menschen Jesus ist jene Denkfigur grundgelegt, von der wir schon mehrfach sprachen: Der Eine kommt im Anderen zu sich selbst. Die Gegensätze sind im Sohn versöhnt. Die Versöhnung von Himmel und Erde, Gut und Böse, Leben und Tod ereignet sich im Sohn Gottes Jesus. Gerade der Philosoph Georg Wilhelm Friedrich Hegel wird die Dialektik der „Versöhnung“ zum Grundprinzip seines Denkens machen und dadurch dem Wort „Versöhnung“ einen neuen Klang geben. Die Aufhebung des Gegensatzes von These und Antithese, die Synthese, ist die Versöhnung. Doch zurück zu den christlichen Ursprüngen. Mehr und mehr kommen die Jünger zur Überzeugung, dass Jesus der „Sohn“ Gottes in singulärer Bedeutung war. Der Gesandte Gottes wurde immer eindeutiger als herabgestiegener Gottessohn und schließlich selbst als Gott bezeichnet. So heißt es im Johannesevangelium schließlich: „Niemand hat Gott je gesehen. Der Einzige, der Gott ist und am Herzen des Vaters ruht, er hat Kunde gebracht". 6

Die Interpretation Jesu als Sohn Gottes, als Messias und schließlich als Gott selbst findet ihren Niederschlag in den Schriften des Neuen Testaments. Damit aber wird klar, dass die biblischen Schriften nicht in demselben Sinn Offenbarung sind wie Tora im Judentum und Koran im Islam. Das eigentliche Wort Gottes, der Logos, ist Jesus selbst, er ist der Offenbarer und die Offenbarung in einem. Nur im abgeleiteten Sinn kann dann auch die Heilige Schrift als Offenbarung verstanden werden.

\footnotetext{
${ }^{4}$ Lk 11,20 .

${ }^{5} \mathrm{Vgl}$. Mk 1,15.

${ }^{6}$ Joh 1,18 .
} 
Unmittelbar in der Zeit nach Jesus ereignet sich eine weitere „Versöhnung“, nämlich die zwischen Juden und Heiden. Nicht zuletzt durch das Wirken des Apostels Paulus wird die jüdische „Sekte“ der Anhänger Jesu zur Weltreligion des Christentums. Und es ist auch kein Zufall, dass die Schriften des Neuen Testaments beginnend mit den Paulusbriefen in griechischer Sprache verfasst sind. Griechische Philosophie und jüdische Offenbarungsreligion verschmelzen $\mathrm{zu}$ einer untrennbaren Einheit. So darf bei der johanneischen Rede von "archê" (Anfang, Prinzip) und „lógos“ immer schon die Fülle der griechischen Rationalität mitgehört werden.

In den ersten fünf bis sechs Jahrhunderten nach Christus bildet sich die neue Religion als Synthese von jüdischem und griechischem Geist aus. Die Kirchenväter verstanden sich gleichermaßen als Erben Mose und Platons. Zugleich mit den ersten philosophischen Deutungsversuchen der jungen Religion entstand die christliche Bibel als Synthese von Altem und Neuem Testament. Sie wurde nun zum herausragenden Zeugnis des Offenbarungsgeschehens um Jesus Christus. Damit aber wurde der Philosophie eine neue Bestimmung gegeben. Philosophia, was ja Liebe zur Weisheit bedeutet, wurde nun begriffen als Liebe zur menschgewordenen Weisheit Gottes, das ist die Liebe zu Jesus Christus. Und Jesus wurde, wie sich der Kirchenvater Augustinus ausdrückt, zur persona veritatits, zur Wahrheit in Person. Die neue Aufgabe der Vernunft wird es, den Logos Gottes, der in Jesus Fleisch geworden ist, auszulegen. Das Denken unterstellt sich der Offenbarung; die Vernunft ordnet sich dem Glauben unter. Anselm von Canterbury wird dieses Verhältnis mit Anspielung auf Augustinus als fides quaerens intellectum bezeichnen, d.h. Glaube, der die Einsicht sucht. Es ergibt sich ein hypothetisches Verhältnis von Glaube und Vernunft. Schon Augustinus hatte mit Jesaja 7,9 formuliert: „Wenn ihr nicht glaubt, werdet ihr nicht einsehen“. Der Glaube wird zur höchsten Autorität des Denkens. Die scholastische Theologie des Mittelalters bringt die hypothetische Vernunft zur Vollendung. Die Offenbarung vermittelt das Wissen Gottes und der Seligen mit der menschlichen Vernunft über die Mitte der Offenbarung, die ihrerseits ihre Vollendung in Jesus von Nazaret hat. Er wird für uns zum Weg zu Gott, wie Thomas von Aquin formuliert. Glaube und Vernunft, Offenbarung und Wissen sind von je eigenem Recht und eigener Reichweite des Erkennens, den Vorrang aber haben in dieser Epoche des Christentums der Glaube bzw. die Offenbarung inne. Es ist an diesem Ort, in der Gegenwart von muslimischen Gelehrten, auch darauf hinzuweisen, dass die Vermittlung des Aristoteles an das Abendland über das islamische Spanien gelaufen ist. Vieles verdankt die abendländische Rationalität dieser Epoche dem islamischen Denken, um hier nur auf Ibn Ruschd zu verweisen.

Zum Spezifischen des Christlichen gehört seine eigentümliche Dynamik. Und so bleibt es nicht beim hypothetischen Verhältnis von Glaube und Wissen, Gnade und Freiheit, vielmehr entwickelt sich mit der Neuzeit spätestens seit dem 15. 
Jahrhundert eine neue Denkform und damit auch ein neues Verständnis von Offenbarung. War bisher die objektive Seite der Offenbarung, Jesus Christus, der Gott unter uns, der Konstruktionspunkt des Glaubens, wird dies nun der subjektive Pol, der Heilige Geist, als der Gott in uns. Deshalb wird es auch möglich, das göttliche und das menschliche Wirken als eine Wechselwirkung oder Gemeinschaft zu verstehen. Weil Gott in uns auf uns einwirkt, vermögen wir auf Gott einzuwirken. Zunächst aber trennen sich Vernunft und Glaube. Luther entbindet die ratio naturalis von ihrer Heilsrelevanz. Doch eigentümlicherweise findet sie bei René Descartes im ego cogito ein eigenes Prinzip. Ebenso verhält es sich mit der Freiheit des Menschen. Die Rolle der natürlichen Freiheit im Heilsgeschehen wird negiert. Aber die neue, gottgewirkte Freiheit eines Christenmenschen entwickelt sich ihrerseits zur absoluten Freiheit im Wesen des Menschen (Jean-Jacques Rousseau). Die zunächst getrennten Wege von Offenbarung und Vernunft werden sich im Verlauf der Neuzeit immer wieder kreuzen. Dabei entstehen neue Synthesen von Glaube und Vernunft. Es ist hier nicht der Ort diese Synthesen in extenso vorzustellen, doch seien hier nur die Namen Johann Gottlieb Leibniz, Gotthold Ephraim Lessing und Immanuel Kant genannt. Obwohl Kant einer Vernunft verpflichtet ist, die ihre prinzipiellen Einsichten rein aus sich selbst hervorbringt, kann er formulieren: „Denn man kann eben sowohl einräumen, daß, wenn das Evangelium die allgemeinen sittlichen Gesetze in ihrer ganzen Reinigkeit nicht vorher gelehrt hätte, die Vernunft bis jetzt sie nicht in solcher Vollkommenheit würde eingesehen haben, obgleich, da sie einmal da sind, man einen jeden von ihrer Richtigkeit u. Gültigkeit (anjetzt) durch die bloße Vernunft überzeugen kann. “7 In seiner Religionsschrift nimmt Jesus Christus eine zentrale Rolle ein, wenn er als „die personificirte Idee des guten Prinzips“8 eingeführt wird. Auch die Bibel als das primäre Zeugnis von Jesus Christus wird gewürdigt. Der Glaube an die Schrift und die mit ihr verbundene Kirche gilt als eine Pflicht eigener Art. ${ }^{9}$ Die Menschen brauchen, so wie sie derzeit verfasst sind, die Offenbarung. Zweck der Heiligen Schrift aber ist es, „bessere Menschen zu machen“. ${ }^{10}$ Freilich geht Kant davon aus, dass im Fortschritt der Menschheitsgeschichte der Glaube an äußere Offenbarung allmählich in einen reinen Vernunftglauben übergeht. So findet bei Kant das Diktum Anselms von der fides quaerens intellectum eine eigene Deutung. Es ließe sich nun auch die affirmative Bezogenheit von Johann Gottlieb Fichte und Georg Wilhelm Friedrich Hegel u.v.a. Philosophen der neuzeitlichen Klassik aufzeigen. Hier mag nun die Behauptung genügen, dass die christliche Offenbarung die Bedingung der Möglichkeit für die Entfaltung neuzeitlichen Denkens ist. Inhaltlich findet sich der Kern des Gedankens in der Wechselwirkung oder Gemeinschaft von menschlichem Individuum und Gott. Eben wegen dieser inneren, in sich

\footnotetext{
${ }^{7}$ Brief an Friedrich Heinrich Jacobi vom 30.08.1789. Akademieausgabe, Bd. 11, Berlin 1922, 76.

${ }^{8}$ Die Religion innerhalb der Grenzen der bloßen Vernunft. Akademieausgabe, Bd. 6, Berlin 1907, 117.

${ }^{9}$ Vgl. ebd., $106 f$.

${ }^{10}$ Ebd., 111.
} 
differenzierten Einheit wird die Freiheit in absoluter Bedeutung zum Prinzip der abendländischen Neuzeit. Interessant wäre in diesem Zusammenhang auch die Bedeutung des calvinistischen Christentums für die Entwicklung der Demokratie zu untersuchen. Auch die bürgerliche Demokratie entspringt im christlichen Bewusstsein von der Autonomie und Freiheit des Individuums. Nur scheinbar wird die Offenbarung überflüssig, wenn die Vernunft erwachsen geworden ist.

Dennoch ist für die westliche Rationalität ein weiterer Gedankenschritt charakteristisch, ein Gedanke, der ebenfalls in der Menschwerdung Gottes und mehr noch im Tod Gottes am Kreuz zu Golgotha gründet. Zwar gibt es bereits in der Aufklärung erste Anzeichen für materialistische und atheistische Tendenzen, zu weltgeschichtlicher Bedeutung freilich kommen sie erst in der nachmetaphysischen Moderne, für die hier Ludwig Feuerbach stehen mag. Feuerbach versucht das Wesen des Christentums darin zu erblicken, dass hier die Menschheit ihr eigenes Wesen in ein Jenseits projiziert habe. In dieser Denkfigur wird im Grunde der alte Primat des Geistes, der Idee, aber auch Gottes zu Gunsten des Sinnlichen, des Phänomenalen und der Welt aufgegeben. Einerseits macht sich hier scheinbar die christliche Offenbarung überflüssig. Wenn das Christentum lehrt, dass die Wahrheit Gottes der Mensch ist, dann wird dadurch nach Feuerbach auch das Christentum selbst obsolet. Doch anders gewendet kann der Gedanke der Moderne eine immense Weitung des christlichen Grundgedankens der Menschwerdung mit sich führen. Die moderne protestantische Theologie hat hier Maßgebliches geleistet. Lassen Sie mich hier nur an die historisch-kritische Schriftbetrachtung erinnern. Zwar ist diese Methode als solche atheistisch, weil sie keine Glaubensvorgabe kennt, doch können gerade deshalb innovative Einsichten in die innere Struktur, in die historische Bedingtheit und damit auch in die geschichtliche Wahrheit der Offenbarungsschriften gefunden werden. Eingebettet in eine Pluralität von Methoden gehört die historische Kritik heute zum festen Bestandteil jeder Schriftexegese. Über die Grenzen der religiösen Betrachtung hinaus lässt sich behaupten, dass die Dynamik des mehr und mehr atheistischen Abendlandes seit dem 19. Jahrhundert nur auf der Basis der radikalen Inkarnation Gottes begriffen werden kann. Die modernen - methodisch gesehen atheistischen Wissenschaften der Moderne, ich nenne hier nur Physik, Chemie, Medizin, Soziologie, Ökonomie, Psychologie, entstehen erst dann, wenn metaphysisch-theologische Fragen zurückgedrängt sind. Martin Heidegger hat gezeigt, dass die „Technik“ die Erbin der Metaphysik ist. Wohlgemerkt in aller Ambivalenz kann die Konstitution der Moderne nur auf der Basis christlicher Offenbarung verstanden werden. Und umgekehrt wird heute die christliche Offenbarung nicht nur mit Hilfe der verschiedenen Formen metaphysischen Denkens (um hier noch einmal Augustinus, Thomas von Aquin, Kant, Fichte und Hegel zu nennen) erschlossen, sondern auch Archäologie, Historie, Sprachwissenschaften usw. werden zur Auslegung der Offenbarung verwendet. 
Ein vorerst letzter Schritt bei der Entfaltung der christlichen Offenbarungsdynamik ist noch zu tun. War die moderne Anthropologie engstens mit dem Tod Gottes verbunden, so kommt nun eine Denkart zur Sprache, die den Tod des (modernen) Menschen thematisiert. Der französische Philosoph Michel Foucault hatte bereits 1966 festgestellt, dass durch die strukturalistische Psychoanalyse und die entsprechende Ethnologie die regionale Begrenztheit dessen offenbar wird, was im abendländischen Kontext als „der Mensch“ bezeichnet wird. Nun erfolgt die Selbstrelativierung des anthropologischen Denkens der Moderne. Die unmittelbare Gegebenheit der Welt wird gebrochen. Die vermittelnden Strukturen, die Zeichen und damit die Textualität und Kontextualität von Wirklichkeit rücken in den Vordergrund. Nach der Verlagerung von der Idee zum weltlichen Phänomen rückt nun die Sprache und mehr noch die Schrift (Jacques Derrida) in den Fokus der Aufmerksamkeit. Damit verbunden ist der Pluralismus als neues Prinzip. Man erkennt, dass es eine prinzipielle Andersheit gibt, die durch keinen universalen Anspruch eingeholt werden kann. Die anderen Kulturen, die anderen Rassen, die anderen sozialen Schichten, das andere Geschlecht usw. werden zu Themen der Analyse. Das universale Zentrum verliert damit an Bedeutung und an seine Stelle tritt die Peripherie, und das Marginale sowie das Ausgeschlossene werden neu gewürdigt. Diese Konstellation der Vernunft, in der gleichermaßen die Objektivität der Offenbarung, die transzendentale Subjektivität des Menschseins (Neuzeit), aber auch die zentrale Stellung des weltlichen Menschen dekonstruiert werden, firmiert häufig unter dem Namen „Postmoderne“. Während die anthropologische Moderne in ihren wesentlichen Positionen (ich nenne nur Marx, Nietzsche und Freud) die Religion und mit ihr das Offenbarungswissen negiert, lässt die Postmoderne von dieser Negation ab. So kann es nicht wundern, dass es in den letzten fünfzig Jahren immer wieder zu einer freilich nunmehr fragmentarischen Wiederkehr der Religion kommt. Schließlich haben Philosophen wie Gianni Vattimo und Jean-Luc Nancy zu zeigen versucht, dass die Schwächung des Denkens, die wir in der Postmoderne feststellen, im tiefsten Inneren eine Konsequenz der christlichen Offenbarung ist. Denn im Philipperbrief lesen wir, dass der in der Gestalt Gottes Daseiende, gemeint ist der präexistente Logos, auf sein Gottsein verzichtet hat und sich entäußerte. ${ }^{11}$ Die Entäußerung (kénôsis) Gottes wird zum Signum für die neue Zeit. Mit Paulus gesprochen, besteht aber gerade in der Schwäche die eigentliche Stärke, die Gott in Wahrheit entspricht. Es ließe sich auch darauf hinweisen, dass sich Jesus selbst in besonderer Weise den Marginalisierten, Ausgeschlossenen und Abweichenden seiner Zeit zugewandt hat.

Lassen Sie mich rekapitulieren: Im Anfang war das Wort. Nach christlichem Glauben wurde das Wort in Jesus von Nazareth Mensch. In seinem Reden und Handeln ist nach Überzeugung die Liebe Gottes sichtbar geworden. Die Liebe ist das Kriterium,

\footnotetext{
${ }^{11}$ Vgl. Phil 2,6 f.
} 
das die Göttlichkeit als solche ausweist, denn „Gott ist die Liebe“. ${ }^{12}$ Die Liebe aber verbindet die Gegensätze: zunächst die Entgegensetzung von Vater und Sohn, von Gott und Mensch, dann aber auch von Mensch und Mensch, gut und böse, reich und arm, Mann und Frau, über alle Grenzen hinweg. Die Heilige Schrift, als Zeugnis der Offenbarung, hat in diesem Gedanken ihre Mitte. Für die Interpretation der Heiligen Schrift als der maßgeblichen Bestimmung des Menschen benötigen wir aber auch die in der Geschichte gewachsenen Wirkungen der Schrift, die Tradition. Diese können wir aber heute nicht mehr auf die bloße kirchliche Überlieferung beschränken, weil die Wirkungsgeschichte der Offenbarung über die Grenzen der Kirche hinaus reicht. Deshalb brauchen wir eine geschichtsbewusste Hermeneutik. Die vielen Formen abendländischen Denkens müssen in die Deutung der Schrift einbezogen werden. Durch diese verschiedenen Perspektiven gewinnen wir aber umgekehrt wieder ein neues und verwandeltes Selbstverständnis. In einer ersten Phase dieser Geschichte lag das Gewicht des Schriftverständnisses auf dem Logos oder der göttlichen Idee. Diese Phase haben wir in zwei Varianten besprochen, der patristisch-scholastischen und der neuzeitlichen. Die erste setzte den Akzent auf die objektive Seite der Offenbarung, Jesus, die Heilige Schrift, die materiale Überlieferung, aber auch die sichtbare Kirche, samt den ihr eigenen Amtsträgern, die, wenn sie in persona Christi handeln, die Schrift auch mit amtlicher Autorität auslegen können. Die zweite Variante legt die Betonung auf die subjektive Seite der Offenbarung, wenn sie vom göttlichen Geist in uns ausgeht. Dieser Geist kann sich im absoluten Glauben zeigen, wie er in der Tradition reformatorischer Kirchen entfaltet wird, aber auch in der absoluten Vernunft, die die Philosophie der Neuzeit prägt. Doch gewinnt das Christentum mit der Aufklärung eine menschheitliche Dimension. Es geht hier nicht nur um eine kirchliche und religiöse Engführung, sondern der Mensch als solcher erhält unabhängig von seiner konkreten Religion eine neue Würde, die allerdings durch die gottmenschliche Einheit Christi inspiriert ist. Die Ringparabel in Lessings Drama „Nathan der Weise“ mag ein Beispiel für das menschheitliche Anliegen der Neuzeit sein, da Juden, Christen und Muslimen eine gleiche menschliche Würde zugesprochen wird. Dann haben wir eine zweite Phase in den Blick genommen. Man kann diese in Abgrenzung zur onto-theo-logischen Denkart bio-anthropo-logisch nennen, da hier das weltliche Leben und der sinnliche Mensch zentral werden. Hier rückt die „Knechtsgestalt“ Jesu in den Blick. Gerade Marx, Nietzsche, Freud und Heidegger entwickeln eine Kritik, um die Knechtung und die Enteignung des Menschen in seinem Wesen $\mathrm{zu}$ beseitigen. Diese Überwindung menschlicher Enteignung an Produktionsmitteln, an vormoralischem Leben und an seiner Triebhaftigkeit, sowie an seinem bloßen In-der-Welt-Sein wirft auch ein neues Licht auf die kritischen Dimensionen der Heiligen Schrift. Schließlich kam eine dritte Phase zur Sprache, die wir als Tele-semeio-logie bezeichnen können. Nicht mehr die äußere Wirklichkeit der materiellen Welt wird

\footnotetext{
${ }^{12}$ 1. Joh $4,8.16$.
} 
hier bestimmend, sondern deren Vermittlung durch Zeichen, Medien und Informationstechnologie. I-pod, Internet und Facebook sind Ikonen dieser neuen Lebenswelten und Denkformen. Auch diese Phase enthält ein kritisches Moment, das allerdings nicht mehr auf eine Revolution, eine ganz andere Zukunft und einen neuen Menschen zielt, sondern auf regionale Veränderungen und eine dekonstruktive Gerechtigkeit, die sich der Relativität ihres eigenen Standpunkts bewusst ist. Letztere Relativität betrifft auch das Verhältnis des Christentums zu anderen Religionen. Mehr als bisher werden Wert und Würde des Judentums, des Islam, aber auch der fernöstlichen Religionen anerkannt.

Eine entscheidende Aufgabe unserer Tage nach dem Ende der Postmoderne besteht meines Erachtens darin, die verschiedenen Phasen der Geschichte, wie sie durch die Selbstmitteilung Gottes begründet wurde, zusammenzudenken. Offenbarung und Vernunft stehen in einer lebendigen Beziehung. Weder die Gabe der Offenbarung noch die Vernunft sind tot. Das heißt aber auch, dass sie leben, sich verändern und wachsen. Die Offenbarung Gottes in Jesus von Nazaret ist nach christlicher Überzeugung das schlechthin Unbedingte. Gott hat gegeben, er hat sich gegeben in Jesus Christus und im Geist der Wahrheit. Diese Selbsthingabe Gottes, seine Entäußerung in Welt und Zeit bedingt eine Geschichte des Lebens und Denkens, die im weitesten Sinn von Adam bis zum letzten Menschen reicht, die aber auch als Geschichte des Christentums, des Abendlands oder der Kirche bezeichnet werden kann. Das Unbedingte ist nur durch das von ihm Bedingte zu begreifen, und das Bedingte erhält nur durch das Unbedingte seinen Sinn. Das Besondere des Christentums besteht wohl darin, dass es Grenzen immer wieder zu überschreiten und doch dabei die Unterschiede zu wahren vermag, dass es sich immer wieder verändert und doch sich selbst gleich bleibt. Das immer Gleiche aber ist - nach Überzeugung der Christen: die göttliche Würde des Menschen. 


\section{Sonia Lotfy \\ Wahy als Bestandteil der menschlichen Geformtheit}

Das erste, was den Menschen ausmacht, ist, dass er ein denkendes Wesen ist. So gibt ihm das Denken eine vorübergehende Vorstellung von sich selbst, von der Welt um ihn herum und von seiner Beziehung zur wahrgenommenen Welt. All dies bewerkstelligt der menschliche Verstand mittels der drei Wahrnehmungsweisen (Sinneswahrnehmung, Vorstellungsvermögen, Fantasie), also um damit für sich selbst Antworten und Vorstellungen hervorzubringen. Diese Vorstellungen entwickeln sich bisweilen zu vorbehaltlos angenommenen Ideen, doch bleiben dem Verstand einige Fragen: Was ist die Ursache für das vergängliche Dasein? Wohin strebt es? Und was ist der Grund seines Glücks, wenn es glücklich ist, und seines Unglücks, wenn es unglücklich ist? Warum glauben die Menschen von alters her, dass es für dieses Dasein einen Schöpfer gibt - im Unterschied zu ihren Vorstellungen - und dass, um zu seiner Erkenntnis zu gelangen, es des Strebens und der Mühe bedarf? Warum stellen wir fest, dass sich die großen Gelehrten und Denker seit langer Zeit über die Beschäftigung mit ihren Sinnen und ihrem Vorstellungsvermögen erheben und sich in grenzenlosen Raum begeben, indem sie nach diesem Schöpfer forschen, der zweifellos in Beziehung zu diesem Verstand und jener Seele steht, die sich nach seiner Erkenntnis sehnt?

Die Antwort auf alle diese Fragen findet sich in einem Wort, nämlich: wahy. Wahrlich, derjenige, der das Dasein hervorgebracht hat, es geformt hat und die Menschen zum Edelsten darin gemacht, hat sie niemals diesen Verstandeskräften überlassen, weil er genau um deren Begrenztheit wusste. Deswegen ist wahy der menschlichen Geformtheit inhärent und mit ihr verknüpft wie das Unerlässliche mit dem, was es unerlässlich macht. Sobald das unerlässlich Machende verschwindet, verschwinden auch unweigerlich die unerlässlich gemachten Dinge, wie es jedem Vernunftbegabten bekannt ist. Gott (t) - Preis sei ihm - hat sich zu keiner Zeit von der Welt zurückgezogen und wird es nicht, solange Himmel und Erde bestehen. Und die Verbindung ist immer und ewig wahy. Was ist aber die wahre Bedeutung von wahy?

Die Sprachwissenschaftler nannten für das Wort wahy viele Bedeutungen, darunter: Zeichen (ishara), Schrift (kitaba), Botschaft (risala), Eingebung (ilham), verborgene und geschriebene Sprache (kalam), Befehl (amr), wahrhafte Schau (ru'ya), Dienstbarmachung (taskhir) ${ }^{1}$. Dann sagten sie, dass wahy sich auf die Eingebung (ilham) beschränkt und ihr Gebrauch in dem, was von Gott aus an die Propheten übertragen wird, überwiegt. Damit meinen sie die vorherrschende Bedeutung im

${ }^{1}$ Siehe: al-'Ain 3/320, Dschamhara al-Lugha 1/231, Tahdhib al-Lugha 5/192, Mudschmal al-Lugha von Ibn Faris 1/919, Maqayis al-Lugha 6/93, Muchtar as-Sihah 1/334, Lisan al-'Arab 15/379. 
Rahmen der islamischen Religion, wie Scheich Mustafa 'Abd ar-Raziq sagte: Wahrlich, der Islam beschränkte wahy auf eine von mehreren Bedeutungen, die die Araber in ihrer Verwendung kannten. Ihr Verständnis entsprach einer von mehreren Arten. Er fasste jenes zu vier Positionen zusammen:

1. Der Ursprung von wahy in der Sprache insgesamt ist die Geheimhaltung und die Benachrichtigung im Verborgenen.

2. Die Ableitung von wahy in der Bedeutung der Eingebung stammt von wahy in der Bedeutung der Schnelligkeit: Denn die Eingebung kommt schnell und ist schnell vorüber.

3. Das Element der Schnelligkeit und das Element des Verborgenen haben einen gemeinsamen Ursprung, so ist Eingebung die schnelle und verborgene Benachrichtigung.

4. Der Ursprung dieser Sache ist das Vermitteln einer Sache an einen anderen. Und die Grundlage von wahy ist das Vermitteln des Eingebenden an den, dem eingegeben wird.

So hat wahy in philologischer Hinsicht eine weitere Bedeutung als in fachterminologischer Hinsicht: Da der Begriff ja Eingebung (ilham) an die Propheten und andere im Allgemeinen umfasst, letzterer Begriff dies aber auf Grund von Enthüllung, Intuition oder Inspiration ausdrückt. Die Verse des edlen Koran verweisen auf diese Bedeutung: So bezieht sich im edlen Koran das Verb waha überwiegend auf Gott ( $\mathrm{t}$ ), wie im Beispiel seiner Rede - er ist groß und erhaben: „Da offenbart' er seinem Knechte, was er ihm offenbarte.“2 und seine Rede ( $t$ ): „Oder er sendet einen Gesandten, dass er mit seiner Erlaubnis offenbart, was er will.“3 Was den, dem eingegeben wird, betrifft, so wird in den meisten Fällen der Prophet genannt (sws) oder ein anderer der Propheten. Es kommen aber auch Verse vor, die deutlich machen, dass der, dem eingegeben wird, keiner der Propheten ist, gemäß seiner Rede ( $\mathrm{t}$ ): „Und damals, als ich den Jüngern eingab: ,Glaubt an mich und meinen Gesandten!““4 und: „Damals, als dein Herr den Engeln eingab: «Ich bin mit euch;». ${ }^{\text {5 }}$ und: „Dein Herr gab der Biene ein: «Mach dir in den Bergen etwas zu Häusern, dazu von den Bäumen und dem, was sie errichten!».“6 und: „Wir gaben Moses Mutter ein: «Nähre ihn an deiner Brust!»."

Dies weist daraufhin, dass Gott ( $\mathrm{t}$ ) - Preis sei ihm - Quelle der Eingebung in diese Welt ist, und zwar mit allem, was und wer in ihr ist. Denn er $(\mathrm{t})$ - Preis sei ihm - ist ein weiser Schöpfer und weiß am besten um seine Schöpfung. Und diese Welt ist nichts anderes als eine durch seinen Befehl ( $t$ ) gelenkte, vollkommene Ordnung,

\footnotetext{
${ }^{2}$ An-Nadschm (Der Stern) 53:10.

${ }^{3}$ Asch-Schura (Die Beratung) 42:51.

${ }^{4}$ Al-Ma'ida (Der Tisch) 5:111.

${ }^{5}$ Al-Anfal (Die Beute) 8:12.

${ }^{6}$ An-Nachl (Die Bienen) 16:68.

${ }^{7}$ Al-Qasas (Die Geschichte) 28:7.
} 
welche die körperlichen Bestandteile der Welt trägt und ihre geistige Reise zur Welt des ewigen Bleibens ordnet. So ist die Wahrheit also eine einzige und sie ist jene Wahrheit, die sich selbst im Laufe der Zeiten ausdrückt. Genauso ist die menschliche Geformtheit eine einzige. So ist der Mensch seit Adam (ra) und bis zu unserer Zeit Mensch. Woher kommt also die Verschiedenheit, wenn die Wahrheit im Ganzen eine ist und das Wesen des Menschen ebenso eines?

Die Antwort: Die Verschiedenheit entsteht durch die menschlichen Ausdrucksweisen, da ihre Sprecher an einer bestimmten Stelle innehalten und die Wahrheit nicht wahrnehmen, wie sie ist, sondern wie sie ihnen scheint, oder wie Gott $(\mathrm{t})$ - Preis sei ihm - sie ihnen auf jener Stufe ihres Weges oder für diese bestimmte Art des Daseins aufdeckt: So sind die göttlichen Reden für jeden von ihnen eine besondere und symbolhafte Komposition (tarkiba) und es werden durch sie bestimmte Verstandeskräfte und Seelenzustände zu erreichen beabsichtigt. So wie die Hautfarben der Menschen und ihr Geschlecht erachtet werden, so werden auch ihre verstandesmäßigen und seelischen Neigungen neben den allgemein vorhandenen Eigenschaften, die das menschliche Wesen teilt, berücksichtigt, wobei immer das eine oder andere überwiegt. Und es gibt Menschen, die eine bildliche Vorstellung und die Messung an sinnlich wahrnehmbaren Dingen benötigen, und es gibt andere, für die jene sinnliche Bemessung keine Bedeutung hat und deren Seele auf Begrifflichkeit und das Streben nach dem, was jenseits des sinnlich Wahrnehmbaren ist, achtet. Dies ist, was der Auserwählte (sws) in seiner Rede zum Ausdruck brachte: „Sprecht die Menschen entsprechend ihres Verstandes an! Meint ihr, Gott und seine Gesandten lügen?" Dies genau deswegen, weil die Seele und der Verstand - ausgestattet mit einer stückhaften Sicht auf das Dasein - meistens das, was sie nicht wahrnehmen, ablehnen. Deswegen gehörte $\mathrm{zu}$ den notwendigen Dingen jener menschlichen Geformtheit, dass diese Welt nicht frei von göttlicher Hilfe und göttlichem Beistand ist, vom Schöpfer der Schöpfung und dem Wissenden um alles, was darin ist. Und er - Preis sei ihm - berichtete uns, dass es keine Gemeinschaft gibt, in der nicht ein Warner auftrat, als er sprach ( $t$ ): „Keine Gemeinschaft gibt es, in der nicht ein Warner auftrat. ${ }^{\text {"8 }}$ Und er sprach - Preis sei ihm: „Siehe, wir offenbarten dir, so wie wir Noah offenbarten und den Propheten nach ihm. Wir offenbarten Abraham und Ismael und Isaak und Jakob; den Stämmen, Jesus, Hiob, Jona, Aaron, Salomo. David gaben wir den Psalter. Und Gesandte, von denen wir dir früher schon erzählten, und andere, von denen wir noch nichts erzählten - und Gott sprach mit Mose unmittelbar -, Gesandte, als Verkünder froher Botschaft und als Warner, damit die Menschen keinen Vorwand hätten gegen Gott, nachdem Gesandte kamen. Gott ist mächtig, weise." ${ }^{\text {"D }}$ Deswegen war der Glaube an alle Propheten und Gesandten ein grundlegender Teil in der islamischen Glaubensdoktrin. Er sagt (t): „Der Gesandte glaubt an das, was ihm von seinem

\footnotetext{
${ }^{8}$ Al-Fatir (Der Schöpfer) 35:24.

${ }^{9}$ An-Nisa' (Die Frauen) 4:163-165.
} 
Herrn herabgesandt, und auch die Gläubigen: Ein jeder glaubt an Gott und seine Engel, seine Bücher und seine Gesandten. "10 Das heißt, wir glauben an die Gesamtheit, denn unter ihnen sind welche, die wir kennen und von denen uns erzählt wurde und unter ihnen sind welche, die wir nicht kennen. Einige der Überlieferungen begrenzten ihre Anzahl, doch ist es richtiger, wie der Imam anNasafi sagte, dass man sie nicht auf eine Anzahl festlegt; denn er glaubte nicht an die Begrenzung der Anzahl, durch welche jemand eingeschlossen werden könnte, der nicht zu ihnen gehört oder einer von ihnen herausfiele, der zu ihnen gehört.

Genauso beziehen die Religionen insgesamt zur Frage der Eingebung Stellung und [behaupten,] dass sie die Mittlerin zwischen dem Schöpfer und der Schöpfung ist: So wie Gott Chadidscha - Gott habe an ihr Wohlgefallen - den Glauben an ihn eingab (sws), bei der ersten Herabkunft der Eingebung zu Waraqa b. Naufal und er ihm den Befehl unterbreitete (und er war ein hochbetagter Scheich, der um die Dinge des Christentums und des Judentums wusste), als Bestätigung dafür, dass er es ist, der damit kam (sws). Es ist vielmehr die [gleiche] göttliche Eingebung, die auf die Propheten vor ihm herabkam.

Es liegt auf der Hand, dass die Eingebung, die die Propheten und Gesandten traf, die Eingebung in spezieller fachterminologischer Bedeutung ist, und diese ist die reine Religion, an der kein Zweifel denkbar ist. Doch im Laufe der Zeit traten Orte, Zeiten sowie gesellschaftliche und politische Bedingungen und anderes dazwischen auf, ohne dass eine Eingebung - in dieser Bedeutung - an sie eintraf - oder dass sie zu ihnen in einer unvollständigen Weise kam, in der sie keine bestimmte Antwort für ihre verstandesmäßigen oder gemütsbedingten Anfragen fanden: Zu den ersten [die dies betraf] gehörten die inspirierten Gottesdiener, die nach der Erkenntnis ihres Schöpfers strebten und sich mit ihrer ganzen Kraft ihm zuwandten. So ließ er sie wissen, wodurch sie $\mathrm{zu}$ ihm gelangen konnten und setzte sie auf eine bestimmte Stufe der Erkenntnis, so dass damit auf immer ein Unterschied gelte zwischen dem frommen Streben und seiner Abwesenheit, auch wenn das fromme Streben alleine dies gar nicht verwirklichen kann:

Wie Thales von Milet (624-546 v. Chr.) sagte: In jedem Lebendigen ist Einsicht. Aus seiner Rede (t): „Es gibt nichts, was nicht sein Lob preist.“" Als Anaximander (619547 v. Chr.) sich über den Beginn des Daseins äußerte, dass er das Apeiron oder das Unbegrenzte ist, das nicht durch das Entstehen beschrieben wird und nicht neu Entstehendem gleicht, sondern ewig und bleibend ist, hat er damit etwas anderes als die eine Wahrheit beabsichtigt?

Und als Pythagoras (572-497 v. Chr.) - nach seiner Untersuchung der Zahlen feststellte, dass der Ursprung des Daseins ohne Zweifel eins sein müsse, allerdings

\footnotetext{
${ }^{10}$ Al-Baqara (Die Kuh) 2:285.

${ }^{11}$ Al-Isra' (Die Nachtreise) 17:44.
} 
nicht im Sinne der Einerzahlen. Es ist doch nicht möglich, dass er sich mit den Zahlen beschäftigen und dabei nicht vonseiten des Verstandes die Einheit des Seins wahrnehmen konnte ${ }^{12}$. Hat er jemand anderes als den einen Gott gemeint?

Und als Sokrates (469-399 v. Chr.) sagte: Erkenne dich selbst! ${ }^{13}$ : Bezweifelt irgendjemand, dass das eine Eingebung Gottes ist - er ist groß und erhaben? Woher sonst weiß der Mensch, dass in der Erkenntnis seiner Seele die Erkenntnis der Weltordnung liegt und auch ein Weg, zu seinem Schöpfer zu gelangen - er ist groß und erhaben? Er sagt - er ist erhaben: „und auch in euch selber. Könnt ihr denn nicht sehen?“14 Und er sagt (sws): „Wer sich selbst kennt, kennt seinen Herrn schon längst."

Es gibt noch viele weitere Beispiele, die des philosophischen und geistigen Erbes im Allgemeinen nicht entbehren und die wir, wenn wir sie an die Religion herantragen, nicht leugnen können und deren Träger wir nicht weit vom religiösen Denken und der göttlichen Verbindung wähnen können. Hinweise dafür bestehen im Buch und in der Sunna, wie in seiner ( $t$ ) Rede: „Gott leitet, wen er will, zu seinem Licht.“15 und seine Rede - er ist erhaben: „Und wem Gott kein Licht macht, der hat kein Licht.“16 Und er sagte (sws): „Es gab vor euch unter den Völkern Erzähler, und wenn es einen gibt in meiner Gemeinde, es 'Umar." Ibn Sina pflegte über einen Sa id b. Abu l-Chair zu sagen: Wahrlich, dieser Mann sieht ein, was wir reden. Das heißt, er sieht die Weisheit in göttlicher Fülle ein - dies, weil die göttlichen Gaben unbegrenzt sind, dazu noch die Fähigkeit des Erhaltens einer Sache, die der Verstand nicht kennt, wie Imam Muhammad 'Abduh sagte: „Ich sehe [Gott] nichts als etwas, das schwer zu erkennen ist außer für den, der nicht wahrnehmen will. Dieser muss seine Verstandesfähigkeit dazu zwingen, nicht zu verstehen. “"17

Die Sache war ähnlich im Hinblick auf eine andere Gruppe von Personen, die es nicht vermochten, das göttliche Selbst zu leugnen und die zur selben Zeit in sich selbst Fragen sahen, die Antworten brauchten, sowie Leere im Herzen, die nach etwas verlangte, das sie füllt. So ließen sie das zu, was zu ihnen in einem Bild kam, das ihre Seelen und Herzen zufriedenstellte, und warteten bei einem Teil der Wahrheit ab, bis zu ihnen auf Erden oder im Jenseits Gewissheit kommen würde dies deswegen, weil die Herzen und Seelen entsprechend der Grundlage ihrer Veranlagung, um das Licht der Weisheit und des Glaubens zu empfangen, geeignet sind, wenn nicht die Finsternis ihrer Frevelhaftigkeit über [das Licht] hereinbricht wie der Unglaube an die Existenz eines Gottes - oder ein Schleier, der [das Licht]

\footnotetext{
${ }^{12}$ SCHAMS AD-DIN ASCH-SCHAZURI, Nuzhat al-arwah wa-raudhat al-afrah fi ta'rich al-hukama' wa-lfalasifa, [Hyderabad, 1976], 95.

${ }^{13}$ YUSUF KARAM, Ta’rich al-Falsafa al-Yunania [Kairo, 1976], 51.

${ }^{14}$ Adh-Dhariyat (Die Aufwirbelnden) 51:21.

${ }^{15}$ An-Nur (Das Licht) 24:35.

${ }^{16}$ An-Nur (Das Licht) 24:40.

${ }^{17}$ MUHAMMAD ABDUH, Risala at-Tauhid [Beirut, 1986], 100.
} 
aufgrund von Sünde oder dem, was ihr entspricht, verhüllt, wie in seiner Rede (t): „Versiegelt ist ihr Herz, sie verstehen nicht. ${ }^{\prime 18}$ und seine Rede ( $t$ ): „O nein! Vielmehr, was sie erwarben, verkrustet ihre Herzen. ${ }^{.19}$ Wenn also sich die Seele den natürlichen Trieben, den Finsternissen der Begierde und der Beschäftigung mit dem, was darunter ist, nämlich dem Verlangen, dem Zorn, dem Neid und dem Betrug, entsagt und sich mit ihrer Ausrichtung der Wahrheit und dem Treffen mit der Welt des höchsten Himmelreichs zuwendet, vereinigt sie sich mit dem höchsten Glück, es erscheint ihr das Geheimnis des Himmelreichs, es spiegelt sich in ihr die Heiligkeit der Gottheit wider und sie sieht die Wunder der großen Zeichen Gottes, so wie er sagte $(\mathrm{t})$ : „Er sah von seinem Herrn die großen Zeichen!“20

All dies weist darauf hin, dass wahy - im Sinne der Eingebung (ilham)- dauerhaft und fortbestehend ist und dass ein allmähliches Aufsteigen gewollt ist; und das gehört zur göttlichen Weisheit: Wenn unser Herr $(\mathrm{t}+\mathrm{t})$ die Anvertrauung der ganzen Wahrheit an jeden auf Erden gewollt hätte, hätte er zu allem Existierenden „Sei“ gesagt, dann wäre das Existierende ein gehorsamer Gläubiger geworden: „Hätte sein Herr gewollt, so würden alle auf der Erde gläubig werden, insgesamt. ${ }^{\text {"21 }}$ Doch liegt in der Verschiedenheit des allmählichen Zugewinns von Erkenntnis sowie dem Fortbestehen der göttlichen Offenbarmachung eine Weisheit. Vielleicht ist das Fortbestehen dieser Welt, bis sie vollendet wird und zu ihrem Beginn zurückkehrt, eine kreisförmige Bewegung der Existenz. Die Freude der Vereinigung kann nur durch Sehnsucht und Streben empfangen werden. Und wenn sich die Existenz auf die beiden Pfeiler Liebe und Erkenntnis stützen würde, so gäbe es beide nur durch die Durchquerung dieser menschlichen Reise. Er sagt ( $\mathrm{t}$ ): „Ich schuf die Dschinne und die Menschen nur, damit sie mir dienen." ${ }^{22}$ Und der wahre Dienst geschieht nur durch Liebe und Erkenntnis: jene Liebe, die den Menschen zum Streben nach der Vereinigung antreibt und die Erkenntnis, die ihrem Besitzer den umfassenden Blick auf das Dasein gewährt. So wird die Weisheit der Verschiedenheit da wahrgenommen, wo der Schöpfer - er ist groß und erhaben - sagt: „Für einen jeden von euch haben wir Bahn und Weg gemacht. Hätte Gott gewollt, er hätte euch zu einer einzigen Gemeinde gemacht - doch wollte er euch mit dem prüfen, was er euch gab.“23 Dann zum Schluss sagt der Weise $(t)$ - Preis sei ihm - : „Euer aller Rückkehr ist zu Gott, er wird euch dann kundtun, worin ihr immer wieder uneins wart. ${ }^{\text {“24 }}$

\footnotetext{
${ }^{18}$ At-Tauba (Die Buße) 9:87.

${ }^{19}$ Al-Mutaffifin (Die Knauserer) 83:14.

${ }^{20}$ An-Nadschm (Der Stern) 53:18.

${ }^{21}$ Yunus (Jona) 10:99.

${ }^{22}$ Adh-Dhariyat (Die Aufwirbelnden) 51:56.

${ }^{23}$ Al-Ma'ida (Der Tisch) 5:48.

${ }^{24} \mathrm{Al}$-Ma'ida (Der Tisch) 5:48.
} 


\section{Programm des Arbeitskreises}

\section{Fr. 27. April 2012}

Eröffnung und Moderation

Prof. Dr. Mahmoud Azab, Leiter des Al-Azhar-Zentrums für Dialog

Grußworte

Prof. Dr. Stefan Leder, Direktor des Orient-Instituts Beirut

Kai Boeckmann, Gesandter, Deutsche Botschaft Kairo

Eröffnungsvortrag

Prof. Dr. Hassan ash-Shafi i, Präsident der Akademie für Arabische Sprache

Eröffnung des Empfangs durch das Grußwort der al-Azhar

Seine Exzellenz der Großimam Herr Prof. Dr. Ahmad al-Tayyib Scheich der Al-Azhar, vertreten durch Professor Dr. Mahmoud Azab

\section{Sa. 28. April 2012}

Abd al-Aziz Saif an-Nasr (Al-Azhar)

Offenbarung und Religion

Reinhold Bernhardt (Bern)

Religion und Offenbarung

Abdalhamid Madkur (Kairo)

Martin Rösel (Rostock)

Bileam: Die wandernde Prophezeiung

\section{So. 29. April 2012}

Joachim Kügler (Bamberg)

Religion ist ein Angebot Gottes, sich ihm zu entziehen, ohne ihn zu vergessen

Al-Qasabi Zalat (Al-Azhar)

Die Offenbarung und ihr gegenüber vorgebrachte Anzweifelungen

Karlheinz Ruhstorfer (Koblenz-Landau)

offenbarung und Religion in christlicher Perspektive

Sonia Lotfy (Al-Azhar)

Wahy als Bestandteil der menschlichen Geformtheit 


\section{Teilnehmerliste des Arbeitskreises}

1. Ahmed Abd-Elsalam, Projektkoordinator, promovierter Islamwissenschaftler OIB

2. Abdullah Abu Hasha, Leiter des deutschen Zentrum in der Al-Azhar

3. Mahmoud Azab, Professor für islamische Kultur und Semitistik, Universität Sorbonne / Azhar; Leiter des Azhar-Zentrums für Interreligiösen Dialog

4. Alsayed Alrahmany, Doktorand für Koranexegese und islamische Theologie, Westfälische Wilhelms-Universität Münster / Al-Azhar Universität, Kairo

5. Reinhold Bernhardt, Professor für Systematik, evangelische Theologie, Universität Bern

6. Islam Dayeh, islamische Hermeneutik, (FU Berlin)

7. Marco Frenschkowski, Professor für Exegese des Neuen Testaments, evangelische Theologie, Universität Leipzig

8. Hans-Joachim Höhn, Professor für Systematische Theologie und Religionsphilosophie, katholische Theologie, Universität zu Köln

9. Mouhanad Khorchide, Professor für islamische Religionspädagogik und Leiter des Zentrums für Islamische Theologie, Westfälische Wilhelms-Universität Münster

10. Joachim Kügler, Professor für Exegese des Neuen Testaments, katholische Theologie, Otto-Friedrich-Universität Bamberg

11. Aaron Langenfeld, Doktorand für Systematische Theologie, katholische Theologie, Universität Paderborn

12. Stefan Leder, Projektleiter, Professor für Arabistik und Islamwissenschaft, Martin-Luther-Universität Halle-Wittenberg, Direktor des Orient-Instituts Beirut

13. Sonia Lotfy, Professorin für Islamische Dogmatik und Fundamentaltheologie, Al-Azhar, Kairo

14. Abd El-Hamid Madkur, Professor für islamische Philosophie, Dar-al-Ulum, Kairo Universität

15. Al-Qasabi Zalat, Professor für Koranexegese und Koranwissenschaften, AlAzhar, Kairo

16. Martin Rösel, Professor für Altes Testament und Altorientalische Religionsgeschichte, evangelische Theologie (Universität Rostock). 
17. Karlheinz Ruhstorfer, Professor für Systematik, katholische Theologie (Universität Koblenz-Landau)

18. Abd al-Aziz Saif an-Nasr, Professor für Fundamentaltheologie und Islamische Philosophie, Al-Azhar, Kairo

19. Muhammad Abdallah al-Sharqawy, Professor für islamische Philosophie und komparative Theologie, Abteilungsleiter, Dar-al-Ulum, Universität Kairo

20. Johannes Schnocks, Professor für Religionsgeschichte des Alten Testaments, katholische Theologie, Westfälische Wilhelms-Universität Münster

21. Stefan Schorch, Professor für Alttestament und Semitistik, evangelische Theologie, Martin-Luther-Universität Halle-Wittenberg.

22. Hasan ash-Shafi'i, Präsident der Ägyptischen Akademie für die Arabische Sprache und Berauter des Großscheichs, Professor für Fundamentaltheologie und Bekenntnislehre, Al-Azhar Kairo

23. Klaus von Stosch, Professor für Systematische Theologie und Leiter des Zentrums für Komparative Theologie und Kulturwissenschaften, katholische Theologie, Universität Paderborn

24. Johannes Thon, promovierter Theologe, evangelische Theologie, MartinLuther-Universität Halle-Wittenberg

Dolmetscher:

1. Sayyid Fathallah, Professor für Literaturwissenschaft und Germanistik (Al-Azhar. Kairo)

2. Dr. Assem al-Imary, (Ain Shams Universität, Kairo) 